\title{
SOME ASPECTS OF THE SALT REQUIREMENTS OF YOUNG RICE PLANTS
}

\author{
BY \\ RAFAEL B. ESPINO \\ Dissertation submitted to the Board of University Studies of the Johns \\ Hopkins University in conformity with the requirements \\ for the degree of Doctor of Philosophy \\ BALTIMORE, 1919
}




\section{Digitized by the Internet Archive in 2017 with funding from}

University of Illinois Urbana-Champaign Alternates 


\subsection{4 \\ Es6s}

\section{REMOTE STORAGE}

\section{VITA}

The writer was born on October 24, 1890 in Samal, Bataan, Philippine Islands. His early education was received in several Spanish private colleges in Manila and in the public schools of Bataan Province. He entered the College of Agriculture of the University of the Philippines in 1910 and received the degree of Bachelor of Agriculture in March, 1915. From 1912 to 1915 he was student assistant in Botany in the College of Agriculture, and from 1915 to 1917 he was Assistant in Botany and also was engaged in graduate and research work in the same College. In June, 1917, he was appointed to a fellowship in the University of the Philippines and given leave of absence. He spent the summer of 1917 at the University of Chicago and entered Johns Hopkins University in October, 1917, where he has been engaged in graduate work until the present time. His principal subject in this University. was Plant Physiology and his subordinate subjects, Botany and Zoölogy (Genetics). 



\title{
SOME ASPECTS OF THE SALT REQUIREMENTS OF YOUNG RICE PLANTS ${ }^{1}$
}

\author{
By Rafael B. Espino \\ Of the College of Agriculture, Los Baños \\ ONE PLATE AND NINE TEXT FIGURES
}

\section{INTRODUCTION}

One of the most important human activities has long dealt with the improvement of methods for securing plant products upon which human nutrition depends. The scientific problems of the nutrition of plants are thus closely connected with the practice of agriculture, and agriculturists as well as plant physiologist:3 have already accomplished much toward outlining and solving some of these problems, with reference to many different kinds of plants. The mineral nutrition and the salt requirements of plants have recently received a great deal of attention, and the methods employed in experimentation in this field are being rapidly improved. Among the methods that have yielded valuable results as to the physiological needs of plants the so-called "water-culture" method is important. By this method the culture plants are grown with their roots in aqueous solutions of various inorganic salts, in various proportions, these solutions having various total concentrations. This may be called the method of solution cultures, although of course the source from which the plants absorb their mineral nutrients is an aqueous solution even when soil or sand is used. "Water culture" is employed in a general sense to denote such solution cultures, but, as Shive ${ }^{2}$ has pointed out, actual water cultures (with distilled or otherwise purified water) are seldom of much value in nutritional experimentation, partly because pure water not

${ }^{1}$ Botanical contribution from the Johns Hopkins University, No. 61. A brief preliminary report of some of the results presented in this paper was given before the 1918 (Baltimore) meeting of the Physiological Section of the Botanical Society of America.

"Shive, John W., A study of physiological balance in nutrient media, Physiol. Res. 1 (1915) 327-397, 331. See also True, R. H., Harmful action of distilled water, Am. Journ. Bot 1 (1914) 255-273; Hibbard, R. P., The question of the toxicity of distilled water, ibid. 2 (1915) 389-401. 
only does not supply the mineral salts needed by the plant, but it also acts to remove salts already within the plant body. The study to be reported in this paper deals with the growth of young rice plants (Oryza sativa, variety "Wateribune") in aqueous solution cultures. No attempt will be made here to review studies made on culture solutions, but the readers are referred to Tottingham's ${ }^{3}$ monograph which gives a very complete resumé of earlier solution-culture experimentation with plants and to later papers that appeared on the subject. A brief review, however, will be made of previous studies on rice which appear to have a direct bearing on the present problem.

\section{REVIEW OF PREVIOUS EXPERIMENTS ON THE MINERAL NUTRITION OF RICE}

The present studies deal with solution cultures, as has been said, and they may serve as a small contribution toward a better knowledge of this field of physiology. Such studies, however, must of course involve some particular kind of organism and the rice plant was chosen as the experimental subject, for several reasons. In the first place, it seemed that the extensive aspect of our knowledge of this phase of physiology deserved attention; there are so many different sorts of plants, and generalizations for all plants are perhaps too easily formed from knowledge of a few kinds. The aim was to select a plant that would probably show some important physiological differences from the ones thus far studied. At the same time the plant used should be one of considerable human interest, for plant production and the practical applications of plant physiology are always demanding more scientific knowledge than is available. These studies were to be purely physiological, but the plant used might well be one of agricultural interest. Also, of course, the plant selected must be suited to solution-culture experiments; soils, and even sand cultures, present problems that are so complicated as to be almost hopeless until some of the simpler problems offered by solution cultures become better understood. Choosing the experimental subject at a time when agricultural operations loomed very large on the world's horizon, when the whole of civilization was in the tightening grip of a quasi famine, it was natural first to consider what plants are

\footnotetext{
${ }^{3}$ Tottingham, Wm. E., A quantitive chemical and physiological study of nutrient solutions for plant cultures, Physiol. Res. 1 (1914) 133-245. See also Shive, J. W., The freezing points of Tottingham's nutrient solutions, Plant World 17 (1914) 345-353.
} 
most important to the human race. If wheat be the most important, then perhaps rice may be the second. Wheat had been studied considerably, though much remains to be done with it, but rice had received no attention by the newer methods of solution culture. Also, various writers had presented evidence to the effect that rice differs from wheat and many other plants in that rice is able to utilize ammonium as a source of nitrogen. Rice also appeared to be well suited to solution cultures. Finally, rice is perhaps the most important plant in the writer's home country; it forms the main vegetable source of food for the great majority of the population of the Philippine Islands, and it is a very important agricultural crop there, as well as in many other parts of the world. Large amounts of it are grown in the southern and western United States, in Italy, India, Africa, Japan, Spain, etc. Lowland rice was selected for the experiments to be reported in this paper.

These studies may therefore be regarded as furnishing some contribution to our knowledge of the physiology of the rice plant. just as they contribute somewhat to our knowledge of solution culture and the mineral nutrition of plants in general. The recent intensive study of the mineral nutrition of plants, through the employment of the systematic schemes of Schreiner and Skinner (1910), Tottingham (1914), Shive (1915), and others, has not thus far included the rice plant, but several valuable studies of a less extensive and systematic sort have been reported for rice. The following paragraphs give a resumé of previous work on the salt nutrition of rice, with which the writer is familiar.

The problem of the mineral nutrition of rice immediately brings up the question of ammonium salts as possible sources of nitrogen for plant nutrition. It appears that plants differ in regard to their ability to utilize ammonium salts. An early publication dealing with this question is that of Bouchardat. ${ }^{1}$ He employed culture solutions with several forms of inorganic ammonium compounds ("sesquicarbonate," bicarbonate, sulphate, "chlorhydrate," and nitrate of ammonium) and experimented on the growth of Mimosa pudica in these solutions. He concluded that the ammonium salts used were not only useless as sources of nitrogen for the plant employed, but that they were highly toxic when supplied in certain concentrations. It was

'Bouchardat, A., De l'action des sels ammoniacaux sur la vegetaux, Compt. Rend. Acad. Sci. Paris 16 (1843) 322-324. 
over thirty years later that Lehmann ${ }^{5}$ published an account of experiments which seemed to show that ammonium sulphate may be a source of nitrogen for certain higher plants. $\mathrm{He}$ employed solution cultures and supplied all the necessary elements in all cases, but some cultures were furnished with nitrogen as a nitrate (calcium nitrate), while the nitrogen of others was supplied as an ammonium salt (ammonium sulphate). He observed that maize plants developed normally for fortyone days (from the seed) in solutions containing ammonium sulphate, while the plants with calcium nitrate showed only poor growth during that period. After this first period of forty-one days, however, his "nitrate" plants recovered and continued with good growth, while his "ammonium" plants became chlorotic and sickly. Also, Lehmann observed that the chlorotic plants of his nitrate group within the first forty-one day period might be made to assume normal growth and appearance, if they were transplanted to a culture solution containing ammonium sulphate; in two days they became green. Furthermore, when healthy plants of his ammonium group were similarly transplanted to a solution containing sodium nitrate, they soon became pale and sickly.

The same author obtained similar results with tobacco plants grown in sand cultures. He supplied the necessary minerals, furnishing nitrogen either as ammonium sulphate or as sodium nitrate. The plants grown in the medium containing ammonium sulphate were healthy and grew normally from the beginning to the end of the experiment. Those supplied with nitrogen as sodium nitrate were chlorotic and unhealthy during the first half of the vegetative period, but they afterwards became green and vigorous, although the final yield was much lower than that obtained from the cultures with ammonium sulphate as the source of nitrogen.

Lupine plants grown in sand cultures in Lehmann's experiments gave better vegetative growth when nitrogen was supplied as sodium nitrate than when it was furnished as ammonium sulphate, but the yield of seed was larger in the latter case.

From these studies Lehmann came to the conclusion that some plants require nitrate nitrogen, others require ammoniacal nitrogen, and still others require one of these two forms of nitrogen during the early stages of growth and the other form during the later stages. While the experimentation on which

\footnotetext{
- Lehmann, Jul., Ueber die zur Ernährung der Pflanzen geeignetste Form des Stickstoffes, Biedermann's Centralbl. Agr.-Chem. 7 (1875) 403-409.
} 
Lehmann based these conclusions would not now be considered as convincing in itself, yet his general conclusions still appear to stand. Of course the modern problem of the nitrogen requirements of plants involves not only nitrates and ammonium salts, but also nitrites and many other compounds containing nitrogen, and must take account of such topics as nitrification, denitrification, and the assimilation of elemental nitrogen. The question regarding the direct utilization of ammonium salts by specific agricultural plants bids fair to maintain an important position in agronomic discussions for a long time to come. It will of course be necessary that each important kind of plant be made the subject of special and rather elaborate experimentation.

Without here attempting to summarize the literature of this broad subject, attention may be directed to Hutchinson and Miller's ${ }^{6}$ experiments and to their discussion. They grew wheat and peas in solution culture and also in sand culture. They conclude that-

* * * agricultural plants of various kinds can produce normal growth when supplied with nitrogen in the form of ammonium salts under conditions which exclude the possibility of nitrification. Some plants grow equally well with ammonium salts or nitrates as source of nitrogen. Other plants, while assimilating ammoniacal nitrogen in the absence of nitrates, appear to prefer nitrates. It is less certain whether ammonium salts can ever produce better final results than nitrates although we have indications that this may be the case.

In connection with the doubt expressed by Hutchinson and Miller, "whether ammonium salts can ever produce better final results than nitrates," the studies on rice by Nagaoka, Kelley, and others, which will be mentioned later, are of interest.

Turning to the rice plant in particular, the problem of its salt nutrition has been touched upon from almost all angles, but in a rather hit-and-miss way. Kellner ${ }^{7}$ conducted perhaps the first solution-culture experiments on lowland rice, with the aim of determining whether this plant thrives best with one or another form of nitrogen-bearing salt. He grew his plants in nutrient solutions supplying all the essential chemical elements for normal growth of ordinary higher plants. In one solution nitrogen was supplied as potassium nitrate, and in another as ammonium sulphate, and his experiments were repeated several

\footnotetext{
${ }^{\circ}$ Hutchinson, H. B., and Miller, N. H. J., Direct assimilation of ammonium salts by plants, Journ. Agr. Sci. 3 (1909) 179-194.

${ }^{7}$ Kellner, O., Agriculturchemische Studien ưber die Reiscultur, Landw. Versuchsst. 30 (1884) 18-32.
} 
times, using the same salts but varying the amounts. He concluded that paddy rice in the early stages of its development grew better in a nutrient medium supplied with ammoniacal nitrogen than in one supplied with nitrate nitrogen, while during the later stages of development the nitrate proved to be a better source of nitrogen than was the ammonium salt. $\mathrm{He}$ also tried culture solutions containing the other necessary elements and having the ammonium salt and the nitrate both present at once, and found that the combination of these forms of nitrogen gave better growth than did either form alone.

The beneficial effect of ammonium sulphate, as well as the unsuitability of nitrates as sources of nitrogen for rice, were also observed by Nagaoka, ${ }^{8}$ who carried out a series of rather extensive pot and plot experiments with upland and lowland varieties of rice grown to maturity. He began his cultures with plants about 42 days old, so that the plants had passed beyond the first stages of growth before they were tested. By means of pot cultures with soil he compared the growth and the yield of a lowland rice supplied with different amounts of ammonium sulphate with those of the same variety supplied, separately, with one of the salts, sodium nitrate, potassium nitrate, calcium nitrate, barium nitrate, strontium nitrate, and magnesium nitrate. He found that plants grown in the media supplying nitrogen in the form of ammonium sulphate alone were green and produced much tillering (branching at the base of the stem), while plants "fed" with one of the nitrates were yellowish and produced but little tillering. The six nitrates tested were about alike in this effect. Nagaoka observed, however, that the seed ripened ten days earlier when the plants had been supplied with a nitrate than when they had been supplied with the ammonium salt.

The field-plot experiments of Nagaoka were planned to study the fertilizer values of sodium nitrate and ammonium sulphate. In these experiments he applied one or the other of the two salts to the soil. The fertilizer application was made before planting and also at intervals during the growth of the plants. Lowland rice was again used and, as in his previous pot experiments, the yield obtained showed that ammonium sulphate was about two and one-half times as good as sodium nitrate in this respect.

In another set of pot experiments, with upland as well as low-

${ }^{8}$ Nagaoka, M., On the behavior of the rice plants to nitrates and ammonium salts, Bull. Coll. Agr. Imp. Univ. Tokyo 6 (1904) 285-334. 
land rice, Nagaoka used a soil to which a fertilizer without nitrogen was similarly applied in all cases. To the pots of one group he added different amounts of sodium nitrate, and to those of another group he added different amounts of ammonium sulphate. Some of the pots of each treatment were kept wet, as in rice paddies, while in other pots the soil was kept merely moist. The results obtained showed that ammonium sulphate gave better yields than did sodium nitrate, for both forms of rice and for both soil-moisture conditions. The ammonium salt was always absorbed to a greater extent than was the nitrate, but the upland variety absorbed more sodium nitrate than did the lowland variety. As to the moisture content of the soil, both varieties gave good yields in either one of the two moisture conditions studied, but the results were better with lowland rice in wet soil and with upland rice in merely moist soil.

The apparent failure of the rice plant to utilize nitric nitrogen and its apparent preference for the ammoniacal form were ascribed by Nagaoka to the fact that paddy rice does "not accumulate a sufficient quantity of sugar in the leaves to convert all of the nitric acid absorbed into protein." The chlorotic appearance of the plants supplied with nitrogen solely as nitrates might be "due to the physiological influence of accumulated nitrates." Nagaoka pointed out that the soil of pots receiving large additions of nitrate gave a slight nitrite reaction, and he suggested that denitrification (resulting in the formation of nitrites from nitrates in the soil) might take place in the rice paddy through the action of microörganisms, so that the excessive amount of nitrites thus formed might poison the plants.

Daikuhara ${ }^{9}$ also found that the application of certain ammonium compounds to the soil was beneficial to rice. He used sand cultures to which limestone and magnesium sulphate were added in various proportions. He also added sodium nitrate to one pot and ammonium sulphate to another. To a third pot ammonium nitrate was added. The total yield (grain and straw) showed that, under the conditions of the experiment, ammonium sulphate was about two and one-half times as beneficial as was sodium nitrate, thus confirm:ng the general conclusion of Nagaoka. Daikuhara found also that the fertilizer value of ammonium nitrate was intermediate between the values of ammonium sulphate and sodium nitrate.

- Daikuhara, G., On the application of magnesium in the form of magnesium sulphate for the needs of the rice plant, Bull. Imp. Central Agr. Exp. Sta. Japan 1 (1905) 24-29. 
Aso and Bahadur ${ }^{10}$ found that a combination of ammonium sulphate and disodium phosphate produced better results with paddy rice in the field than did combinations of any other salts in their tests.

Krauss ${ }^{11}$ also reported results from pot and field experiments with rice, indicating that (of the different nitrogenous fertilizers that he tested) ammonium sulphate ranked above calcium nitrate and sodium nitrate by the criterion of yield of grain.

The superior fertilizer value of ammonium sulphate, as compared with the values of sodium nitrate, calcium nitrate, magnesium nitrate, and ammonium nitrate, was also noted for the rice plant by Kelly. ${ }^{12} \mathrm{He}$ employed lowland rice in both field and pot cultures, adding nitrogenous fertilizers before planting and, in other cases, at intervals during the culture period. The cultures supplied with ammonium sulphate showed good growth and gave good yields of both straw and grain, while those in which nitrogen was supplied to the soil only as sodium nitrate gave but low yields. Apparently this nitrate was ineffective as a fertilizer. He also found that the ammonium salt applied before planting proved more beneficial than did the same salt applied at intervals during the culture period. In pot cultures the addition of nitrate to the soil proved beneficial in the latter part of the growth period, from near the flowering stage to maturity. This last observation agrees with that recorded for maize by Lehmann (1875). Kelly suggested that this difference in the response of the rice plant to soil fertilization with sodium nitrate and with ammonium sulphate, might be due to the fact that the lowland rice plant "has in a large measure lost the power of reducing nitrates," which, in turn, might be due to the fact that this plant has been "grown for centuries under conditions that largely exclude the formation of nitrates." While these considerations may be of interest in connection with genetics and phylogeny, still the physiological reasons for the observed state of affairs (which must be sought in the plant itself) remain untouched. From the standpoint of genetics it may be asked whether the paddy rice plant ever had the power of reducing nitrates. Kelley appreciated the unsatisfactory sta-

${ }^{10} \mathrm{Aso}, \mathrm{K}$., and Bahadur, R., On the influence of the reaction of the manure upon the yield, Bull. Coll. Agr. Imp. Univ. Tokyo 7 (1906) 39-46.

${ }^{11}$ Krauss, F. G., Ann. Rept. Hawaii Agr. Exp. Sta. 1907 (1907) 67-90. Ibid. 1908 (1908) 65-84.

${ }^{12}$ Kelley, W. P., The assimilation of nitrogen by rice, Hawaii Agr. Exp. Sta. Bull. 24 U. S. Dept. Agr., Washington, D. C., 1911. 
tus of the problem, however, and ended his discussion by emphasizing the need for much more study along these lines; he said that "further experiments will be conducted to determine the correctness of this view," but this promise has apparently not yet been fulfilled.

Similar beneficial effects of ammonium sulphate upon rice plants were observed by Daikuhara and Imaseki, ${ }^{13}$ with pot cultures. They found that ammonium sulphate alone was superior to sodium nitrate alone and also to a combination of these two salts.

From field experiments W. H. Harrison ${ }^{14}$ concluded that nitrates were unsuitable for rice, but that ammonium compounds, or manures that yield ammonia under anaërobic conditions of fermentation, were of great value. J. B. Harrison, ${ }^{15}$ on the other hand, reported that the application of ammonium sulphate to field plats of rice resulted in a decreased yield. This lower yield, however, was thought to be due to lodging, which occurred on account of the very luxuriant growth that took place in the plats supplied with ammonium sulphate rather than to any directly injurious effect of the salt.

Further experimental evidence in favor of the idea that ammonium salts are good sources of nitrogen for rice is available from later work by Kelley, ${ }^{18}$ who conducted a series of field trials. Ammonium sulphate was added to one plat and sodium nitrate to another, the addition being made before the time of planting. To the soils of other plats nitrogenous fertilizers were added from time to time during the development of the plants. The results agreed in indicating the superiority of ammonium sulphate over sodium nitrate. Kelley concluded that-

a complete fertilizer proved no more effective than ammonium sulphate alone, whereas the application of both ammonium sulphate and potassium sulphate caused a decrease as compared with that obtained from ammonium sulphate alone.

${ }^{13}$ Daikuhara, G., and Imaseki, T., On the behavior of nitrate in paddy soils, Bull. Imp. Central Agr. Exp. Sta. Japan 1 (1907) 7-36. (Cited by Kelley, 1911.)

${ }^{14}$ Harrison, W. H., The principles of paddy manuring, Journ. Board Agr. Brit. Guiana 61 (1912) 37-40. Ibid. 62 (1912) 71-77.

${ }^{15}$ Harrison, J. B., Experiments with varieties of rice at the Botanic Garden, 1912, Journ. Board Agr. Brit. Guiana 7 (1913) 42-43.

${ }^{10}$ Kelley, W. P., Rice soils of Hawaii: Their fertilization and management, Hawaii Agr. Exp. Sta. Bull. 31 U. S. Dept. Agr., Washington, D. C. (1914). 
Besides the various nitrates and ammonium salts, other forms of nitrogen-bearing substances have been tried with rice, but a review of the literature on these will not be given here.

\section{SUMMARY}

From the foregoing review of the more definite contributions that have been made toward a knowledge of the mineral nutrition of rice, it appears that there is good reason to suppose that:

(1) This plant requires the same chemical elements as do other higher plants.

(2) The young plants are not suited to deriving their nitrogen from nitrates but thrive very well when ammonium sulphate (or probably other ammonium salt, such as the chloride, nitrate, etc.) is supplied.

(3) Older plants are able to derive their nitrogen supply from nitrates, but may be able to thrive without the nitrate ion when the ammonium ion is supplied at a proper rate.

None of the points just mentioned is at all well established in a quantitative way; much of the experimentation on which our present knowledge of these matters is based has been car. ried on with field soils, whose various properties were mostly unknown, so that (for this reason among others) the results of different experimenters are generally not logically comparable. The apparent importance of the relation between nitrate and ammonium as sources of nitrogen for young rice plants, and of the question regarding the physiological balance for rice between the three main kations that are generally required by plants (potassium, calcium, and magnesium), makes it appear that more attention needs to be given to the simpler physiological aspects of these relations. It was with these points particularly in mind that the solution-culture studies on rice seedlings here to be reported were undertaken. This work is presented as a beginning only. As is general in such cases, the experimental analysis is very incomplete and probably more questions are raised than are answered, even in a preliminary way. In spite of the enormous amount of work needed to obtain satisfactory conclusions regarding the physiological problems dealt with by the solution-culture method, it seems obvious that the relations of any given plant form to the soil in which it is growing will hardly be understood at all well before the behavior of that p!ant toward free solutions has been rather thoroughly worked out. Furthermore, if the problems of plant nutrition that are 
presented by solution cultures are complex, those presented by soil cultures are many times more complex. While field experimentation with agricultural plants will of course go on in large volume, for economic reasons it seems desirable that the simpler physiological problems that may be attacked by solution cultures should be dealt with whenever opportunity allows. It should be repeatedly emphasized that the aim of study of this sort is to bring about a better understanding of the nutritional requirements of the plants considered, not to give information regarding the fertilizer treatment of soils. After the plant itself is fairly well understood when growing under the simplest possible sets of conditions, then soil experimentation may perhaps be planned so as to furnish results directly valuable in field culture. The studies here reported deal simply with the rice plant as a machine, and the solution-culture method offers the simplest form of satisfactory root environment that can be devised. The problems of the physical and chemical characteristics of any soil that might be employed are here avoided altogether.

\section{GENERAL SURVEY OF THE PRESENT STUDY}

These studies were planned to throw some light on the salt relations of young lowland rice plants when grown in solution cultures in a greenhouse. It was proposed, first, to find out whether any set of salt proportions and total concentrations possible with the 3-salt type of solution, studied by Shive, might be suitable for good growth of the young rice plants. As was already foreshadowed in the results of earlier workers with rice, it turned out that it is impossible to obtain good growth of this plant (for the first few weeks of its growth from the seed) in any one of these 3-salt solutions.

It was then proposed to supply the plants with the ammonium ion, following the suggestions of the literature. This was done by employing the single ammonium salt, ammonium sulphate; other ammonium salts were not tested. Since ammonium is a kation, and since there is no question but that the rice plant requires all three of the main kations (potassium, calcium, and magnesium) needed by higher plants in general, it logically follows that ammonium cannot be directly supplied in a complete, nutrient solution unless the latter contains four salts. The second stage of these studies therefore dealt with a 4-salt type of solution containing the four kations (potassium, calcium, magnesium, and ammonium) as well as the generally requisite anions (nitrate, phosphate, and sulphate). Many different sets 
of salt proportions and a number of different total concentrations of this 4-salt type of nutrient solution were tested, and certain ones of these proved to be excellent for the plants employed.

The question then arose, whether the presence of the nitrate ion in the medium might not be either unnecesary or even positively harmful to the young rice plants, and the third stage of these studies dealt with still another 4-salt type solution, which contained all the generally necessary mineral elements but contained no nitrate. Nitrogen was supplied here only as ammonium sulphate. This type of solution was also tested with many different sets of salt proportions and with a number of different total concentrations. The results showed that some of these solutions gave very good general growth, but the best of them were not as good as the best ones containing nitrate; this type of solution always produced a characteristic leaf injury.

The work here reported was carried out in the Laboratory of Plant Physiology of the Johns Hopkins University; and the writer's acknowledgments and thanks are hereby expressed for the facilities of that laboratory, and for instruction, advice, and guidance given him by Prof. B. E. Livingston and Dr. H. E. Pulling.

\section{EXPERIMENTATION}

SEEDS AND SEEDLINGS

The rice used in this study was kindly furnished by the United States Department of Agriculture. It is of the lowland type bearing the name "Wateribune," and this stock of seed was grown, under irrigation, at the Crowley Station of the Louisiana Agricultural Experiment Station. This variety is often grown on a small scale without irrigation in the Southeastern States, but always with very moist soil.

In starting an experimental series, about two thousand seeds were first placed in about 300 cubic centimeters of tap water in an open glass pan (15 centimeters in diameter), where they were allowed to soak for twenty-four hours. They were then placed between folds of wet absorbent paper (paper toweling, about like thin filter paper), where they remained another twenty-four hours. At the end of this period germination was visibly beginning so that the plumule protruded slightly. The germinating seeds were next distributed on a net of paraffined cotton threads (mosquito netting, mesh about' 1.5 millimeters square), which was stretched horizontally over the opening of a cylindrical earthen jar (55 centimeters in diameter and 40 
centimeters deep). The jar was kept full of tap water so that the seeds were supported at about the surface of the liquid. Unlike wheat, this rice does not ferment rapidly when the water about it remains unchanged, and this fact, together with the large volume (about 90 liters) of water lying below the seeds, made it seem unnecessary to change the water during the germination period. The germination jar stood in a greenhouse room, exposed to sunlight. The seedlings remained on the net till the shoots were from 3 to 5 centimeters long, requiring a period of from ten to fifteen days, depending on weather conditions, especially temperature.

At the end of the germination period uniform and apparently vigorous seedlings were selected for the cultures. ${ }^{17}$ These were placed in a dish of tap water, from which they were taken one by one, and mounted in paraffined cork stoppers of the form used by Shive (1915). Each stopper had six holes and six seedlings were held, one in each hole, by means of properly compressed plugs of cotton. These preparations were then put in place in the openings of the culture bottles, which were of the 250 cubic centimeter form used by Shive (1915). Cardboard covers like the ones described by that writer (1915) were placed around the bottles so as to keep the interior nearly dark. Each bottle contained 250 cubic centimeters of the proper nutrient solution and the roots of the seedlings were almost entirely immersed in the liquid. The seeds were supported just beneath the lower surface of the stopper and were not in contact with the liquid.

\section{SOLUTIONS}

\section{SINGLE-SALT STOCK SOLUTIONS}

In preparing the culturé solutions single-salt solutions of halfvolume molecular ${ }^{18}$ concentration were first prepared. The salts used were "Baker analyzed" monopotassium phosphate $\left(\mathrm{KH}_{2} \mathrm{PO}_{4}\right)$, calcium nitrate $\left[\mathrm{Ca}\left(\mathrm{NO}_{3}\right)_{2}\right]$, magnesium sulphate $\left(\mathrm{MgSO}_{4}\right)$, ammonium sulphate $\left[\left(\mathrm{NH}_{4}\right)_{2} \mathrm{SO}_{4}\right]$ and monocalcium phosphate $\left[\mathrm{Ca}\left(\mathrm{H}_{2} \mathrm{PO}_{4}\right)_{2}\right] .{ }^{18}$ No attempt was made to dry the salts or to determine their water contents, the data on water

${ }^{27}$ On internal differences between seedlings that might be supposed to be alike, see Stiles, W., On the the relation between the concentration of the nutrient solution and the rate of growth of plants in water cultura Ann. Bot. 29 (1915) 89-96.

is The stock solution of monocalcium phosphate was twelfth-molecular instead of half-molecular. 
content furnished on the label being taken as a basis for preparing the solution in each case. Doubtless some errors were introduced by this procedure. The study was to be only preliminery in character, however, and this kind of work always involves many unknown and uncontrollable conditions, some of which are surely more influential in determining the growth of the plants than are the errors introduced by empioying the manufacturers' data on water content, so that special analyses (with their relatively great consumption of time) seemed undesirable in the present case. It was at first intended that samples of the single-salt stock solutions should be subjected later to quantitative determinations, in order to obtain their actual concentrations, but time was finally lacking for this. It is undoubtedly better, in work of this kind, to make up the solutions and then determine their concentrations by analytical methods, than to attempt to dry the salts to a known water content before dissolving. The errors here considered of course apply only to calcium nitrate, ammonium sulphate, and monocalcium phosphate; the other two salts are practically dry as they come on the market.

The ferric phosphate $\left(\mathrm{FePO}_{4}\right)$ used was prepared according to the procedure of Shive and Tottingham; that is, the ferric nitrate $\left[\mathrm{Fe}\left(\mathrm{NO}_{3}\right)_{3}\right]$ was allowed to react with monopotassium phosphate $\left(\mathrm{KH}_{2} \mathrm{PO}_{4}\right)$, forming the precipitate, which was then thoroughly washed with distilled water. The precipitate divides very finely and settles to the bottom of the container only after considerable time. When this material was needed for addition to the culture bottles (when new cultures were to be started or solutions were to be renewed) the bottle containing the precipitate and its supernatant water were thoroughly shaken so as to give a uniform suspension. Five cubic centimeters of this suspension, containing about 11 milligrams of ferric phosphate, were added to each 250 cubic centimeters of culture solution. The slight further dilution resulting from this addition of 5 cubic centimeters of water to each 250 cubic centimeters of culture solution was regarded as insignificant.

The distilled water used was that of the laboratory, derived from a Barnstead still, the same as was used by Hawkins, ${ }^{19}$ Shive (1915), and Tottingham (1914).

\footnotetext{
${ }^{19}$ Hawkins, Lon A., The influence of calcium, magnesium and potassium nitrates upon the toxicity of certain heavy metals toward fungus spores, Physiol. Res. 1 (1913) 57-92.
} 
THE STOCK CULTURE SOLUTIONS

Three types of nutrient solution were studied:

(1) The 3-salt type studied by Shive $(1915,1917)$ with wheat and buckwheat, ${ }^{20}$ which has been called the 3-salt type I by Livingston and Tottingham. ${ }^{21}$ This contains, besides a small amount of ferric phosphate, the three salts monopotassium phosphate, calcium nitrate, and magnesium sulphate.

(2) A 4-salt type with both ammonium and nitrate. This contains, besides ferric phosphate, the four salts monopotassium phosphate, calcium nitrate, magnesium sulphate, and ammonium sulphate. It will be termed the 4 -salt type A.

(3) A 4-salt type with ammonium but without nitrate. This contains, besides ferric phosphate, the four salts monopotassium phosphate, monocalcium phosphate, magnesium sulphate, and ammonium sulphate. It will be termed the 4-salt type B.

For each of these three types stock culture solutions were prepared from the requisite single-salt stock solutions and dis-. tilled water, the total concentrations of the stock culture solutions of each type being alike and as high as that used for the most concentrated culture solution. No ferric phosphate was added to the stock culture solutions. For each type there were as many of these stock solutions as there were different sets of salt proportions in the list to be tested. From any given stock culture solution the various total concentrations needed for the cultures employing that particular set of salt proportions could be readily obtained, either directly or by simple dilution. These concentrated stock culture solutions were stored in much-used glass bottles (of about 3.5 liters' capacity), practically in darkness, and they were drawn upon from time to time as the culture solutions were renewed. In the case of the 3-salt type these stock culture solutions were kept for about a month; in the case of the two 4-salt types they were kept twice as long. In no case was there any evidence suggesting alteration in the stock solutions; at least none beyond the occasional appearance of small fungus colonies, which were always removed with a glass tube as soon as they became conspicuous.

The employment of concentrated stock culture solutions from which the actual culture solutions were obtained, by simple dilution-a procedure that saves very much time, tends to simplify the culture work, and avoids the possibility of many errors

\footnotetext{
${ }^{20}$ Shive, John W., A study of physiological balance of buckwheat grown in three-salt solutions, New Jersey Agr. Exp. Sta. Bull. 319 (1917) 5-63.

${ }^{21}$ Livingston, B. E., and Tottingham, Wm. E., A new three-salt nutrient solution for plant culture, Am. Journ. Bot. 5 (1918) 337-346.
} 
- was made possible in these studies by the adoption of a new method of dealing with salt proportions. Whereas Tottingham, Shive, and others have based their salt proportions on the partial osmotic values of the various component salts (thus involving the principle of increased dissociation with greater dilution), the salt proportions of the present studies were considered without regard to ionization and were stated simply as molecular salt proportions. All stock culture solutions for any given type were planned to contain the same number of salt molecules per unit of volume; they differed from one another only in the manner in which this number was apportioned among the three or four different kinds of molecules (salts). When this method is adopted the several salts are placed together in the stock culture solution, with a certain set of molecular salt proportions, and the addition of water to this solution does not alter these proportions; they remain the same for all dilutions of this stock solution, although the total concentration is changed by the dilution process. This method of treatment does not at all imply that the various molecules of salt all remain intact in the mixed solution; it is of course appreciated that dissociation must be supposed to occur, and to a higher degree with successively lower total concentrations; but the degree of dissociation of each of the component salts in any culture solution becomes a matter for special study and does not enter into the simple description of the solution.

It can be seen that this plan makes it possible to state the salt proportions with much greater simplicity than can be attained when osmotic salt proportions are employed; that the statement of atomic proportions (and also of ionic proportions, calling an atomic group an ion whether or not it is dissociated from its molecule) is similarly simplified; and that any total osmotic value (total concentration) that is lower than that of the stock culture solution in question may be obtained for any given set of molecular salt proportions by simple dilution from the corresponding stock culture solution. Of course the osmotic value of any solution is determined, for any temperature, etc., by (1) the salts employed, (2) their molecular proportions, and (3) their various degrees of ionization. This value may be approximately calculated by making certain assumptions, but the most satisfactory way to determine it is by means of the freezing-point method. All osmotic values mentioned in this paper are merely rough approximations derived from the values obtained by Tottingham and Shive for somewhat similar mix- 
tures. Lack of time prevented the actual determinations of the freezing points of the solutions used in these experiments.

The three series of stock culture solutions will now be described in order.

Three-salt type I.-Fifteen different sets of molecular salt proportions were tested for this solution type. The fifteen different stock culture solutions all agree in having a total of 0.0245 gram-molecule of salt per liter and the molecular partial concentration of each of the three salts differs from solution to solution throughout the series by increments of one-seventh of the total molecular concentration; that is, by increments of 0.0035 gram-molecule. These fifteen different 3 -salt stock solutions may be designated according to the positions of the points representing them on a 3-coördinate diagram similar to the one used by Schreiner and Skinner, Shive, and others. The diagram here used is shown in fig. 1. The different sets of molecular salt proportions will be named by formulas similar to those employed by Shive, only that the letter $\mathrm{S}$ will be here used (for solution) instead of $\mathrm{C}$ (for culture). R1S1 is the solution represented by the lower left apex of the triangular diagram; R1S3 is the one represented by the third point from the left end of the lowest row of points; R3S3 is represented by the third point, counting from the left, in the third row; R5S1 is represented by the top apex of the diagram (since the fifth row has but a single point), etc. In this diagram every solution of the lowest row has oneseventh of its total molecular concentration made up of monopo-

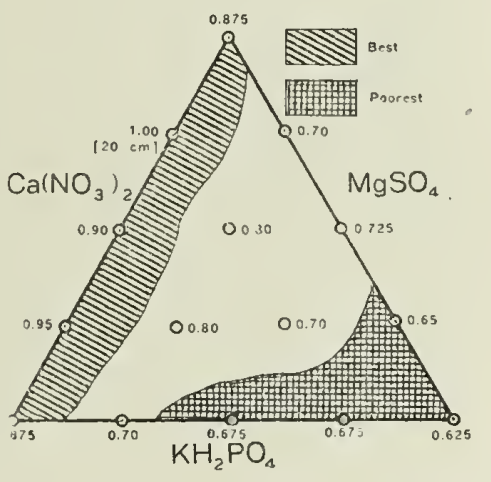

Fra. 1. Relative values of top length for series 4 , with 3 -salt solution type I (increments of one-seventh, tcral concentration of 0.0061 gram-molecule per liter or 0.23 atmsophere). Lightly shaded area includes best-balanced sets of salt proportions, heavily shaded area includes poorest sets. tassium phosphate, every one on the left margin has one-seventh made up of calcium nitrate, and every one on the right margin has one-seventh made up of magnesium sulphate.

The different sets of molecular salt proportions and the molecular partial concentrations of the one salt monopotassium phosphate are shown in Table 1. From these data the molecular partial concentrations of the other two salts can be readily computed. 
TABLE 1.-Description of stock culture solutions of s-salt type $I$.

['Total concentration 0.0245 gram-molecule (of all salts taken together) per liter.]

\begin{tabular}{|c|c|c|c|c|c|}
\hline Solution No. & 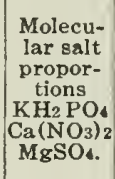 & $\begin{array}{c}\text { Volume } \\
\text { of molec- } \\
\text { ular } \\
\text { partial } \\
\text { concen- } \\
\text { tration } \\
\text { of } \mathrm{KH}_{2} \\
\text { PO4. }\end{array}$ & Solution No. & $\begin{array}{l}\text { Molecu- } \\
\text { lar salt } \\
\text { propor- } \\
\text { tions } \\
\mathrm{KH}_{2} \mathrm{PO}_{4} \\
\mathrm{Ca}\left(\mathrm{NO}_{3}\right)_{2} \\
\text { MgSO4. }\end{array}$ & $\begin{array}{l}\text { Volume } \\
\text { of molec- } \\
\text { ular } \\
\text { partial } \\
\text { concen- } \\
\text { tration } \\
\text { of KH. } \\
\text { PO. }\end{array}$ \\
\hline R1S1_... & $1: 1: 5$ & \multirow{5}{*}{0.0035} & R3S1 & \multirow{9}{*}{$\begin{array}{l}3: 1: 3 \\
3: 2: 2 \\
3: 3: 1 \\
4: 1: 2 \\
1: 2: 1 \\
5: 1: 1\end{array}$} & \multirow{6}{*}{0.0105} \\
\hline S2 & $1: 2: 4$ & & S2 & & \\
\hline S3.... & $1: 3: 3$ & & S3 & & \\
\hline S4 & $1: 4: 2$ & & R4S1 & & \\
\hline S5 & $1: 5: 1$ & & S2 & & \\
\hline R2S1 & $2: 1: 1$ & \multirow{4}{*}{0.0070} & R5S1_.................... & & \\
\hline S2 & $2: 2: 3$ & & & & \multirow{3}{*}{$0.017 \mathrm{~s}$} \\
\hline S3 ............ & $2: 3: 2$ & & & & \\
\hline $\mathrm{S} 4 \ldots \ldots$ & $2: 4: 1$ & & & & \\
\hline
\end{tabular}

Four-salt type A.-(Monopotassium phosphate, calcium nitrate, magnesium sulphate, ammonium sulphate). Thirty-five different sets of molecular salt proportions were tested for this solution type. The thirty-five stock culture solutions all agree in having a total of 0.0384 gram-molecule of salt per liter and the molecular partial concentration of each of the four salts differs from solution to solution throughout the series by increments of one-eighth of the total molecular concentration; that is, by increments of 0.0048 gram-molecule. These thirty-five different 4-salt stock solutions may be designated according to the positions of the points representing them on a 4-coördinate (solid) diagram similar to the one used by Tottingham. The diagram here used is shown in fig. 2. It is like that employed

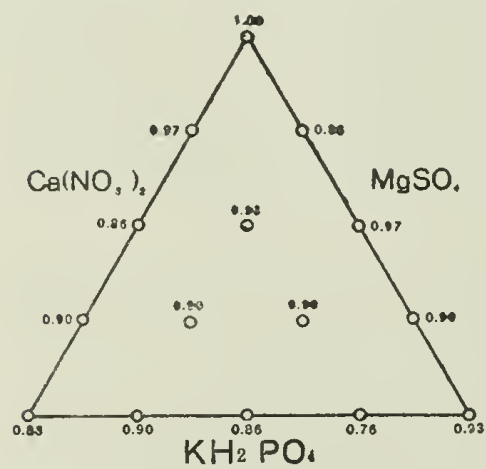

FIG. 2. Relative values of root length for series 4 , with 3 -salt solution type I (increments of one-seventh, total concentration of 0.0061 gram-molecule per liter or 0.23 atmosphere). by Tottingham except that the several equilateral triangles on which the equilateral tetrahedron is built are here represented somewhat in perspective and are placed one above the other, the tetrahedron itself being indicated in outline and having its vertical axis represented as much longer than the other axes, in order to accommodate for the perspective views of the component triangles. Tottingham represented the several triangles all on the same plane, 
where they could be drawn as equilateral without distortion. The different sets of molecular salt proportions will be named by formulas similar to those employed by Tottingham, the letter $\mathrm{S}$ being here used in place of the $\mathrm{C}$ in his formulas. T1R1S1 is the solution (or set of salt proportions) represented by the lower front apex of the diagram; T1R2S4 is the one represented by the fourth point, counting from the left, in the second row from the front of the lowest triangle; T3R1S2 is represented by the second point, counting from the left, in the front row of the third triangle from the bottom; T5R1S1 is represented by the top apex of the tetrahedron (since the fifth triangle has but a single point), etc. In this diagram every solution of the lowest triangle has ore-eighth of its total molecular concentra-

TABLE 2.-Descriptions of stock culture solutions of 4-salt types $A$ and $B$ ( $A$, with both ammonium and nitrate; $B$, without nitrate)."

[Total concentration, 0.0381 gram-molecule (of all salts taken together) per liter.]

\begin{tabular}{|c|c|c|c|c|c|}
\hline Solution No. & $\begin{array}{c}\text { Molecu- } \\
\text { lar salt } \\
\text { propor- } \\
\text { tions } \\
\mathrm{KH}_{2} \mathrm{PO}_{4} \\
\left(\mathrm{NH}_{4}\right)_{2} \\
\mathrm{SO}_{4} \mathrm{Ca} \\
\left(\mathrm{NO}_{3}\right)_{2} \\
\mathrm{MgSO}_{4}\end{array}$ & $\begin{array}{l}\text { Volume } \\
\text { of molec- } \\
\text { ular par- } \\
\text { tial con- } \\
\text { centra- } \\
\text { tion of } \\
\mathrm{KH}_{2} \mathrm{PO} 4\end{array}$ & Solntion No. & $\begin{array}{c}\text { Molecu- } \\
\text { lar salt } \\
\text { propor- } \\
\text { tions } \\
\mathrm{KH}_{2} \mathrm{PO}_{4} \\
\left(\mathrm{NH}_{4}\right)_{2} \\
\mathrm{SO}_{4} \mathrm{Ca}_{2} \\
\left(\mathrm{NO}_{3}\right)_{2} \\
\mathrm{MgSO}_{4} \text {. }\end{array}$ & $\begin{array}{l}\text { Volume } \\
\text { of molec- } \\
\text { ular par- } \\
\text { tial con- } \\
\text { centra- } \\
\text { tion of } \\
\mathrm{KH}{ }_{2} \mathrm{PO}\end{array}$ \\
\hline T1R1S1 ... & $1: 1: 1: 5$ & \multirow{20}{*}{0.0048} & T2RIS1 & $2: 1: 1: 4$ & \multirow{13}{*}{0.0096} \\
\hline $\mathrm{S} 2$ & $1: 1: 2: 4$ & & S2 & $2: 1: 2: 8$ & \\
\hline S3 ..... & $1: 1: 3: 9$ & & S3 $\ldots$-. & $2: 1: 3: 2$ & \\
\hline$S_{4} \ldots \ldots$ & $1: 1: 4: 2$ & & $81 \ldots$ & $2: 1: 4: 1$ & \\
\hline S5 & $1: 1: 5: 1$ & & R2S1 & $2: 2: 1: 3$ & \\
\hline R2S1 ..... & $1: 2: 1: 1$ & & S2 & $2: 2: 2: 2$ & \\
\hline S2 $\ldots$ & $1: 2: 2: 3$ & & $83 \ldots$ & $2: 2: 3: 1$ & \\
\hline S3 _... & $1: 2: 3: 2$ & & R3S1 .... & $2: 3: 1: 2$ & \\
\hline S4 & $1: 2: 4: 1$ & & S2 & $2: 3: 2: 1$ & \\
\hline R3S1 & $1: 3: 1: 3$ & & R4S1 & $2: 4: 1: 1$ & \\
\hline S2 - & $1: 3: 8: 2$ & & T3R1S1 & $3: 1: 1: 3$ & \\
\hline S3 & $1: 3: 3: 1$ & & S2 & $3: 1: 2: 2$ & \\
\hline R4S1 ....... & $1: 4: 1: 2$ & & S3 & $3: 1: 3: 1$ & \\
\hline S2 & $1: 4: 2: 1$ & & R2S1 _.-.. & $3: 2: 1: 2$ & 0.0141 \\
\hline \multirow[t]{6}{*}{ R5S1 } & $1: 6: 1: 1$ & & S2 _-_. & $3: 2: 2: 1$ & \\
\hline & & & R3S1 & $3: 3: 1: 1$ & \\
\hline & & & T4R1S1 & $4: 1: 1: 2$ & \\
\hline & & & S2 & $4: 1: 2: 1$ & 0.0192 \\
\hline & & & R2S1 & $4: 2: 1: 1$ & \\
\hline & & & T5R1S1 & $5: 1: 1: 1$ & 0.0240 \\
\hline
\end{tabular}

a The salts named are those of trpe A; for type B, monocalcium phosphate replaced ealeium nitrate as here given. 
tion made up of monopotassium phosphate, each of those of the front margin of each triangle has one-eighth made up of ammonium sulphate, every one of the left margin of each triangle has one-eighth made up of calcium nitrate, and every one of the right margin has one-eighth made up of magnesium sulphate, etc. The solution at the top apex of the solid diagram (T5R1S1) has the salt monopotassium phosphate represented by five-eighths of its total molecular concentration, while each of the remaining three salts is represented by only one-eighth of the total.

The different sets of molecular salt proportions for solution types $\mathrm{A}$ and $\mathrm{B}$, and the molecular partial concentrations of the one salt monopotassium phosphate, are shown in Table 2. From these data the molecular partial concentrations of the other three salts can be readily computed.

Four-salt type B.-(Monopotassium phosphate, monocalcium phosphate, magnesium sulphate, ammonium sulphate.) This type of solution differs from type A only in this particular, that it contains no calcium nitrate but has its calcium supplied as monocalcium phosphate. While type A contains both ammonium and nitrate as the nitrogen-bearing ions, type B contains only'ammonium. Type B was studied in the same way as type A and the solution designations, salt proportions, total molecular concentrations, etc., are alike for the two types.

THE CULTURE SOLUTIONS

Each time a supply of culture solution was required, for starting a culture or for the renewal of its solution, this supply was prepared by merely drawing off some of the corresponding stock solution (in a few cases) or else by diluting some of that stock solution, the degree of dilution being of course determined by the total concentration required for the particular culture in question. Finally, after the solution for any series had been placed in the culture bottles, the ferric phosphate suspension was added. The culture solutions thus prepared were not stored in quantity and each lot was always placed at the disposal of the plants within twenty-four hours after it had been made up.

In renewing the solutions a set of culture bottles were first prepared and filled with their respective solutions. Then each cork, bearing its plants, was transferred from the bottle used during the previous period to the corresponding bottle of the newly prepared set. The plants were thus out of solution only momentarily. 
Since the physical, chemical, and physiological properties of any complex solution depend (for any temperature, etc.) upon (1) the nature of the solutes contained, (2) their proportions in the mixture, and (3) the total concentration of the solution,,$^{22}$ it is of course necessary, in such a study as this, to make comparisons between various nutrient solutions not only with reference to the kinds of salts used and their proportions in the solution, but also with reference to total concentration. It was therefore planned to determine approximately the best total concentration (for the growth of these seedling rice plants under the non-solution conditions employed for each culture series) for each set of salt proportions tested. This means that several different degrees of dilution of each one of the thirty-five stock culture solutions already characterized, had to be employed. Table 3 shows the different total concentrations that were actually used in each case. It also shows the time of year when each series of tests was made, as indicated by the dates. The different series are set forth under each of the three solution types in the order of their total concentrations.

During the culture period the culture solutions were renewed at intervals of three or four days, after the first five days. In connection with this sort of work it should not be forgotten that a given solution begins to alter in respect to its chemical and physical properties as soon as it is brought into contact with the plant roots, and that this alteration continues (in unknown ways) until the old, altered solution is removed and replaced by a fresh one having the standard properties of the old one at the start. The supply of the various ions and molecules at the absorbing surfaces of the roots is of course determined by the respective partial concentrations of these in that

Different writers state this generalization in various ways, frequently from a distinctly not all-inclusive point of view. Some misunderstandings as to the nature of the questions involved and considerable resultant discussion have occurred in the literature, but the matter is too complicated for the present writer to attempt a broad discussion of it here. Especially have students of solution cultures given particular attention to these three controlling conditions as related to the physiological value of a nutrient solution. Whatever may prove to be the most useful way of giving quantitative values to these conditions, it seems quite clear that a plant growing in an aqueous solution may be made to grow faster or slower, better or worse, by altering any one, or two, or all three, of these characteristics of the solution; provided of course that other environmental conditions are not altered in a compensating manner, that the change or changes in the solutions are sufficiently great, and that the changed conditions are maintained for a sufficient length of time. 
portion of the solution that lies closely adjacent to the root surfaces. These partial concentrations should of course be maintained constant in experiments of this kind, but the large

TABLE 3.-Summary of the experimental series, showing dates, solution type, and total molecular concentration (also estimated osmotic value as o fraction of an atmosphere of pressure) for each series.

\begin{tabular}{|c|c|c|c|c|c|c|c|c|c|c|}
\hline \multirow{3}{*}{ Serics. } & \multicolumn{4}{|c|}{ Date (1918). } & \multicolumn{6}{|c|}{ Total concentration. * } \\
\hline & \multirow{2}{*}{\multicolumn{2}{|c|}{ Beginning. }} & \multirow{2}{*}{\multicolumn{2}{|c|}{ Ending. }} & \multicolumn{2}{|c|}{ 3-salt type I. } & \multicolumn{2}{|c|}{ 4-salt type A. } & \multicolumn{2}{|c|}{ 4-salt type B. } \\
\hline & & & & & $\begin{array}{c}\text { Gram- } \\
\text { molecule } \\
\text { per liter. }\end{array}$ & $\begin{array}{l}\text { Atmos- } \\
\text { phere. }\end{array}$ & $\begin{array}{c}\text { Gram- } \\
\text { molecule } \\
\text { per liter. }\end{array}$ & $\begin{array}{l}\text { Atmos. } \\
\text { phere. }\end{array}$ & $\begin{array}{l}\text { Gram- } \\
\text { molecule } \\
\text { per liter. }\end{array}$ & $\begin{array}{l}\text { Atmos- } \\
\text { phere. }\end{array}$ \\
\hline $1 \ldots$ & March & 21 & April & 11 & 0.002 & 0.01 & & & & \\
\hline 2 & March & 21 & April & 11 & \multirow{3}{*}{0.012} & \multirow{3}{*}{0.05} & & & & \\
\hline 3 & March & 24 & April & 11 & & & & & & \\
\hline $4 \ldots$. & February & 22 & March & 14 & & & & & & \\
\hline 5.... & March & 21 & April & 11 & \multirow[t]{2}{*}{0.0061} & \multirow[t]{2}{*}{0.23} & & & & \\
\hline 6 & March & 24 & April & 11 & & & & & & \\
\hline 7--- & March & 21 & April & 11 & \multirow{2}{*}{0.0123} & \multirow{2}{*}{0.46} & & & & \\
\hline 8.-- & March & 24 & April & 11 & & & & & & \\
\hline 9 & March & 21 & April & 11 & 0.0245 & 0.93 & & & & \\
\hline $10 \mathrm{~b}$ & March & 11 & April & 5 & 0.0002 & 0.01 & & & & \\
\hline $11 \ldots$ & \multicolumn{2}{|c|}{ - } & \multicolumn{2}{|c|}{ - } & 0.0012 & 0.05 & 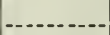 & & & \\
\hline $12 \ldots$ & \multicolumn{2}{|c|}{ - } & \multicolumn{2}{|c|}{ - } & \multirow{3}{*}{$\begin{array}{l}0.0061 \\
0.0123\end{array}$} & \multirow{3}{*}{$\begin{array}{l}0.23 \\
0.93\end{array}$} & & & & \\
\hline 13 & \multicolumn{2}{|c|}{ - } & - & --- & & & & & & \\
\hline 14 & June & 19 & July & 9 & & & 0.0008 & 0.04 & & \\
\hline 15 & May & 24 & June & 14 & & & 00016 & & & \\
\hline $16 \ldots$ & June & 19 & July & 9 & & & 0.0016 & 0.08 & & \\
\hline $17 \ldots$ & May & 1 & May & 22 & & & & & & \\
\hline 18 & May & 24 & June & 14 & & & 0.0038 & 0.20 & & \\
\hline 19 & June & 19 & July & 9 & & & & & & \\
\hline $20 \ldots$ & June & 19 & July & 9 & & & 0.0077 & 0.40 & & \\
\hline $21 \ldots$ & May & 24 & June & 14 & & & 0.0192 & 1.00 & & \\
\hline $22 \ldots$ & May & 1 & May & 22 & & & 0.0384 & 2.00 & & \\
\hline 23 & August & 3 & August & 23 & & & & & & \\
\hline 24 & Septemher & 9 & September & 29 & & & & & 0.0008 & 0.04 \\
\hline 25 & August & 8 & August & 23 & & & & & & \\
\hline 26 & September & 9 & Septemher & 29 & & & & & 0.0016 & 0.08 \\
\hline $27 \ldots$ & August & 3 & August & 23 & & & & & 0.0038 & 0.20 \\
\hline $28 \ldots$ & September & 9 & Septemher & 29 & & & & & & \\
\hline
\end{tabular}

a Total fraction of a gram-molecule of all salts per liter, and estimated osmotic value as a fraction of an atmosphere of pressure.

b Series $10,11,12$, and 13 were with wheat, for comparison with the results ohtained hy Shive.

amounts of solutions needed and the work involved to accomplish this made it seem undesirable to attempt the use of continuously renewed solutions ${ }^{23}$ in these preliminary studies; when

Trelease, S. F., and Free, E. E., The effect of renewal of culture solutions on the growth of the young wheat plants in water-cultures, Johns Hopkins Univ. Cir. (March, 1917) 425 and 426. 
the time is ripe for it, continuous renewal will surely be resorted to. With the present state of knowledge and technic it may be remarked that the solutions in culture bottles are probably always in a state of convection, so that the solution next to the roots is probably never very different from that at a greater distance. It may therefore be supposed that the culture solution alters as a whole and at a much lower rate than would be the case close to the roots if convection were prevented (as by the presence of sand, agar, etc.). Sufficiently rapid convection would amount to continuous renewal of the solution around any given root; and, if the volume of solution held in the culture bottle is great enough (or if the alteration in the solution, caused by the activity of the roots, is slow enough), then the rate of alteration becomes insignificant, so that the solution about the roots may be considered as being practically maintained constant as to its properties. It has frequently been mentioned in the literature that, if continuous and rather rapid renewal of culture solutions is not employed, the desideratum is more nearly approached with greater volume of the solution (size of culture jar) and greater frequency of renewal. In the present studies 250 cubic centimeters of solution were always employed for six plants, and solution renewal occurred at intervals of three or four days after the first five days, as has been said. The experimental conditions would of course have been more nearly ideal with a larger volume and with more frequent renewal. It may well be that the nature of the results obtained would have been insignificantly different had the conditions been more nearly ideal, but the results presented below are to be regarded as applicable only with reference to the general method here employed. With more time and more work other and farther-reaching results might surely be obtained, along this line as well as along other lines.

A chemical condition that is more or less definitely effective within the liquid media of solution cultures, but that is seldom or never adequately dealt with in this kind of work, is the oxygen supply of the root systems. It is clear that most roots require free oxygen ${ }^{24}$ - that they are aërobic-and there is reason to believe that rice ${ }^{25}$ belongs in this class. It may be conjectured, however, that the roots of young rice plants do

"Free, E. E., The effect of aëration on the growth of buckwheat in water-cultures, Johns Hopkins Univ. Cir. (March, 1917) 198 and 199.

${ }^{25}$ Nagai, I., Some studies on the germination of the seed of Oryza sativa, Journ. Coll. Agr. Imp. Univ., Tokyo 3 (1916) 109-158. 
not require a very high partial concentration of oxygen in the solution in which they are growing, since these plants thrive excellently when rooted in mud containing large amounts of organic matter (reducing agents). No special method was employed to aërate the solutions in the tests here considered, but it may be assumed that all cultures were about alike in this regard and that the supply of oxygen the root surfaces was considerable. The solutions were of course exposed to the air, for the corks bearing the seedlings were far from airtight. That good growth was obtained in some cultures indicates that the oxygen supply was adequate, at least with reference to the non-oxygen conditions employed. With more or less rapid supply of oxygen to the roots, and possibly with other solution and non-solution conditions than those here giving best growth, it is of course possible that still better growth might be obtained. No attempt was made to study the influence of oxygen partial concentration in the media used in these experiments.

From the preceding paragraphs it is clear that the solution conditions (salts, salt proportions, total concentration, oxygen partial concentration, as well as the partial concentrations of excreted substances) altered in some unascertained manner from the time the seedlings were placed in the culture bottles to the time of the first renewal of the solution. At the time of renewal

* the solution conditions were suddenly brought back to the state in which they were at the beginning of the culture. Then alteration began once more and continued for three or four days, when these conditions were again brought back to standard. The standardization of these conditions was subsequently repeated at intervals of three or four days till the end of the culture period.

No attempt was made to determine how the solutions changed between renewals. The line of study here suggested has attracted considerable attention in the past and will surely be continued by plant physiologists, but it has not yet been applied to rice in any thorough manner.

\section{THE NON-SOLUTION CONDITIONS OF THE ENVIRONMENT}

By non-solution conditions of the surroundings are here meant all those conditions that may have influenced the growth of these plants, excepting the conditions that are determined directly by the salts, salt proportions, and total concentration of each culture solution. These non-solution conditions of the evironment were 
practically the same for all the cultures of any single series, and they were the same for all series that were carried out simultaneously (see dates given in Table 3). To approach practical uniformity among simultaneous cultures, the culture bottles were placed on motor-driven rotating tables such as were used by Shive (1915). The tables stood in one of the greenhouse rooms, being located as those of Shive had been.

During the course of each culture series records of the air temperature in the greenhouse in which the cultures were carried out were obtained by means of a thermograph in the shade, under one of the rotating tables. Daily records of the evaporating power of the air and of radiation (sunshine) were also made, by means of the radio-atmometer (white and black spheres). ${ }^{36}$ These records will serve to show, in a general way, the temperature, the moisture, and the total radiation conditions for each experiment series.

\section{PLANT RECORDS}

For some cultures the volume of solution remaining in the culture bottle at each solution renewal was measured, and the volume absorbed by the plants for the preceding period was determined. Finally, from these determinations was obtained the total volume of solution absorbed by the plants for the entire three-week period. This may be taken as practically the same as the total volume of water transpired during the period.

At the end of the experiment period each set of cultures was separated into three groups representing good, medium, and poor growth, respectively, and a representative from each group was photographed. Notes on the appearance of the plants and the mean lengths of tops and of roots were approximately determined. The plants were then removed from the stopper, the remnant of the seed was discarded in each case, and the tops were severed from the roots at the point of attachment to the seed. The dry weights of tops and of roots (the six plants in each culture being treated as a whole) were then obtained in the usual way, the drying being done finally at a temperature of about $105^{\circ} \mathrm{C}$.

In some cases the green weights of tops were approximately determined, to obtain information on the water content, etc. The severed tops from each culture were immediately transferred into a test tube which was then closed and stored in a refrigerator until weighing could be accomplished, which in this case

${ }^{26}$ Livingston, B. E., Atmometry and the porous cup atmometer, Plant World 18 (1915) 21-30, 51-74, 95-111, 143-149. 
was within twenty-four hours. The tube with its contents was weighed, the plant material was removed (and preserved for the dry-weight determination), and the tube was finally weighed dry. From the data thus obtained the green weight and the water content of the tops were determined, the latter being finally expressed as percentage on the basis of green weights.

\section{RESULTS}

\section{AËRIAL CONDITIONS OF THE EXPERIMENT SERIES}

Before proceeding to the presentation of the results obtained from the plants it will be well to present, once for all, the data that characterize the aërial conditions for the various experiment

TABLE 4.-Maximum and minimum temperatures and average daily atmometric and radio-atmometric indices for the different experiment periods.

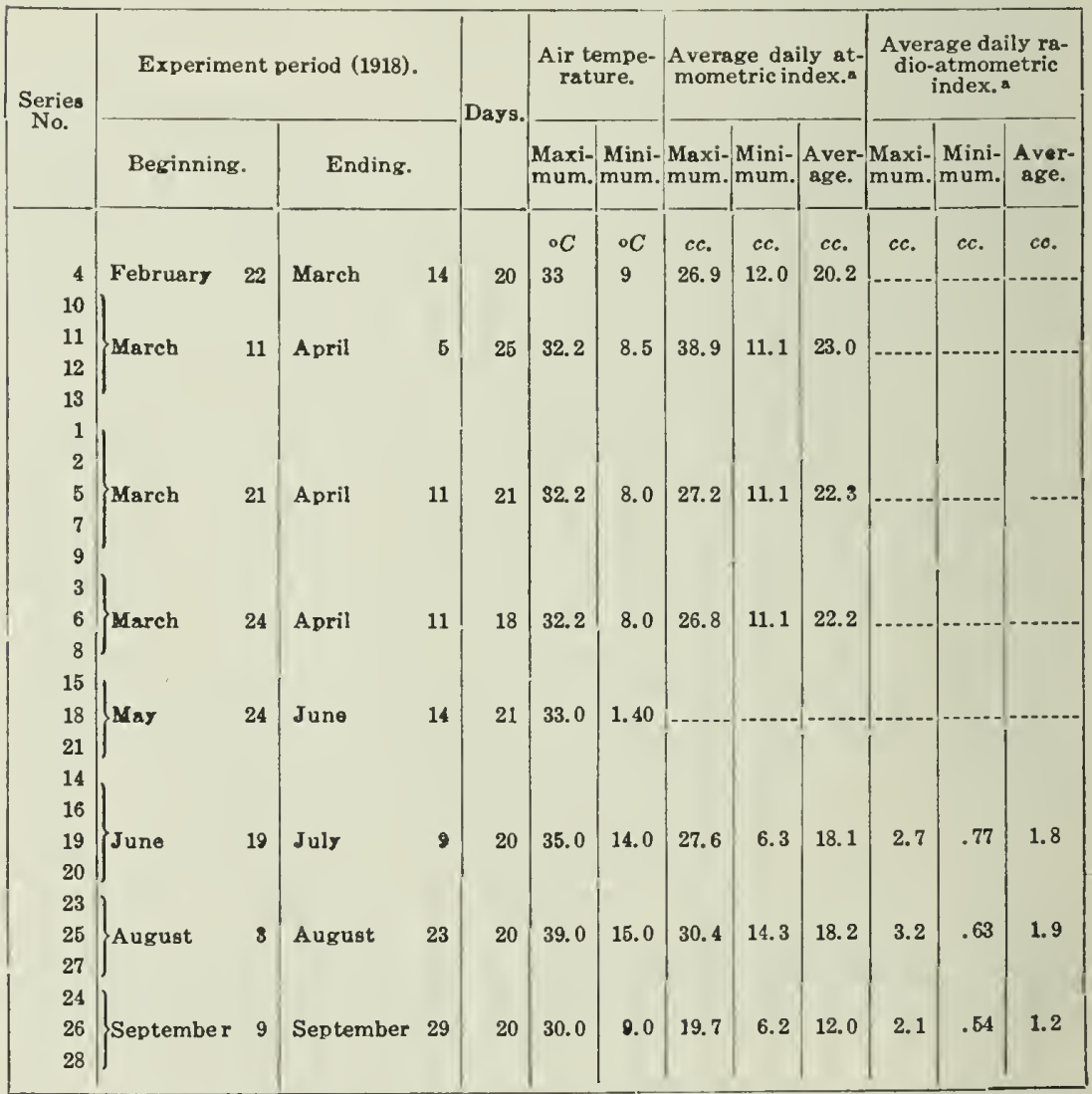

- The atmometric index is the daily rate of water loss from standard white spherical porous-cup atmometer. The radio-atmometric index is the daily excess of water loss from tandard black spherical atmometer, above that from the white. 
series as far as these were obtained. This information will aid in making comparisons with similar series that have been carried out by other students or that may be carried out in the future, and will also furnish some fragmentary evidence regarding the sort of aërial conditions that prevail in a greenhouse at Baltimore for the seasons considered. They are set forth in Table 4.

\section{PLANT RECORDS}

The numerical plant data derived from these experiments and to be considered below include the following values, though these values were not all obtained for all cultures or for all series:

(1) Dry yield of tops (six plants).

(2) Dry yield of roots (six plants).

(3) Green weight of tops (six plants) and percentage of water content.

(4) Total absorption (six plants).

(5) Water requirement per unit of dry weight.

(6) Approximate length of tops (mean for six plants).

(7) Approximate length of roots (mean for six plants).

The results will be presented below, the three types of solution being considered in order.

THREE-SALT TYPE I (MONOPOTASSIUM PHOSPHATE, CALCIUM NITRATE, MAGNESIUM SULPHATE)

Numerical data were not generally obtained for the rice plants grown in the 3-salt solutions of type I, since it was evident throughout these series that none of the cultures were producing what might be called good growth; all exhibited much poorer growth than was obtained from the better solutions of the two types with ammonium. As to the comparative physiological values of the fifteen different sets of salt proportions tested, solutions R1S1, R2S1, R3S1, R4S1, and R5S1 always appeared to be nearly alike and much better than any of the others, while solutions R1S3, R1S4, R1S5, and R2S4 were nearly alike and always belonged to the poor group. These statements refer to all the different total concentrations tested. The comparative values of the fifteen different sets of salt proportions may be represented by the length values for tops, which were obtained for series 4. The relative quantities standing for these top values are shown in the diagram of fig. 1 , for which the largest value (actually 20 centimeters) is considered as unity. It is seen at once that the region nearest the left margin of this diagram represents the best-balanced sets of salt proportions, while the region of the right apex represents the poorest sets. 
The solution represented by the right apex itself (R1S5) is by far the poorest of the series, giving tops only 62.5 per cent as long as those given by solution R4S1, which is the best of the series. This means that solutions having relatively low partial concentrations of the calcium salt are the best. None of the five best sets of salt proportions has over one-seventh of its molecular total made up of calcium nitrate. The three solutions having four-sevenths or five-sevenths made up of calcium nitrate (which are also characterized by low partial concentration of magnesium sulphate) all lie in the poor group.

The root lengths were also obtained for series 4 , and they are shown by their relative values on the diagram of fig. 2 , but they bring out no clear generalization. In this case unity (1.00) represents an actual value of 14.5 centimeters.

Although the 3-salt solutions of the present study are planned by volume-molecular rather than by osmotic salt proportions (the latter having been used by Shive), yet it will be of interest to compare the generalization stated above for these young rice plants, with the outcome of Shive's series for wheat (1915), buckwheat (1917), and soy bean. ${ }^{27}$

The triangular diagrams in question are shown in fig. 3 , in which the diagram of fig. 1 is repeated for the sake of comparison. Considering the main regions of good and poor growth, as marked on these diagrams, for wheat it appears that the best sets of salt proportions are near the center of the triangle, with the three salts in somewhat nearly equal proportions, while the poorest sets have very low partial concentrations of monopotassium phosphate and calcium nitrate and very high partial concentrations of magnesium sulphate. For buckwheat low or medium partial concentrations of calcium nitrate together with medium partial concentrations of monopotassium phosphate represent the best sets of proportions, while the poorest sets have low partial concentrations of magnesium sulphate together with medium and high concentrations of monopotassium phosphate. For soy bean [these data have been derived from Shive's table of results given (1918) on page 109] it appears that low partial concentrations of monopotassium phosphate clearly limit the region of good balance, while high ones represent poor balance. It is remarkable that the diagram for soy bean is very similar to that for rice, except that good physiological balance for soy bean seems to require a very low supply of monopotassium phos-

\footnotetext{
${ }^{27}$ Shive, John W., Toxicity of monobasic phosphates towards soy-beans grown in soil- and solution-cultures, Soils Sci. 5 (1918) 87-122.
} 
phate, while calcium nitrate seems to constitute a corresponding limit for rice; if the soy-bean diagram were rotated a third of a revolution in the clockwise direction it would correspond very closely to the rice diagram.

The points just brought out emphasize what seems likely to be a very important general principle in the science of plant nutrition; namely, that different plant forms may require entirely

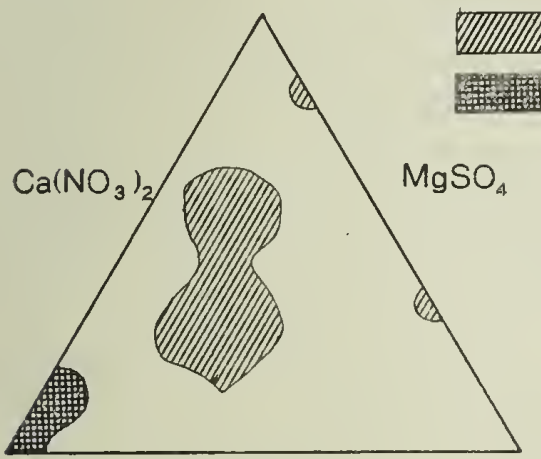

$\mathrm{KH}_{2} \mathrm{PO}_{4}$

Shive, wheat, 1.75 atmospheres.

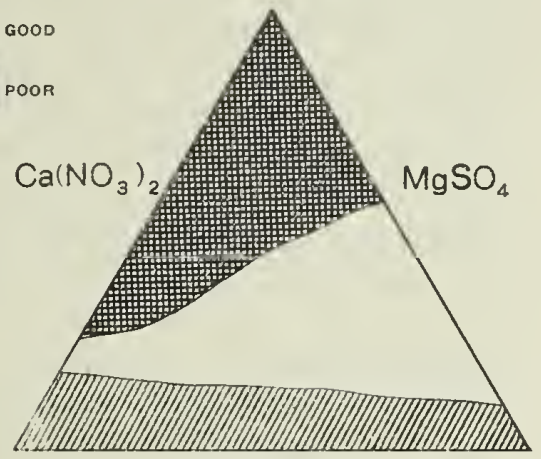

$\mathrm{KH}_{2} \mathrm{PO}_{4}$

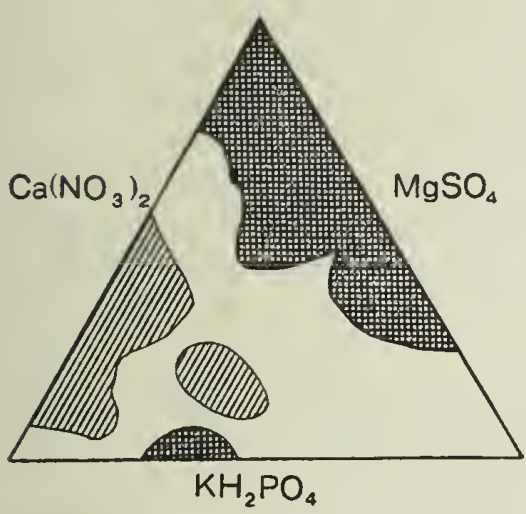

Shive, buckwheat, 1.75 atmospheres.

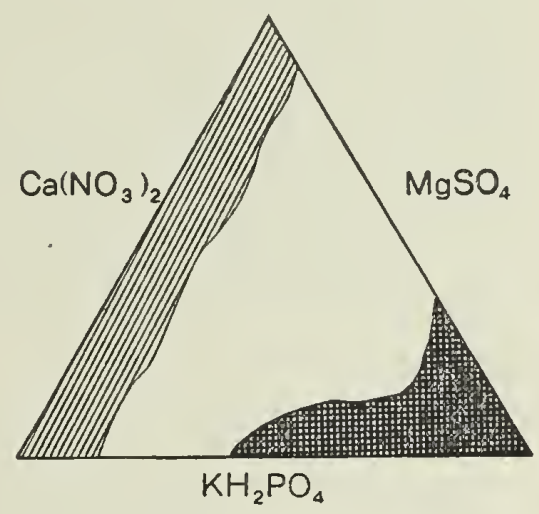

Espino, rice, 0.23 atmosphees.

FIG. 3. Good and poor sets of salt proportions for four plant forms.

different sets of salt proportions for good physiological balance. The comparison just made involves only four plants and no two show a tendency to agree as to the solution characteristics that give best growth. It is of course to be expected that, as the salt requirements of other plants are made known, and as those of the plants here considered become better understood, it will be found that there are a number of types of salt requirement, 
among which the different plant forms will be found to be distributed. It should be emphasized that the data for the four plants thus far studied indicate no solution as well balanced for all, although those with lowest partial concentrations of both monopotassium phosphate and calcium nitrate should be well balanced for both soy bean and rice.

Aside from the question of salt proportions, it is to be noted that Shive's best solutions for wheat and buckwheat have osmotic values of 1.75 atmospheres, and that the best solution he records for soy bean has an osmotic value of 2.5 atmospheres; while the best total concentration for rice, with this type of solution, proved to be about 0.2 atmosphere. In connection with all these considerations it is to be remembered that none of these 3-salt solutions gave really good growth to the young rice plants; what is termed "good" on the lowest diagram of fig. 3 is only relatively good-that is, the best obtained with this solution type. It is thus suggested that the best solution for these rice plants will be found to have a very low total concentration, as compared with the best solutions for wheat, buckwheat, and soy bean. This is borne out by the findings to be reported in the following sections of this paper.

It seems, therefore, that the total concentration best suited to the growth of a given plant is determined not only by the salts and salt proportions but also by the kind of plant considered; also probably by the developmental stage of the plant and by the non-solution conditions of the environment. Different plant forms show different requirements with respect to the total concentration as well as with regard to salt proportions.

The general appearance of the rice plantlets after growing three weeks in the best of these 3-salt solutions is shown by the photograph, Plate 1, fig. 6 .

\section{FOUR-SALT TYPE A (MONOPOTASSIUM PHOSPHATE, CALCIUM NITRATE, MAGNE- SIUM SULPHATE, AMMONIUM SULPHATE)}

Introductory. - The results obtained with the four-salt solution type $\mathrm{A}^{28}$ refer to nine different experimental series (series 14 to 22 inclusive, see Table 3 ) and to six different total concentrations. The numerical results will be presented after values, but the general appearance of the plants has been considered.

General appearance.-After five or six days in the culture

${ }^{28} \mathrm{~A}$ single set of salt proportions of this type of solution was used by Wolkoff; see Wolkoff, M. I., Effect of ammonium sulphate in nutrient solution on the growth of soy beans in sand cultures, Soil Sci. 5 (1918) 123-150. 
solutions differences in the appearance of the plants generally began to be manifest and these differences became more striking as the cultures became older. With higher total concentrations these differences became pronounced sooner than with lower total concentrations. All of the cultures of series 14 to 22 inclusive gave better plants than were obtained in distilled-water cultures simultaneously carried out; the lowest total concentration tried (series 14, 0.0008 gram-molecule per liter, or 0.04 atmosphere) gave better growth in all of its salt proportions than did distilled water. Of the six total concentrations tested, it was generally true that the plants grew faster at first in the weaker solutions, but after about ten days of growth some of the cultures having the second or third total concentration (series 15 and 16, 0.0016 gram-molecule or 0.08 atmosphere, and series 17,18 , and 19, 0.0038 gram-molecule per liter, or 0.2 atmosphere) showed the most rapid growth.

Most of the cultures with the three weaker total concentrations gave good growth, and the best plants of these series were much better in appearance than were the best ones obtained in any of the 3-salt series with rice. There was generally some drying of the tips of the leaves, especially in the first half of the culture period, and this feature was developed more strongly as the total concentration was higher; but it appeared not to be related to salt proportions, for it was about the same for all. While the dead regions of the leaf tips were only about 0.5 centimeter long with the lowest total concentration used, they were two or three times as long with the fourth of the total concentrations (series 20, 0.0077 gram-molecule per liter, or 0.40 atmosphere). The best cultures of series 14 to 20 (with the four lower concentrations) showed good color and the plants were apparently normal in every way.

The highest two total concentrations (series 21 and 22, 0.0192 and 0.0384 gram-molecule per liter, or 1 and 2 atmospheres, respectively) gave poor growth with all salt proportions, the plants appearing markedly stunted, and the leaves drying badly at the tips or even so far as to affect nearly the whole blade. Chlorotic leaves were common with these two stronger total concentrations. For these two series no quantitative plant measurements were made, and they will not be considered in the sections that follow.

In connection with this observation that the highest two concentrations tested showed no sets of salt proportions at all suited to the growth of these plants, it is of interest to emphasize the 
fact that the lower one of these two highest total concentrations (series 21, 0.0192 gram-molecule per liter, or 1 atmosphere) was much less concentrated than Shive's best solution for young wheat plants. Whatever may be the details in this connection, it is safe to say that Shive's wheat grew excellently in solutions with osmotic values of $\mathbf{1 . 7 5}$ atmospheres, or even higher, while the rice of the present studies failed to develop even fairly well, with any set of salt proportions, if the osmotic value was greater than about 0.4 atmosphere. Turning to the other plants that have been studied in a systematic way by Shive (1917), by Shive and Martin, ${ }^{29}$ and by Shive (soybeans, 1918), it will be seen that buckwheat gave about twice as much in dry yields of tops with the best sets of salt proportions for a total concentration of 1.75 atmospheres as it did with the best ones for a concentration of 0.1 or 4 atmospheres; so that it is evident that rice does not require nearly so high a total concentration for its best growth while young as does buckwheat. Also, Shive obtained excellent growth for soy beans with a total concentration value of 2.5 atmospheres, which indicates that this plant thrives best for the first few weeks in solutions much more concentrated than can well be borne by young rice plants. It may safely be said that rice differs remarkably from wheat, buckwheat, and soy bean, in that, in the case of these three plants, the total concentrations of the nutrient salt mixtures that show best growth in the young ones (when the salt proportions are properly arranged) have osmotic values well above 1 atmosphere, while this value is only about 0.5 atmosphere, or even lower, in the case of rice.

These considerations regarding the comparative ability of rice, wheat, buckwheat, and soy bean to withstand high total concentration of the culture solution, providing the salt proportions are properly arranged, will be still further emphasized when the quantitative data of the present studies are considered.

Throughout these series with the 4-salt solution type $\mathrm{A}$, the yellowing of the leaves was generally more intense for the smaller plants; that is, chlorosis and stunted growth appeared to be controlled by the same sets of conditions. The more pronounced differences in size were paralleled by similar differences in dry yield.

${ }^{29}$ Shive, John W., and Martin, William H., A comparative study of salt requirements for young and for mature buckwheat plants in solution cultures, Journ. Agr. Res. 14 (1918) 151-175. Idem, A comparison of salt requirements for young and for mature buckwheat plants in water cultures and sand cultures, Am. Journ. Bot. 5 (1918) 186-191. 
There was generally good agreement in the appearance of the six plants of any culture. Occasionally a seedling died, but this was rare. For such cases the quantitative data have been computed to represent six plants, although actually based on only five.

As to the different sets of salt proportions, the appearance of the plants became progressively poorer (especially with reference to chlorosis and size) with higher relative partial concentrations of monopotassium phosphate; that is, as the top apex of the tetrahedral diagram is approached, the plants are shown to have become more and more stunted and chlorotic. The bestappearing plants represent sets of salt proportions given in the lowest or the lowest two triangles of the diagram and the poorest plants represent the sets at or near the top apex.

Dry yield of tops.-The dry yield of tops from series 14 to 20 is shown in Table 5, all values being expressed in terms of the corresponding value for culture T1R1S1 of the same series. The actual value (fraction of a gram) for the last-named culture is given in parentheses beneath the value 1.00 , in each case. Values marked $\mathrm{H}$ belong to the highest seven values obtained in the given series, those marked $L$ belong to the lowest seven. These two groups of seven values (there are generally more than seven cultures included, on account of like values from two or more of them) will be called the high and the low groups. The date of beginning of each series is given beneath the series number.

Inspection of Table 5 brings out the fact that, where repetitions were made there are frequent discrepancies, a given solution giving a high relative value for one trial and a medium or low value for another trial. These discrepancies are attributable to unknown conditions (perhaps largely to the nonsolution conditions called climatic). It will be remembered that these different trials were made at different seasons of the year, as indicated by the dates. It has been emphasized by other writers that the relative value of any solution must be expected to be different for different sets of non-solution conditions, providing, of course, that the latter differences are large enough to be effective. Whatever may have been the conditional differences that were at work in these cases of discrepancy, it is clear that comparisons between the physiological properties of the solutions here considered (as to whether they gave high, medium, or low yields of tops) must be made only in a broad and general way. It is to be supposed that, had series 14 and 
20 been repeated, they also would have shown discrepancies similar to the ones shown for series 15 and 16 and for series 17 to 19. It is obvious that better control of non-solution conditions must be employed before such comparisons as the ones

TABE 5.-Relative dry yields of tops (six plants), from series with 4 -salt solution type $A$.

[The value for culture T1R1S1 is always taken as unity and the others are expressed in terms of this. The actual value (grams) for this culture is given in parentheses below the assumed value of unity, in each case.]

\begin{tabular}{|c|c|c|c|c|c|c|c|}
\hline \multirow{2}{*}{ Solution No. } & \multirow{2}{*}{$\begin{array}{c}\text { Total con- } \\
\text { centration } \\
0.0008 \\
\text { gram- } \\
\text { molecule } \\
\text { per liter, or } \\
0.04 \text { at- } \\
\text { mosphere. } \\
\text { Series 14. } \\
\text { June 19. }\end{array}$} & \multicolumn{2}{|c|}{$\begin{array}{l}\text { Total concentration } \\
0.0016 \text { gram-molecule } \\
\text { per liter, or } 0.08 \text { atmos- } \\
\text { phere. }\end{array}$} & \multicolumn{3}{|c|}{$\begin{array}{l}\text { Total concentration } 0.0038 \text { gram- } \\
\text { molecule per liter, or } 0.2 \text { atmos- } \\
\text { phere. }\end{array}$} & \multirow{2}{*}{$\begin{array}{c}\text { Total con- } \\
\text { centration } \\
0.0077 \\
\text { gram- } \\
\text { molecule per } \\
\text { liter, or } 0.4 \\
\text { atmosphere. } \\
\text { Series 20, } \\
\text { June 19. }\end{array}$} \\
\hline & & $\begin{array}{l}\text { Series } 15, \\
\text { May } 24 .\end{array}$ & $\begin{array}{l}\text { Series 16, } \\
\text { June } 19 .\end{array}$ & $\begin{array}{l}\text { Series } 17 . \\
\text { May } 1 .\end{array}$ & $\begin{array}{l}\text { Series } 18, \\
\text { May } 24 .\end{array}$ & $\begin{array}{l}\text { Series } 19 \\
\text { June } 19 .\end{array}$ & \\
\hline T1R1S1_.. & $\begin{array}{c}1.00 \\
(0.198)\end{array}$ & $\begin{array}{c}\text { H } 1.00 \\
\quad(0.416)\end{array}$ & $\begin{array}{l}\text { H } 1.00 \\
\quad(0.239)\end{array}$ & $\begin{array}{l}\text { H } 1.00 \\
\quad(0.354)\end{array}$ & $\begin{array}{l}\text { H } 1.00 \\
\quad(0.420)\end{array}$ & $\begin{array}{c}\text { H } 1.00 \\
(0.243)\end{array}$ & $\begin{array}{c}\text { H } 1.00 \\
(0.226)\end{array}$ \\
\hline S2_... & 0.98 & Н 0.98 & H 0.98 & H 1.02 & H 0.97 & 0.86 & 0.73 \\
\hline S3... & 0.99 & H 0.96 & H 0.96 & 0.85 & H 0.94 & 0.84 & 0.73 \\
\hline S4_.... & $0.74 \mathrm{~L}$ & 0.90 & 0.95 & H 0.89 & H 0.91 & 0.79 & 0.69 \\
\hline S5..... & $0.83 \mathrm{~L}$ & $0.81 \mathrm{~L}$ & 0.85 & 0.74 & 0.80 & $0.68 \mathrm{~L}$ & 0.64 \\
\hline R2S1..... & 1.04 & H 0.98 & H 1.02 & H 0.96 & H 0.96 & H 0.91 & H 0.82 \\
\hline S2 & H 1.16 & Н 0.94 & 0.94 & 0.87 & H 1.00 & 0.84 & H 0.88 \\
\hline S3... & H 1.09 & H 0.92 & 0.87 & Н 0.93 & 0.77 & 0.82 & 0.71 \\
\hline S4 & H 1.08 & 0.88 & $0.80 \mathrm{~L}$ & Н 0.92 & 0.79 & 0.83 & 0.65 \\
\hline R3S1... & H 1.08 & $\mathrm{H} 0.93$ & H 1.00 & 0.82 & 0.82 & 0.89 & H 1.04 \\
\hline S2 & 1.08 & H 0.93 & Н 0.99 & 0.80 & H 0.95 & H 0.95 & H 0.91 \\
\hline S3 & 0.94 & $0.80 \mathrm{~L}$ & 0.87 & 0.74 & 0.88 & Н 0.95 & -0.71 \\
\hline R4S1 & 1.00 & 0.88 & 0.92 & H 0.95 & 0.90 & H 1.04 & H 0.93 \\
\hline S2 & H 1.14 & $0.80 \mathrm{~L}$ & 0.87 & H 0.92 & H 0.94 & Н 0.92 & 0.74 \\
\hline R5S1 & 0.94 & $0.79 \mathrm{~L}$ & 0.93 & 0.80 & 0.81 & 0.76 & 0.68 \\
\hline T2R1S1_... & 1.01 & H 0.97 & 0.92 & 0.81 & H 0.96 & H0.97. & H 0.85 \\
\hline S2 & $0.90 \mathrm{~L}$ & 0.91 & 0.85 & 0.69 & H 0.95 & 0.82 & 0.73 \\
\hline S3... & $0.86 \mathrm{~L}$ & 0.86 & $0.83 \mathrm{~L}$ & 0.77 & $0.74 \mathrm{~L}$ & 0.86 & 0.65 \\
\hline S4 & $0.78 \mathrm{~L}$ & 0.85 & $0.80 \mathrm{~L}$ & $0.62 \mathrm{~L}$ & $0.67 \mathrm{~L}$ & $0.51 \mathrm{~L}$ & $0.58 \mathrm{~L}$ \\
\hline R2S1 & 0.93 & 0.89 & H 0.96 & 0.84 & 0.79 & 0.87 & 0.63 \\
\hline S2 & H 1.11 & 0.88 & H 1.17 & $0.65 \mathrm{~L}$ & 0.77 & Н 0.99 & 0.73 \\
\hline S3 & $0.92 \mathrm{~L}$ & $0.84 \mathrm{~L}$ & $0.68 \mathrm{~L}$ & 0.68 & $0.73 \mathrm{~L}$ & $0.72 \mathrm{~L}$ & $0.61 \mathrm{~L}$ \\
\hline R3S1 & H 1.16 & 0.92 & 0.89 & 0.69 & 0.89 & $0.72 \mathrm{~L}$ & 0.77 \\
\hline S2_.... & H 1.08 & 0.87 & 0.91 & $0.66 \mathrm{~L}$ & 0.87 & 0.75 & 0.72 \\
\hline R4S1 & 1.03 & 0.87 & 0.92 & 0.72 & H 0.92 & 0.86 & $0.56 \mathrm{~L}$ \\
\hline T3R1S1_.... & 1.02 & 0.90 & 0.90 & 0.75 & 0.79 & $0.47 \mathrm{~L}$ & 0.70 \\
\hline S2..... & 1.04 & $0.75 \mathrm{~L}$ & 0.85 & $0.62 \mathrm{~L}$ & $0.67 \mathrm{~L}$ & $0.71 \mathrm{~L}$ & 0.69 \\
\hline S3 & $0.86 \mathrm{~L}$ & $0.80 \mathrm{~L}$ & $0.74 \mathrm{~L}$ & $0.54 \mathrm{~L}$ & $0.67 \mathrm{~L}$ & $0.58 \mathrm{~L}$ & $0.35 \mathrm{~L}$ \\
\hline R2S1..... & H 1.14 & $0.82 \mathrm{~L}$ & H 1.20 & 0.71 & 0.86 & $0.73 \mathrm{~L}$ & 0.75 \\
\hline S2.... & 1.03 & 0.87 & $0.72 \mathrm{~L}$ & $0.62 \mathrm{~L}$ & 0.88 & $0.71 \mathrm{~L}$ & $0.53 \mathrm{~L}$ \\
\hline R3S1 & H 1.21 & Н 0.96 & 0.92 & $0.66 \mathrm{~L}$ & $0.71 \mathrm{~L}$ & $0.73 \mathrm{~L}$ & $0.58 \mathrm{~L}$ \\
\hline T4R1S1_.... & 0.94 & 0.87 & $0.72 \mathrm{~L}$ & $0.61 \mathrm{~L}$ & $0.70 \mathrm{~L}$ & 0.79 & $0.60 \mathrm{~L}$ \\
\hline S2 & $0.88 \mathrm{~L}$ & $0.83 \mathrm{~L}$ & $0.69 \mathrm{~L}$ & $0.45 \mathrm{~L}$ & $0.64 \mathrm{~L}$ & $0.51 \mathrm{~L}$ & $0.68 \mathrm{~L}$ \\
\hline R2S1...... & H 1.10 & 0.87 & $0.81 \mathrm{~L}$ & $0.56 \mathrm{~L}$ & $0.76 \mathrm{~L}$ & 0.75 & $0.63 \mathrm{~L}$ \\
\hline T5R1S1..... & H 1.09 & 0.88 & $0.80 \mathrm{~L}$ & $0.54 \mathrm{~L}$ & $0.74 \mathrm{~L}$ & $058 \mathrm{~L}$ & $0.67 \mathrm{~L}$ \\
\hline
\end{tabular}


here made may be interpreted in any great degree of detail. Until such controls (especially of air and light conditions) become available, all that can be done is to make the survey for such problems as this rather superficial, to discuss the moreand the less-promising solutions for the uncertain range in the complex of non-solution conditions with which the whole investigation deals. This will be attempted in the present case, and the generalizations that are presented below are to be regarded as only tentatively established; they are meant to apply to such non-solution conditional complexes as were met with in the greenhouse here used, between May 1 and July 9 .

It is seen from Table 5 that no set of salt proportions falls in the high group $(\mathrm{H})$ for all series and that only two sets (T3R1S3 and T4R1S2) fall in the low group (L) for all series. Furthermore, no set of proportions falls in the medium group (unmarked in the table) for all series. Inspection of the actual top yields (from which the relative values of Table 5 have been computed) leads to the conclusion that the solutions of series 14 (the lowest total concentration dealt with) are in general too dilute to give the best growth of these plantlets, and, similarly, that those of series 20 (the highest total concentration studied) are too concentrated. This statement is supported by the data of Table 6, which shows the ranges of the actual topyield values for the high and low groups, for the four series carried out simultaneously beginning June 19. A similar summary of the ranges for root-yield values is given in the same table.

TABLE 6.-Highest and lowest yields of tops and of roots (milligrams) in the high and in the low groups for the four series carried out simultaneously beginning June 19.

\begin{tabular}{|c|c|c|c|c|c|c|c|c|c|}
\hline & & \multicolumn{2}{|c|}{$\begin{array}{c}\text { Series } 14 \text { (low- } \\
\text { est total concen- } \\
\text { tration). }\end{array}$} & \multicolumn{2}{|c|}{$\begin{array}{l}\text { Series } 16 \text { (low- } \\
\text { medium total } \\
\text { concentration). }\end{array}$} & \multicolumn{2}{|c|}{$\begin{array}{l}\text { Series } 19 \text { (high- } \\
\text { medium total } \\
\text { concentration). }\end{array}$} & \multicolumn{2}{|c|}{$\begin{array}{l}\text { Series } 20 \text { (high- } \\
\text { est total con- } \\
\text { centration). }\end{array}$} \\
\hline & & Highest. & Lowest. & Highest. & Lowest. & Highest. & Lowest. & Highest. & Lowest. \\
\hline Tops_.. & High group.. & 240 & 214 & 287 & 235 & 253 & 224 & 236 & 185 \\
\hline Do & Low group.-. & 184 & 154 & 192 & 163 & 176 & 115 & 138 & 80 \\
\hline Roots_. & High group.- & 85 & 72 & 78 & 72 & 74 & 64 & 82 & 50 \\
\hline Do... & Low group..- & 65 & 54 & 62 & 52 & 53 & 42 & 45 & 36 \\
\hline
\end{tabular}

From the upper part of Table 6 it appears that the maximum top yields from series 14 and 20 are both lower than either of the corresponding maxima for the two remaining series, and that the minimum top yields for the high group for series 14 
and 20 are likewise lower than the corresponding minima for the two other series. For the low group the evidence is not so clear, but both minimum and maximum for series 16 are higher than the corresponding minima and maxima for series 14 and 20.

On the whole, it seems safe to conclude that the most promising solution for these young rice plants is to be looked for among solutions having total concentrations higher than the lowest and lower than the highest concentration here considered. For this reason attention will be mainly turned toward the series employing the two medium total concentrations (series 15 and 16 , and series 17 to 19 ).

Before leaving the general subject of the comparison of the four different total concentrations, however, it may be remarked that both high and low yields are shown for all the triangles of the tetrahedral diagram (except the top one) for the lowest total concentration, but that the two groups become more and more sharply segregated with higher total concentrations, so that with the highest concentration (series 20) all the high values but one (T2R1S1, which has a comparatively low value for the high group) occur in the lowest triangle (T1), while no low values at all are shown for that triangle. This progressive segregation of the high values toward the lowest triangle of the diagram, with progressively higher total concentrations, may be considered to mean that the higher the total concentration the smaller must be the relative partial pressure of monopotassium phosphate, if excellent growth is to be expected. No segregation of this sort is apparent for series 14, with the lowest concentration studied, and the distribution of the low and high top-yield values in this series fails to suggest any definite relation between salt proportions and these values. This fact, together with other data for series 14 , seem to indicate that the total concentration is here too low to produce the best growth of these plants and to bring out their salt relations as has been mentioned. Omitting this series, we may observe that just two solutions (T1R1S1 and T1R2S1) gave high values in all the remaining series, so that these two solutions appear, on the whole, to be most nearly balanced for these plants, for the whole range of total concentrations dealt with.

Turning now to a special study of the solutions having medium total concentration (series 15 to 19), the upper part of Table 6 indicates that the low-medium was generally better suited to the production of top yields than was the high-medium total con- 
centration. Another comparison between these two total concentrations is possible, however, from the data of series 15 and 18, carried out simultaneously in the period beginning May 24, and data for this comparison are given in Table 7, which is planned like Table 6 . For ready comparison, the data for series 16 and 19 are here repeated from the other table. For each series of each period the higher of the two comparable values is shown in bold-face type.

TABLE 7.-Highest and lowest yields of tops and of roots (milligrams) in the high and in the low groups for the low-medium and high-medium total concentrations (series 15, 16, 18, and 19).

\begin{tabular}{|c|c|c|c|c|c|c|c|c|c|}
\hline & \multirow{3}{*}{$\cdot$} & \multicolumn{4}{|c|}{ Period beginning May 24 . } & \multicolumn{4}{|c|}{ Period beginning June 19.} \\
\hline 7 & & \multicolumn{2}{|c|}{$\begin{array}{l}\text { Series } 15 \text { (low- } \\
\text { medium total } \\
\text { concentration). }\end{array}$} & \multicolumn{2}{|c|}{$\begin{array}{l}\text { Series } 18 \text { (high- } \\
\text { medium total } \\
\text { concentration). }\end{array}$} & \multicolumn{2}{|c|}{$\begin{array}{l}\text { Series } 16 \text { (low- } \\
\text { medium total } \\
\text { concentration). }\end{array}$} & \multicolumn{2}{|c|}{$\begin{array}{l}\text { Series } 19 \text { (high- } \\
\text { medium total } \\
\text { concentration). }\end{array}$} \\
\hline & & Highest. & Lowest. & Highest. & Lowest. & Highest. & Lowest. & Highest. & Lowest. \\
\hline Tops_.. & High group.- & 416 & 389 & $4 \div 0$ & 394 & 287 & 235 & 253 & 224 \\
\hline Do_-- & Low group.-- & 345 & 313 & 309 & 267 & 192 & 163 & 176 & 115 \\
\hline Roots.- & High group-- & 128 & 118 & 120 & 108 & 78 & i2 & 74 & 64 \\
\hline Do... & Low group... & 98 & 71 & 90 & 55 & 62 & 52 & 53 & 42 \\
\hline
\end{tabular}

It appears from the upper part of Table 7 that, in three cases out of four, both maximum and minimum top values for the high group, and also for the low group, are greater for the lowmedium total concentration than for the high-medium, while preference is suggested for the high-medium total concentration in the fourth case, that of May 24, of the high group. In this case the differences are much smaller than in the others and they are too slight to be considered as significant (420 milligrams is not significantly greater than 416 , nor 394 than 389 ). It may be added here that the evidence from root yields in the lower part of Table 7 points in the same direction, the agreement being actually better here than in the case of top yields, for the only comparison that gives preference to the high-medium total concentration on this basis is that between the two minima for the low group, 75 and 71 milligrams.

From these and other considerations it seems clear that the low-medium total concentration (0.0016 gram-molecule per liter, or 0.08 atmosphere) is to be regarded as generally more promising, for these plants and these non-solution conditions and for this 4-salt type of medium, than is the high-medium total concentration ( 0.0038 gram-molecule per liter, or 0.2 atmosphere). The differences are not generally relatively very great, 
however, and it may be safer to conclude from the limited data (and considering the discrepancies shown by the repetitions) that the most promising total concentration lies within the range between these two, perhaps nearer to the lower limit than the upper.

Reverting to Table 5 and taking up now the comparative physiological values for top yield of the various sets of salt proportions for the two medium total concentrations, it will be instructive to study the agreements and disagreements between

TABLE 8.-Showing symbols for top and root yield of series 15 to 19.

\begin{tabular}{|c|c|c|c|c|}
\hline \multirow[b]{2}{*}{ Solution No. } & \multicolumn{2}{|c|}{ Top yields. } & \multicolumn{2}{|c|}{ Root yields. } \\
\hline & $\begin{array}{l}\text { Low-medium } \\
\text { total concen- } \\
\text { tration. } \\
\text { Series } 15,16 .\end{array}$ & $\begin{array}{l}\text { High-medium } \\
\text { total concen- } \\
\text { tration. } \\
\text { Series } 17-19 .\end{array}$ & $\begin{array}{l}\text { Low-medium } \\
\text { total concen- } \\
\text { tration. } \\
\text { Series } 15,16 .\end{array}$ & $\begin{array}{l}\text { High-medium } \\
\text { total concen- } \\
\text { tration. } \\
\text { Series } 17-19 .\end{array}$ \\
\hline T1R1S1 ...... & $\mathrm{H}$ & $\mathrm{H}$ & H & $\mathbf{H}$ \\
\hline $\mathrm{S} 2$ & $\mathbf{H}$ & $\mathrm{Hm}$ & $\mathrm{H}$ & $\mathrm{H}$ \\
\hline S3 & $\mathrm{H}$ & Mh & $\mathbf{H}$ & $\mathbf{H}$ \\
\hline $\mathrm{S} 4$ & M & $\mathrm{Hm}$ & M & Mh \\
\hline S5 & LM & $\mathrm{Ml}$ & $\mathbf{L}$ & Ml \\
\hline R2S1 & $\mathrm{H}$ & $\mathrm{H}$ & $\mathbf{H}$ & $\mathrm{H}$ \\
\hline S2 & HM & $\mathrm{Mh}$ & $\mathrm{H}$ & $\mathrm{Hm}$ \\
\hline S3 & $\mathrm{HM}$ & Mh & M & $\mathrm{Mh}$ \\
\hline $\mathrm{S} 4$ & $\mathrm{LM}$ & $\mathrm{Mh}$ & $\mathrm{L}$ & HML \\
\hline R3S1 _......... & $\mathrm{H}$ & M & $\mathrm{HM}$ & $\mathrm{Mh}$ \\
\hline $\mathrm{S} 2$ & HL & $\mathrm{Hm}$ & LM & $\mathrm{Mh}$ \\
\hline S3 & LM & Mh & $\mathrm{L}$ & HML \\
\hline R4S1 & M & $\mathrm{Hm}$ & $\mathrm{L}$ & $\mathrm{Mh}$ \\
\hline $\mathrm{S} 2$ & LM & $\mathrm{H}$ & $\mathrm{L}$ & $\mathrm{H}$ \\
\hline R5S1 & LM & M & $\mathrm{L}$ & M \\
\hline T2R1S1 & HM & $\mathrm{Hm}$ & $\mathrm{H}$ & $\mathrm{H}$ \\
\hline $\mathrm{S} 2 \ldots$ & M & Mh & $\mathrm{H}$ & $\mathrm{Hm}$ \\
\hline S3 & LM & Ml & M & M \\
\hline $\mathrm{S} 4$ & LM & $\mathrm{L}$ & $\mathrm{LM}$ & $\mathbf{L}$ \\
\hline R2S1 & HM & $\mathbf{M}$ & $\mathrm{HM}$ & $\mathrm{Hm}$ \\
\hline S2 & HM & HML & $\mathrm{H}$ & $\mathrm{Hm}$ \\
\hline S3 & $\mathrm{L}$ & $\mathrm{Lm}$ & $\mathrm{L}$ & M \\
\hline R3S1 & M & MI & HL & HML \\
\hline $\mathrm{S} 2$ & M & Ml & $\mathrm{L}$ & Ml \\
\hline R4S1 & M & Mh & HL & Mh \\
\hline T3R1S1 & M & Ml & $\mathbf{H}$ & Mh \\
\hline $\mathrm{S} 2$ & LM & $\mathrm{L}$ & M & Ml \\
\hline S3 _......... & $\mathrm{L}$ & $\mathrm{L}$ & $\mathrm{LM}$ & $\mathrm{L}$ \\
\hline R2S1 & $\mathrm{LH}$ & Ml & HM & $\mathbf{M}$ \\
\hline $\mathrm{S} 2 \ldots$ & LM & $\mathrm{Lm}$ & $\mathbf{M}$ & Mh \\
\hline R3S1 & HM & $\mathbf{L}$ & HM & $\mathrm{Lm}$ \\
\hline T4R1S1 & LM & $\mathrm{Lm}$ & $\mathrm{HL}$ & $\mathrm{Lm}$ \\
\hline $\mathrm{S} 2$ & $\mathrm{~L}$ & $\mathbf{L}$ & LM & $\mathrm{L}$ \\
\hline R2S1 & LM & $\mathrm{Lm}$ & HM & $\mathrm{Ml}$ \\
\hline T5R1S1 & LM & $\mathbf{L}$ & HM & $\mathbf{L}$ \\
\hline
\end{tabular}


the two low-medium series and between the three high-medium series, also between the low-medium and the high-medium concentrations, as indicated by the groups (high, medium, and low) in which the various sets of salt proportions fall.

These agreements and disagreements are set forth in Table 8, which also includes the corresponding data for root yields. In this table the letters $\mathrm{H}, \mathrm{M}$, and L are employed to show in which group any given set of salt proportions fell for each trial. In the case of the lower of these two medium total concentrations there were two trials, and disagreement between the two is shown by the use of both letters (thus, HM denotes that one trial showed the solution in question as in the high group, while the other trial showed it as in the medium group). In the case of the higher total concentration there were three trials. When all were different in their indications all three letters are given in the table; when two of them agreed but the third was different, only two letters appear, but one is lower-case, to denote that only one trial is thus referred to. Thus, if the three trials call for L, L, and MI respectively, the designation is Lm, etc.

Table 8 shows that solutions T1R1S1, T1R1S2, and T1R2S1 agree in giving high top yields, while solutions T2R2S3, T3R1S3, and T4R1S2 agree in giving low top yields, for both total concentrations. The other solutions show medium top yields or are more or less questionable, as far as the data go. It seems safe to conclude that the first three solutions just named may be expected to produce excellent top growth for this sort of plants, when the total concentration is between 0.0016 and 0.0038 grammolecule per liter (0.08-0.2 atmosphere), while the last three mentioned may be taken as representing the poorly balanced sets of salt proportions of these series. The distribution of these and the other solutions on the tetrahedral diagram, together with the chemical interpretation of this, will be deferred till after the root yields have been presented.

Dry yields of roots.-The relative dry yields of roots from series 14 to 20 are presented in Table 9, in a manner quite like that followed for the top yields in Table 5 .

From Table 9 it appears that disagreements are fully as frequent among the root yields as among those of tops, and the remarks made concerning the discrepancies in the other case will apply here also.

It appears that solution T1R1S1 and T2R1S1 agreed in giving high root yields for all series, and that no one of the thirty-five sets of salt proportions gave low root yields for all series. 
TABLE 9.-Roots, relative dry yields (six plants), from series with 4-salt solution type $A$.

[The value for culture T1R1S1 is always taken as unity and the others are expressed in terms of this. The actual value (grams) for this culture is given in parentheses below the assumed value of unity, in each case.]

\begin{tabular}{|c|c|c|c|c|c|c|c|}
\hline \multirow{2}{*}{$\begin{array}{l}\text { Solution. } \\
\text { No. }\end{array}$} & \multirow{2}{*}{$\begin{array}{c}0.0008 \text { gram } \\
\text { molecule } \\
\text { per liter, or } \\
0.04 \text { atmos- } \\
\text { phere. } \\
\begin{array}{c}\text { Series } 14, \\
\text { June } 19 .\end{array}\end{array}$} & \multicolumn{2}{|c|}{$\begin{array}{l}0.0016 \text { gram-molec- } \\
\text { ule per liter, or } 0.08 \\
\text { atmosphere. }\end{array}$} & \multicolumn{3}{|c|}{$\begin{array}{l}0.0038 \text { gram-molecule per liter, } \\
\text { or } 0.2 \text { atmosphere. }\end{array}$} & \multirow{2}{*}{$\begin{array}{c}0.0077 \text { gram- } \\
\text { molecule } \\
\text { per liter, or } \\
0.4 \text { atmos- } \\
\text { phere. } \\
\begin{array}{c}\text { Series } 20, \\
\text { June } 19 .\end{array}\end{array}$} \\
\hline & & $\begin{array}{l}\text { Series 15, } \\
\text { May } 24 .\end{array}$ & $\begin{array}{l}\text { Series } 16 \text {, } \\
\text { June } 19 .\end{array}$ & $\begin{array}{c}\text { Series } 17, \\
\text { May } 1 .\end{array}$ & $\begin{array}{c}\text { Series } 18 \text {, } \\
\text { May } 24\end{array}$ & $\begin{array}{c}\text { Series } 19 \\
\text { June } 19 .\end{array}$ & \\
\hline T1R1S1 & $\begin{array}{l}H 1.00 \\
(0.185)\end{array}$ & $\begin{array}{l}\text { H } 1.00 \\
\quad(0.128)\end{array}$ & $\begin{array}{l}\text { H } 1.00 \\
\quad(0.078)\end{array}$ & $\begin{array}{l}\text { H } 1.00 \\
\quad(0.098)\end{array}$ & $\begin{array}{l}\text { H } 1.00 \\
\quad(0.120)\end{array}$ & $\begin{array}{l}\mathrm{H} 1.00 \\
(0.074)\end{array}$ & $\begin{array}{l}\text { H } 1.00 \\
\quad(0.068)\end{array}$ \\
\hline S2 & 0.81 & H 0.98 & H 0.94 & H 1.02 & H 0.93 & H 0.92 & Н 0.75 \\
\hline S3.- & 0.79 & H 0.94 & H 0.90 & Н 0.92 & H 0.90 & H 0.92 & 0.78 \\
\hline S4 & 0.71 & 0.89 & 0.85 & H 0.95 & 0.87 & 0.76 & 0.68 \\
\hline S5-. & $0.64 \mathrm{~L}$ & $0.77 \mathrm{~L}$ & $0.80 \mathrm{~L}$ & 0.78 & 0.78 & $0.68 \mathrm{~L}$ & 0.69 \\
\hline R2S1 & 0.79 & Н 0.98 & H 1.00 & H 1.01 & Н 0.96 & H 0.91 & H 0.75 \\
\hline S2 & H 0.85 & H 0.91 & H 0.90 & 0.89 & H 0.96 & H 0.85 & H 1.20 \\
\hline S3... & 0.84 & 0.84 & 0.86 & H 0.95 & 0.78 & 0.84 & $\mathrm{H} 0.75$ \\
\hline S4 & 0.76 & $0.63 \mathrm{~L}$ & $0.80 \mathrm{~L}$ & Н 0.92 & $0.75 \mathrm{~L}$ & 0.81 & 0.71 \\
\hline R3S1_.. & H 0.85 & 0.79 & H 0.91 & 0.84 & 0.83 & H 0.85 & H 0.87 \\
\hline S2.. & $0.67 \mathrm{~L}$ & $0.67 \mathrm{~L}$ & 0.85 & 0.87 & H 0.99 & H 0.93 & H 0.81 \\
\hline S3. - & 0.78 & $0.64 \mathrm{~L}$ & $0.71 \mathrm{~L}$ & $0.67 \mathrm{~L}$ & 0.88 & Н 0.92 & H 0.74 \\
\hline R4S1 & $0.64 \mathrm{~L}$ & $0.61 \mathrm{~L}$ & $0.74 \mathrm{~L}$ & Н 0.97 & 0.80 & 0.81 & 0.71 \\
\hline S2 & $0.74 \mathrm{~L}$ & $0.56 \mathrm{~L}$ & $0.67 \mathrm{~L}$ & Н 0.92 & Н 0.92 & Н 0.91 & $0.65 \mathrm{~L}$ \\
\hline R5S1. & $0.64 \mathrm{~L}$ & $0.56 \mathrm{~L}$ & $0.69 \mathrm{~L}$ & 0.84 & 0.63 & 0.76 & $0.56 \mathrm{~L}$ \\
\hline T2R1S1_- & Н 0.91 & Н 0.95 & Н 0.94 & H 0.95 & H 0.95 & H 0.95 & H 0.85 \\
\hline S2 & $0.71 \mathrm{~L}$ & H 0.92 & H 0.91 & 0.90 & H 0.92 & H 0.93 & $\mathrm{H} 0.75$ \\
\hline S3... & $0.66 \mathrm{~L}$ & 0.90 & 0.87 & 0.89 & 0.80 & 0.84 & 0.73 \\
\hline S4 & $0.71 \mathrm{~L}$ & 0.81 & $0.80 \mathrm{~L}$ & $0.71 \mathrm{~L}$ & $0.68 \mathrm{~L}$ & 0.64 & 0.71 \\
\hline R2S1 & $0.68 \mathrm{~L}$ & 0.83 & H 0.90 & H 0.95 & 0.84 & H 0.89 & $0.66 \mathrm{~L}$ \\
\hline S2 & $0.74 \mathrm{~L}$ & H 0.93 & Н 0.92 & $0.71 \mathrm{~L}$ & 0.82 & H 0.95 & H 0.74 \\
\hline S3.-. & $0.73 \mathrm{~L}$ & $0.77 \mathrm{~L}$ & $0.74 \mathrm{~L}$ & 0.83 & 0.80 & 0.78 & H 0.75 \\
\hline R3S1 & 0.80 & Н 0.92 & $0.77 \mathrm{~L}$ & Н 0.91 & 0.85 & 0.72 & $0.66 \mathrm{~L}$ \\
\hline S2 & 0.77 & $0.67 \mathrm{~L}$ & $0.74 \mathrm{~L}$ & 0.90 & $0.73 \mathrm{~L}$ & 0.87 & 0.72 \\
\hline $\mathrm{R} 4 \mathrm{~S} 1 \ldots$ & 0.78 & H 0.91 & $0.77 \mathrm{~L}$ & 0.87 & 0.85 & H 0.95 & $0.53 \mathrm{~L}$ \\
\hline T3R1S1... & H 0.94 & H 0.98 & H 0.95 & 0.74 & H 0.90 & 0.76 & H 0.75 \\
\hline S2 & H 0.86 & 0.81 & 0.87 & $0.72 \mathrm{~L}$ & 0.78 & 0.73 & 0.69 \\
\hline S3... & 0.80 & $0.78 \mathrm{~L}$ & 0.85 & $0.68 \mathrm{~L}$ & $0.72 \mathrm{~L}$ & $0.69 \mathrm{~L}$ & $0.53 \mathrm{~L}$ \\
\hline R2S1_..- & H 0.94 & 0.88 & Н 0.97 & 0.86 & 0.85 & 0.81 & 0.69 \\
\hline S2 & H 0.88 & 0.84 & 0.81 & 0.80 & H 0.93 & 0.77 & $0.63 \mathrm{~L}$ \\
\hline R3S1 & 0.80 & H 0.98 & 0.87 & 0.79 & $0.71 \mathrm{~L}$ & $0.70 \mathrm{~L}$ & $0.62 \mathrm{~L}$ \\
\hline T4R1S1... & H 0.88 & H 0.92 & $0.78 \mathrm{~L}$ & $0.73 \mathrm{~L}$ & $0.76 \mathrm{~L}$ & 0.82 & $0.65 \mathrm{~L}$ \\
\hline S2 & $0.71 \mathrm{~L}$ & 0.81 & $0.77 \mathrm{~L}$ & $0.58 \mathrm{~L}$ & $0.67 \mathrm{~L}$ & $0.57 \mathrm{~L}$ & 0.68 \\
\hline R2S1 .... & Н 0.89 & Н 0.92 & 0.89 & $0.67 \mathrm{~L}$ & 0.79 & 0.81 & $0.54 \mathrm{~L}$ \\
\hline T5R1S1 & H 1.00 & Н 0.98 & 0.81 & $0.51 \mathrm{~L}$ & $0.75 \mathrm{~L}$ & $0.62 \mathrm{~L}$ & $0.66 \mathrm{~L}$ \\
\hline
\end{tabular}

The range limits given in the lower part of Table 6 indicate a less marked distinction in favor of the two medium total concentrations (as compared with the lowest and highest, series 14 and 20 ) than is shown for top yields. Nevertheless, partly because the physiological meaning of the dry yield of roots is 
not at all understood and partly because the possible errors in cutting, weighing, etc., are much greater for roots than for tops, the same general plan will here be followed as was resorted to in the case of the top yields. Attention will be mainly restricted to the two medium total concentrations, series 15 and 19.

Before leaving the general subject of total concentration it may be remarked that the low and the high root yields are not in any case as clearly segregated as are the corresponding ones for tops; but, with the higher total concentrations, there is a marked tendency for low values to correspond especially to the third, fourth, and fifth triangles of the tetrahedral diagram; that is, to high relative partial concentrations of monopotassium phosphate. As in the case of top yields, the most certainly wellbalanced sets of salt proportions have low relative partial concentrations of this salt.

In connection with Table 7 it has been noted that the limited information at hand appears to indicate that the lower of the two medium total concentrations may be appreciably better for root yields, as well as for top yields, than is the higher. Since the differences are not great, they require no emphasis at this time, however.

The agreements and disagreements between the similar series, with regard to root yields, are given in Table 8 , the notation of which has already been explained. Reference to that table brings out the fact that the following five sets of salt proportions agreed in giving high root yields for all five trials: T1R1S1, T1R1S2', T1R1S3, T1R2S1, and T2R1S1. The first two and the fourth one of these have been noted as showing the same outstanding agreement for top yields. None of the solutions show this kind of agreement for low root yields.

TOP AND ROOT YIELDS IN RELATION TO SALT PROPORTIONS

The relations between yield and salt proportions may be brought out best by the use of the tetrahedral diagram. The symbols shown in Table 8, for tops and for roots, and for the low-medium and high-medium total concentrations, are plotted diagramatically in figs. 4 to 7 . The only alteration made in entering the letters on the diagrams has been to change HL to $\mathrm{M}$, on the supposition that a solution giving high yield in one trial and low yield in another trial should be represented as belonging to the medium group. The areas of the diagrams representing high yields and those representing low yields are distinguished by shading. In outlining these areas, combinations 
of letters-denoting uncertainty in the data-are treated as belonging to the medium group.

It seems undesirable, considering the discrepancies as to details, to attempt to combine these four diagrams into a single one, but the following remarks will draw attention to the main points on which such a combination might be based. We may begin by considering the two total concentrations separately, as to the degree of agreement between the data for tops and those for roots. For the lower of the two medium concentrations

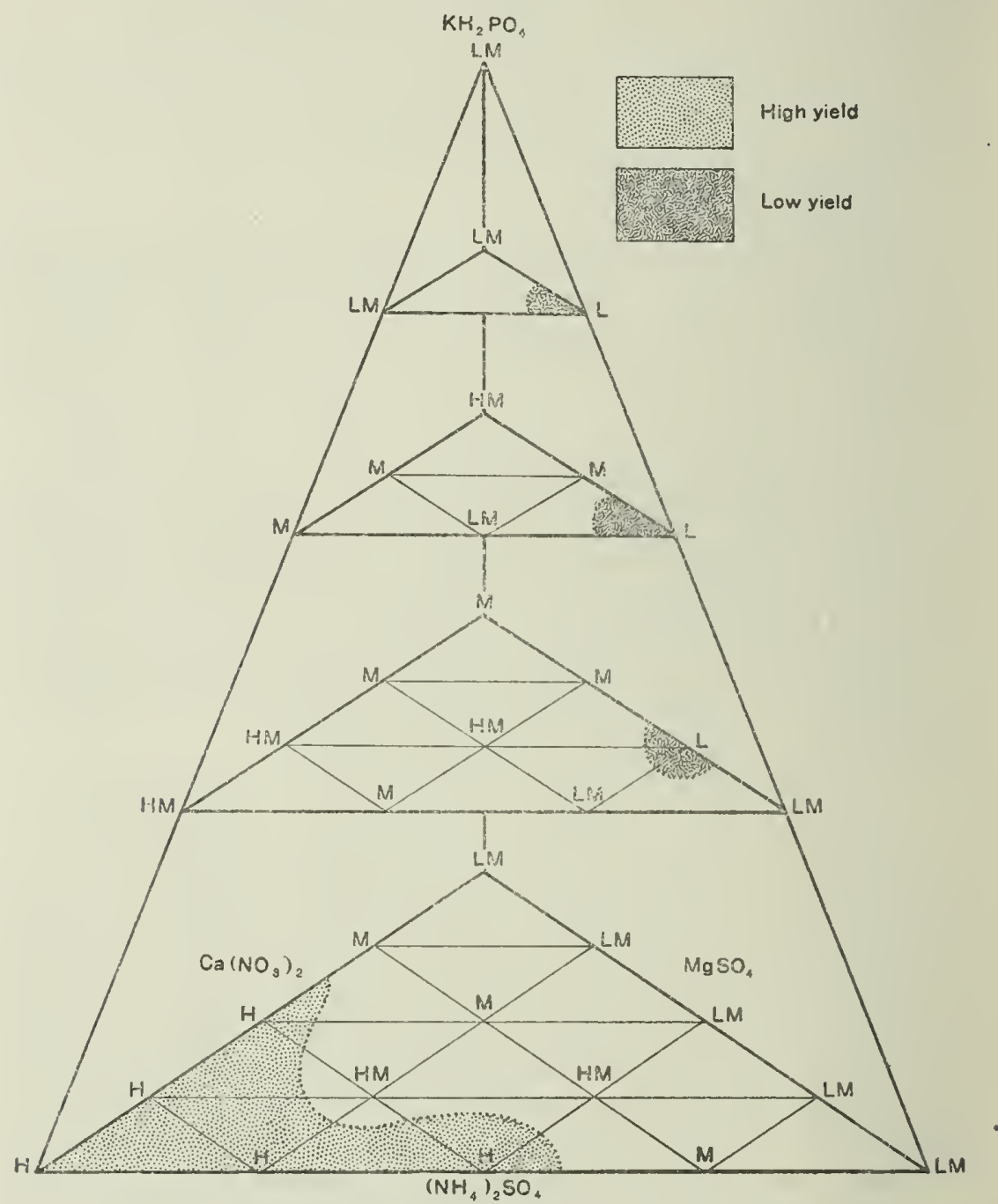

FIG. 4. Top-yield values for the thirty-five different sets of salt proportions, with low-medium total concentration. 
considred ( 0.0016 gram-molecule per liter, or 0.08 atmosphere) the diagram for top yield (fig. 4) shows five sets of salt proportions as of the high group, all lying in the forward left portion of the lowest triangle. No set of proportions in the lowest triangle is indicated for the low group, but three sets are shown; one in the second, one in the third, and one in the fourth triangle, all at or adjacent to the forward right apex. The corresponding diagram for root yield (fig. 5) shows about the same low region in the lowest triangle as is shown for top yield, but here also there are three high sets of proportions; in the

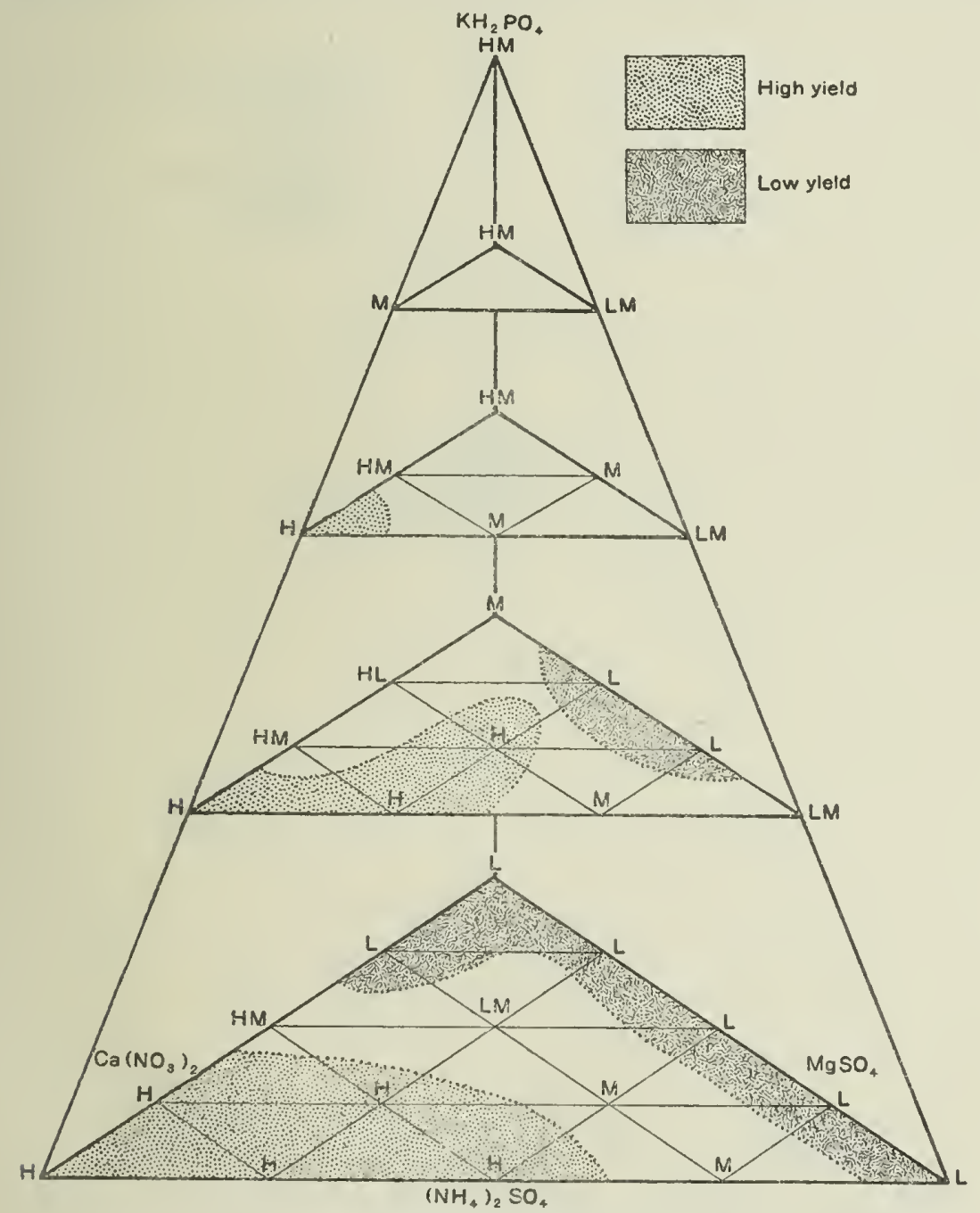

FIG. 5. Root-yield values for the thirty-five different sets of salt proportions, with lowmedium total concentration. 
middle, in the forward left portion of the second triangle, and at the forward left apex of the third triangle. On this rootyield diagram the low region occupies the whole right margin of the lowest triangle and a portion of the same margin of the second triangle. Just one set of proportions (T2R2S3) is set down as in the low group on both diagrams.

It is especially interesting to note that the yields of tops and of roots agree very well, a feature of these results that is different from what has been indicated for wheat and buckwheat by Shive's work; that writer frequently found low root yields

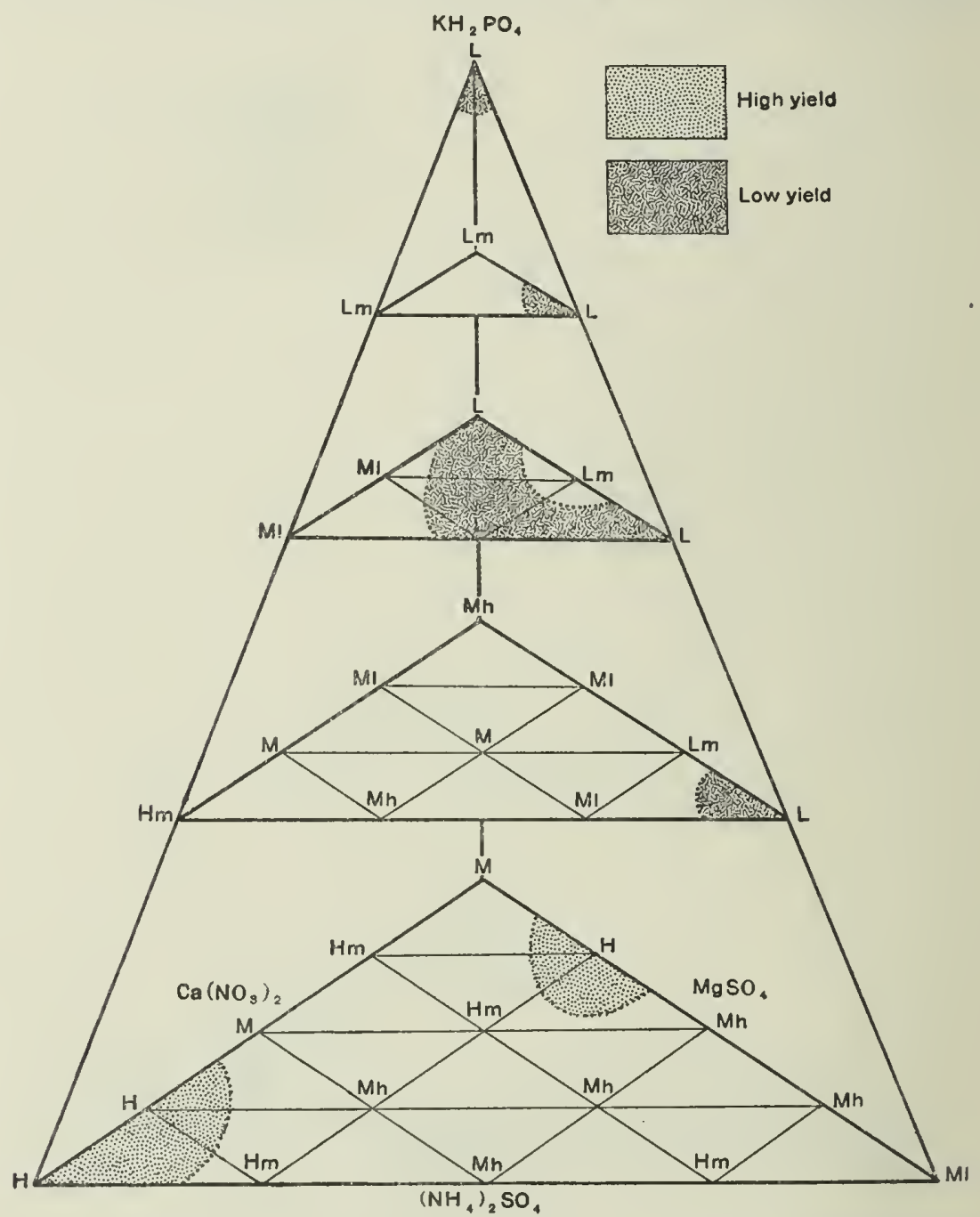

FIG. 6. Top-yield values for the thirty-five different sets of salt proportions, with high-medium total concentration. 
accompanying high top yields and, conversely, it appears that the young rice plants generally show parallel, rather than opposite, effects upon top and root production.

Turning to the higher total concentration $(0.0038$ grammolecule per liter, or 0.2 atmosphere), only two sets of salt proportions are indicated as of the high group of top yields (fig. 6) in the forward left region of the lowest triangle (the high designation given to solution T1R4S2 appears to be erratic in some way). On this top diagram the low region comprises six sets of salt proportions, lying at the forward right apices of the second,

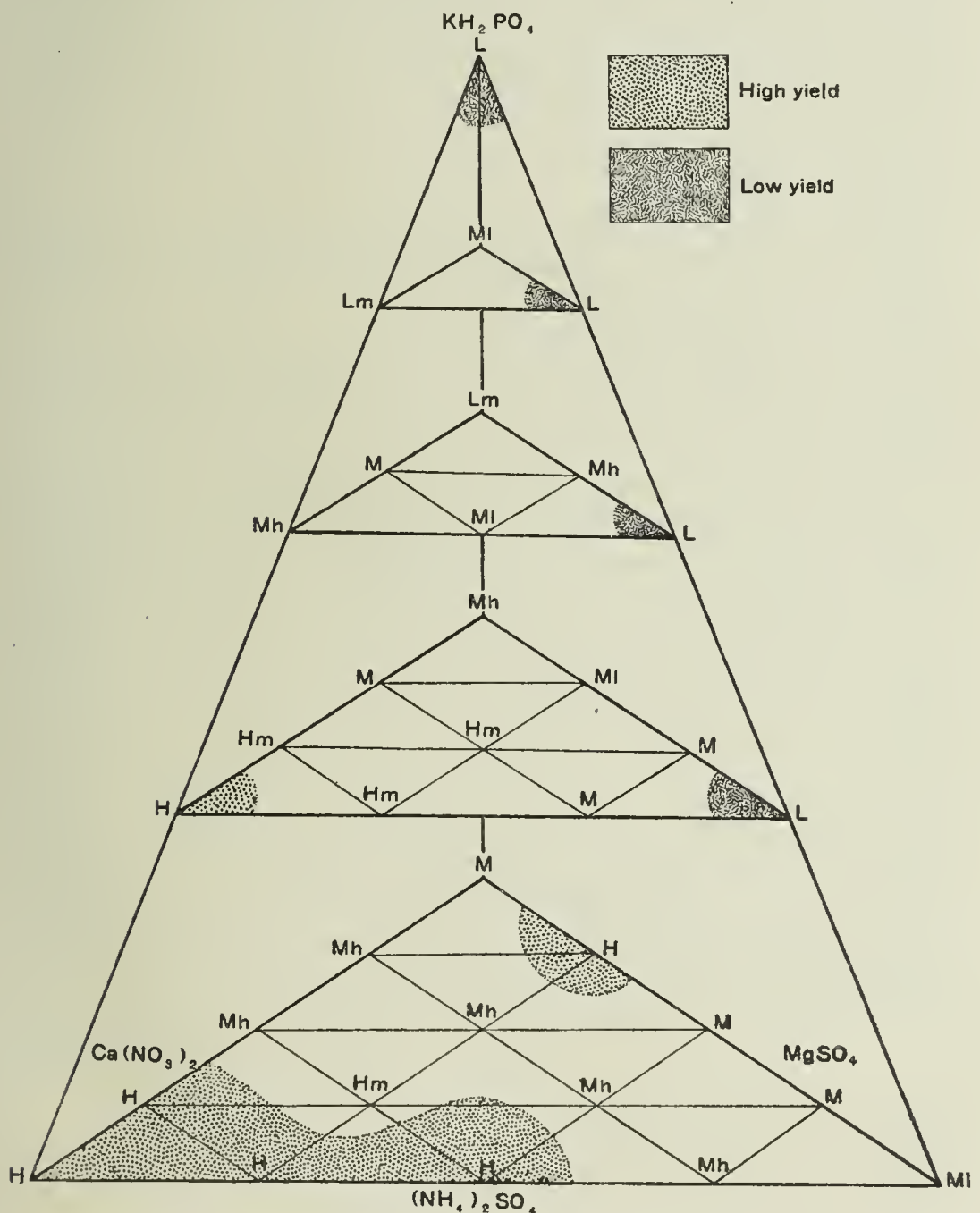

Fig. 7. Root-yield values for the thirty-five different sets of salt proportions, with highmedium total concentration. 
third, and fourth triangles and the top apex of the whole tetrahedron, and at the rear apex and the forward central region of the third triangle. The corresponding diagram for root yield (fig. 7) shows a high region near the forward right apex of the lowest triangle (much as for the lower total concentration in regard to both tops and roots) and it agrees with the diagram for tops in giving a high designation to solution T1R4S2 (which may be erratic here also). The forward left apex of the second triangle is also indicated as of the high group, as in the case of the lower concentration and root yields (fig. 5).

The low region of this root diagram (fig. 7) occupies the forward right apices of the second, third, and fourth triangles and the top apex of the tetrahedron as a whole. It differs from the corresponding top diagram (fig. 6) only in that the low region is not here extended beyond the forward right apex in the third triangle.

With the higher of these two total concentrations it is again clear that top and root yields tend to be parallel, just as with the lower total concentration.

Finally, it should be noted that two sets of salt proportions, T1R1S1 and T1R2S1, are shown as of the high group on all four diagrams.

Study of the preceding pages and of the diagrams of figs. 4 to 7 leads to the following guarded generalizations. It appears that solutions T1R1S1, T1R1S2, and T1R2S1 are to be regarded as having about the best salt proportions for the development of these plants, with the other conditions involved in these studies, and it similarly appears that solutions T1R1S5, T2R1S4, T3R1S3, T4R1S2, and T5R1S1 are to be regarded as very unbalanced and injurious. Under the given non-solution conditions and with total concentrations lying between 0.0016 and 0.0038 gram-molecule per liter, these plants are found to give highest yields of both roots and tops when the culture solution contains relatively large proportions of magnesium sulphate, and relatively small proportions of the other three salts, themselves present in nearly equal proportions. The three solutions just indicated as best have the salt proportions shown below:

\begin{tabular}{|c|c|c|c|c|}
\hline Solution No. & $\mathrm{KH}_{2} \mathrm{PO}_{4}$. & $\left(\mathrm{NH}_{4}\right)_{2} \mathrm{SO}_{4}$. & $\mathrm{Ca}\left(\mathrm{NO}_{3}\right)_{2}$. & $\mathrm{MgSO}_{4}$. \\
\hline TIR1S1 ......... & 1 & 1 & 1 & 5 \\
\hline T1R1S2 & 1 & 1 & 2 & 4 \\
\hline T1R2S1 & 1 & 2 & 1 & 4 \\
\hline
\end{tabular}


Perhaps a recommendation as to the best set of salt proportions for this solution type for these young rice plants, etc., might be obtained by averaging these proportions, thus obtaining solution $\mathrm{T} 1 \mathrm{R} 1 \frac{1}{3} \mathrm{~S} 1 \frac{1}{3}$, with molecular proportions $1: 1 \frac{1}{3}: 1 \frac{1}{3}: 4 \frac{1}{3}$. It may even be desirable to leave the relative value for magnesium sulphate as it is in R1S2 and R2S1 and allow the hypothetically best solution to be T1R $1 \frac{1}{2} \mathrm{~S} 1 \frac{1}{2}$, with molecular proportions $1: 1 \frac{1}{2}: 1 \frac{1}{2}: 4$. Judging from the information at hand, either T1R $1 \frac{1}{3} \mathrm{~S} 1 \frac{1}{3}$ or T1R $1 \frac{1}{2} \mathrm{~S} 1 \frac{1}{2}$ should give excellent results for both tops and roots. There seems to be no reason for increasing the molecular proportional value of monopotassium phosphate above unity (one-eighth of the total molecular concentration of all salts taken together) for the hypothetical best set of proportions.

From this generalization it appears that these young rice plants differ in their physiological salt requirements from many other plants, notably from wheat, buckwheat, and soy bean, especially in the fact that the former need relatively a very high partial concentration of magnesium sulphate, and about equal and relatively very low partial concentrations of monopotassium phosphate and calcium nitrate. As has been seen, these rice plants are also peculiar in that they cannot develop satisfactorily when supplied with monopotassium phosphate, calcium nitrate. and magnesium sulphate in any possible proportions, but do develop excellently in the 4-salt solution type here employed, containing the three salts just mentioned and also ammonium sulphate. It may be of interest to note that the hypothetically best sets of salt proportions suggested above, T1R $1 \frac{1}{3} \mathrm{~S} 1 \frac{1}{3}$ and $\mathrm{T} 1 \mathrm{R} 1 \frac{1}{2} \mathrm{~S} 1 \frac{1}{2}$, are characterized by $\mathrm{Ca}: \mathrm{Mg}$ ratio values of $1 \frac{1}{3}: 4 \frac{1}{3}$ $(1: 3.25=0.308)$ and $1 \frac{1}{2}: 4(1: 2.67=0.375)$, respectively. If we adopt the quite undesirable method of considering such ratio values as derived by considering the two metals as their oxides and employing the ratio of the weights of the oxides rather than the atomic or molecular ratio, it may be said that the atomic ratio $\mathrm{Ca}: \mathrm{Mg}=0.308$ is equivalent to the molecular ratio $\mathrm{CaO}: \mathrm{MgO}$ $=0.308$, or the weight ratio $\mathrm{CaO}: \mathrm{MgO}=0.375$. The complete sets of atomic and ionic ratio values for the hypothetically best set of salt proportions T1R1 $11_{3} 1_{3}^{\frac{1}{3}}$ are as follows (neglecting the H-ion) :

$\mathrm{K}: \mathrm{Ca}: \mathrm{Mg}: \mathrm{N}: \mathrm{P}: \mathrm{S}=1: 1 \frac{1}{3}: 4 \frac{1}{3}: 5 \frac{1}{3}: 1: 5 \frac{2}{3}$.

$\mathrm{K}: \mathrm{Ca}: \mathrm{Mg}: \mathrm{NH}_{4}: \mathrm{NO}_{3}: \mathrm{PO}_{4}: \mathrm{SO}_{4}=1: 1 \frac{1}{3}: 4 \frac{1}{3}: 2 \frac{2}{3}: 2 \frac{2}{3}: 1: 5 \frac{2}{3}$. 
With reference to what sets of molecular salt proportions constitute bad physiological balance for these plants, it has been mentioned that, in general, progressively higher relative partial concentrations of monopotassium phosphate give progressively poorer yields. At the same time it is to be noted that bad physiological balance generally accompanies low relative partial concentrations of magnesium sulphate. Perhaps the worst solution of this 4-salt type may, as here tested, be represented by T3R1S3 or by T4R1S2. These have the molecular salt proportions shown below:

\begin{tabular}{|c|c|c|c|c|}
\hline Solution No. & $\mathrm{KH}_{2} \mathrm{PO}_{4}$. & $\left(\mathrm{NH}_{4}\right)_{2} \mathrm{SO}_{4}$. & $\mathrm{Ca}\left(\mathrm{NO}_{3}\right)_{2}$ & $\mathrm{MgSO}_{4}$ \\
\hline T3R1S3 . & 3 & 1 & 3 & 1 \\
\hline T4R1S2 & 4 & 1 & 2 & 1 \\
\hline
\end{tabular}

They are characterized by high relative proportions of monopotassium phosphate and calcium nitrate, and by low proportions of ammonium sulphate and magnesium sulphate. But the best solutions for top and root yields are also characterized by low relative proportions of the ammonium salt, as has been seen, so that the distinguishing characters of these very poorly balanced solutions are high proportions of monopotassium phosphate and calcium nitrate and low proportions of magnesium sulphate. From the nature of the results that have been presented and from the nature of the problem itself, it is undesirable to attempt to fix upon any one of the sets of salt proportions as most poorly balanced; to attempt this would lead to discussion of the general problem of toxicity and starvation.

Referring to the studies of earlier students of rice culture and of the salt nutrition of the rice plant, the conclusions just brought forth appear to substantiate the more general ones that have been expressed in the literature; namely, that young rice plants require ammonium and cannot thrive with nitrate as the only source of nitrogen, and that rice needs relatively little potassium and relatively much magnesium, while it cannot generally bear much calcium. An additional point, not emphasized in the literature, is that the best growth of young rice is not to be expected with anything but comparatively low proportions of the ammonium salt, although the present studies suggest' that smmonium sulphate is not so injurious in higher proportions as is monopotassium phosphate. Perhaps it may be said to be about as injurious as calcium nitrate.

Lengths of tops and roots. - As has been said, the approximate 
average length of tops and of roots was obtained at the end of the culture period, for each culture of series 14 to 20. Discrepancies between the different trials of the same series, as to the relative physiological values of the various sets of salt proportions, are more pronounced in top length than in dry yield, and in root length than in top length, and the general consistency of the whole array of values for top and root length is of a low order. This may be considered as indicating that these length values are not as good criteria as are the dry yields, for bringing out differences in growth in the various cultures as here studied. It should be noted, however, that the method used in obtaining these approximate values involved considerable personal judgment and was not based on precision measurements and mathematical treatment. All things considered, it seems unnecessary to present all these length values here, although some samples for tops will be shown below. In spite of the discrepancies and inconsistencies of this mass of data, it generally appears that sets of salt proportions that appear most satisfactory by the criterion of dry yield also appear very satisfactory by the criterion of top length, and the solutions that appear to be badly balanced according to the one criterion also exhibit very poor growth according to the other.

Table 10 shows the actual and relative top-length values for the three sets of salt proportions chosen as the most promising, and for the two sets chosen as least promising on the basis of dry yields. The relative value is placed in parenthesis after the actual value in each case.

TABLE 10.-Approximate mean length of tops for selected solution of 4-salt solution type $A$.

\begin{tabular}{|c|c|c|c|c|c|c|c|}
\hline $\begin{array}{l}\text { Solution } \\
\text { No. }\end{array}$ & $\begin{array}{l}\text { Series 14, } \\
\text { June } 19 .\end{array}$ & $\begin{array}{l}\text { Series } 15, \\
\text { May } 24 .\end{array}$ & $\begin{array}{c}\text { Series 16, } \\
\text { June 19. }\end{array}$ & $\begin{array}{c}\text { Series } 17, \\
\text { May } 1 .\end{array}$ & $\begin{array}{c}\text { Series } 18, \\
\text { May } 24 .\end{array}$ & $\begin{array}{l}\text { Series 19, } \\
\text { June 19. }\end{array}$ & $\begin{array}{r}\text { Series } 20 \\
\text { June } 19\end{array}$ \\
\hline T1R1S1. & $\begin{array}{c}c m . \\
30.0(1.00)\end{array}$ & $\begin{array}{c}\mathrm{cm} . \\
40.0(1.00)\end{array}$ & $\begin{array}{c}\mathrm{cm} . \\
35.0(1.00)\end{array}$ & $\begin{array}{c}c m . \\
38.5(1.00)\end{array}$ & $\begin{array}{c}c m . \\
36.0(1.00)\end{array}$ & $\begin{array}{c}c m . \\
33.4(1.00)\end{array}$ & $\begin{array}{c}\mathrm{cm} . \\
31.3(1.00)\end{array}$ \\
\hline T1R1S2_ & $29.5(0.98)$ & $38.3(0.96)$ & $34.4(0.97)$ & $39.0(1.01)$ & $35.0(0.97)$ & $30.0(0.90)$ & $27.7(0.89)$ \\
\hline T1R2S1_. & $31.5(1.05)$ & 39. $5(0.99)$ & $32.6(0.93)$ & $38.0(0.99)$ & $38.2(1.06)$ & $30.0(0.90)$ & $29.0(0.93)$ \\
\hline T3R1S3.. & $26.3(0.88)$ & $30.6(0.77)$ & $27.0(0.77)$ & $26.0(0.68)$ & $29.8(0.83)$ & $23.8(0.71)$ & $17.0(0.54)$ \\
\hline T4R1S2 & $28.5(0.95)$ & $33.5(0.84)$ & $26.6(0.76)$ & $23.0(0.60)$ & $29.3(0.81)$ & 23. $0(0.69)$ & $20.3(0.65)$ \\
\hline
\end{tabular}

It is clear that the best three sets of salt proportions of Table 10 agree in showing the two medium total concentrations as about alike and markedly better than either the lowest or the highest total concentration here considered, thus supporting the conclusion derived from the data of dry yield. This is not so clear for the two badly balanced sets of salt proportions in this 
table, for the values for series 14 are both higher than the corresponding ones for series 19 and one of them is higher than the corresponding one for series 16 . It is to be remembered that series $14,16,19$, and 20 were simultaneously carried out, as also were series 15 and 18 . The highest total concentration (series 20) gave top length values much lower than the corresponding ones of any other concentration. As to the comparison between the two medium total concentrations, these two badly balanced sets of salt proportions agree, by both trials, in showing higher values for the low-medium concentration than for the other. Finally, there is no doubt, from the data in Table 10 , that the first three solutions belong to the high or wellbalanced group, while the last two belong to the low or badly balanced group. On the whole, the indications of these data for top length agree very well with those derived from the dryyield data for tops and roots.

Green weight and water content of tops.-For the four series carried out in the period beginning June 19, the green weights of tops were determined, and these are shown in Table 11. There were just four series $(14,16,19$, and 20$)$ and each had a different total concentration, so that there are no repetitions to be considered in regard to green weight, but these four series were carried out simultaneously so that they should be comparable as far as non-solution conditions are concerned. In Table 11 the letters $H$ and $L$ are fixed to the values belonging to the high and low groups, respectively, as in the cases of dry yields (Tables 5 and 9 ).

Considering the comparative physiological values of the four different total concentrations, as shown in Table 11, it is seen that for the lowest total concentration all but one (T4) of the five triangles of the tetrahedral diagram have one or more high green-weight values, and that all but one (T5) have one or more low values also. On the other hand, for the highest total concentration the lowest triangle of the diagram has seven values of the high group and none of the low group, the second triangle has one high value and two low values, and the remaining three triangles have one or more low values each, but no high value. As in the case of the dry yields of tops, the higher the total concentrationithe more segregated the high values in the lower part of the diagram and the low values in the upper part. As the total concentration is progressively higher the ability of the plants to withstand the higher partial concentration of monopotassium phosphate becomes markedly diminished. For the highest total 
TABLE 11.-Green weight of tops (six plants), actual values, from series with 4-salt solution type A, for culture period June 19 to July 9.

\begin{tabular}{|c|c|c|c|c|}
\hline Solution No. & \begin{tabular}{|c|} 
Total concen- \\
tration 0.0008 \\
gram-molecule \\
per liter, or \\
0.04 atmos- \\
phere (series \\
14).
\end{tabular} & $\begin{array}{c}\text { Total concen- } \\
\text { tration } 0.0016 \\
\text { gram-molecule } \\
\text { per liter, or } \\
0.08 \text { atmos- } \\
\text { phere (series } \\
\text { 16). }\end{array}$ & $\begin{array}{l}\text { Total concen- } \\
\text { tration } 0.0038 \\
\text { gram-molecule } \\
\text { per liter, or } 0.2 \\
\text { atmosphere } \\
\text { (series 19). }\end{array}$ & $\begin{array}{l}\text { Total concen- } \\
\text { tration } 0.0077 \\
\text { gram-molecule } \\
\text { per liter, or } 0.4 \\
\text { atmosphere } \\
\text { (serles 20). }\end{array}$ \\
\hline T1R1S1_. & $\begin{array}{r}\text { grams. } \\
1.24\end{array}$ & $\begin{array}{l}\text { grams. } \\
\text { H } 1.78\end{array}$ & $\begin{array}{l}\text { grams. } \\
\text { H } 1.68\end{array}$ & $\begin{array}{l}\text { grams. } \\
\text { H } 1.39\end{array}$ \\
\hline $\mathrm{S} 2$ & 1.22 & H 1.69 & 1.42 & H 1.12 \\
\hline S3 $\ldots . .$. & 1.23 & 1.51 & 1.36 & 1.00 \\
\hline S4_-.-- & 1.19 & 1.45 & 1.29 & 0.85 \\
\hline S5 & $1.00 \mathrm{~L}$ & 1.27 & 1.07 & 0.84 \\
\hline R2S1...... & 1.20 & H 1.56 & 1.43 & H 1.12 \\
\hline S2 & H 1.41 & 1.31 & 1.35 & H 1.24 \\
\hline S3 & 1.28 & 1.35 & 1.33 & 0.96 \\
\hline $\mathrm{S} 4$ & 1.27 & $1.25 \mathrm{~L}$ & 1.35 & 0.91 \\
\hline R3S1.......... & 1.24 & 1.47 & H1.46 & H 1.43 \\
\hline $\mathrm{S} 2 \ldots$ & 1.23 & 1.47 & H 1.53 & H 1.27 \\
\hline S3 & 1.28 & 1.32 & H 1.57 & 0.97 \\
\hline $\mathrm{R} 4 \mathrm{~S} 1$ & 1.26 & 1.37 & H 1.65 & H 1.26 \\
\hline S2 & H 1.36 & 1.28 & 1.45 & 1.02 \\
\hline R5S1 & $1.16 \mathrm{~L}$ & 1.37 & 1.14 & 0.86 \\
\hline T2R1S1................. & 1.22 & 1.45 & H 1.55 & H 1.17 \\
\hline S2 & $1.12 \mathrm{~L}$ & H 1.61 & 1.06 & 1.02 \\
\hline S3 $\ldots \ldots$ & $1.11 \mathrm{~L}$ & 1.30 & $1.01 \mathrm{~L}$ & 0.92 \\
\hline $\mathrm{S} 4$ & $1.02 \mathrm{~L}$ & 1.28 & $0.82 \mathrm{~L}$ & $0.78 \mathrm{~L}$ \\
\hline R2S1 & 1.19 & 1.48 & 1.39 & 0.87 \\
\hline S2 & H 1.43 & H 1.80 & H 1.58 & 1.02 \\
\hline S3 3 & $1.18 \mathrm{~L}$ & $1.02 \mathrm{~L}$ & 1.13 & $0.79 \mathrm{~L}$ \\
\hline R3S1 & H 1.40 & 1.32 & $1.04 \mathrm{~L}$ & H 1.08 \\
\hline S2 & 1.35 & 1.42 & 1.18 & 0.96 \\
\hline R4S1 & 1.28 & 1.42 & 1.31 & 0.82 \\
\hline T3R1S1_... & 1.27 & H 1.52 & $1.02 \mathrm{~L}$ & 0.99 \\
\hline $\mathrm{S} 2$ & H 1.38 & 1.30 & 1.10 & $0 . \dot{93}$ \\
\hline S3 & $1.15 \mathrm{~L}$ & $1.21 \mathrm{~L}$ & $0.94 \mathrm{~L}$ & $0.45 \mathrm{~L}$ \\
\hline 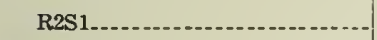 & H 1.42 & H 1.55 & 1.13 & 1.06 \\
\hline $\mathrm{S} 2$ & 1.29 & $1.09 \mathrm{~L}$ & 1.06 & $0.72 \mathrm{~L}$ \\
\hline R3S1 & H 1.54 & 1.44 & 1.14 & $0.76 \mathrm{~L}$ \\
\hline T4RIS1 & $1.16 \mathrm{~L}$ & $1.14 \mathrm{~L}$ & 1.26 & 0.82 \\
\hline $\mathrm{S} 2$ & $1.11 \mathrm{~L}$ & $1.05 \mathrm{~L}$ & $0.75 \mathrm{~L}$ & $0.76 \mathrm{~L}$ \\
\hline R2S1 & 1.35 & $1.23 \mathrm{~L}$ & 1.10 & $0.57 \mathrm{~L}$ \\
\hline T5R1S1 & H 1.40 & $1.21 \mathrm{~L}$ & $0.84 \mathrm{~L}$ & $0.75 \mathrm{~L}$ \\
\hline
\end{tabular}

concentration, no high value occurs for any set of salt proportions in which monopotassium phosphate makes up more than twoeighths of the total molecular concentration. For the lowest total concentration this salt may make up five-eighths of the total and a high green-weight value may be produced.

Furthermore, low values shown in the lower two or three triangles of the diagram correspond to relatively low partial concentration of magnesium sulphate, and to high ones of cal. 
cium nitrate, and the high values in these triangles correspond to high partial concentrations of magnesium sulphate and low ones of the calcium salt.

Considering each set of salt proportions singly, it is seen from Table 11 that the highest green weight most generally occurs with the low-medium total concentration (series 16); this is true for 20 out of the 35 sets of salt proportions tested. Of the remaining 15 sets, 7 show the highest green weight for the highmedium total concentration (series 19), and in all other cases (8) the highest value occurs for the lowest total concentration (series 14); in no case does the highest total concentration (series 20) give the highest green-weight value. This supports the conclusion reached from the study of the dry yields of tops and roots, that both of the medium concentrations are to be considered relatively good for these plants, but that the low-medium total concentration is probably to be regarded as more nearly optimal than the high-medium. The last point is more strongly emphasized here than in the case of dry yields.

Green weight of tops has frequently been employed as a criterion for comparing the physiological efficiencies of different environmental complexes, although it does not appear to have been used by earlier workers with solution cultures arranged for a thorough study of salt proportions. Since green weight consists, in any case, of the corresponding dry weight plus the corresponding water content, it is quite possible that the greenweight criterion (or the water content per weight unit of dry yield, or per weight unit of green weight itself) may bring out other physiological relations than those shown by the dry-yield criterion. For example, with a given total concentration, one set of salt proportions may give a higher dry-yield value than is given by another set, or the two sets may give equal values, and at the same time the first set may give a percentage of water content either less, equal to, or greater than that given by the other set. The salt proportions may influence not only the dryyield production but also (possibly in an entirely different manner) the power of the plant to retain water. Two plants may have the same dry weight but may be markedly different physiologically (and in regard to commercial value), according to the amount of water retained in their tissue; one might be much more succulent than the other, etc. Such possibilities are suggested in the literature.

On account of these considerations it will be valuable to make a comparison between the indications of the dry-yield and of 
the green-weight criteria for these four simultaneous series with young rice plants; for these cultures the dry yields of tops are also available, as has been shown. For the sake of this comparison Table 12 has been prepared. On account of the numerous discrepancies among the indications from repeated series it seems best not to consider any dry yield data here excepting those of the four simultaneous series in question, where the proposed comparisons may be made directly and without any complications introduced by differences in climatic and other non-

TABLE 12.-Comparison between dry yield and green weight of tops, as to the indications from the four simultaneous series $(14,16,19$, and 20), beginning June 19.

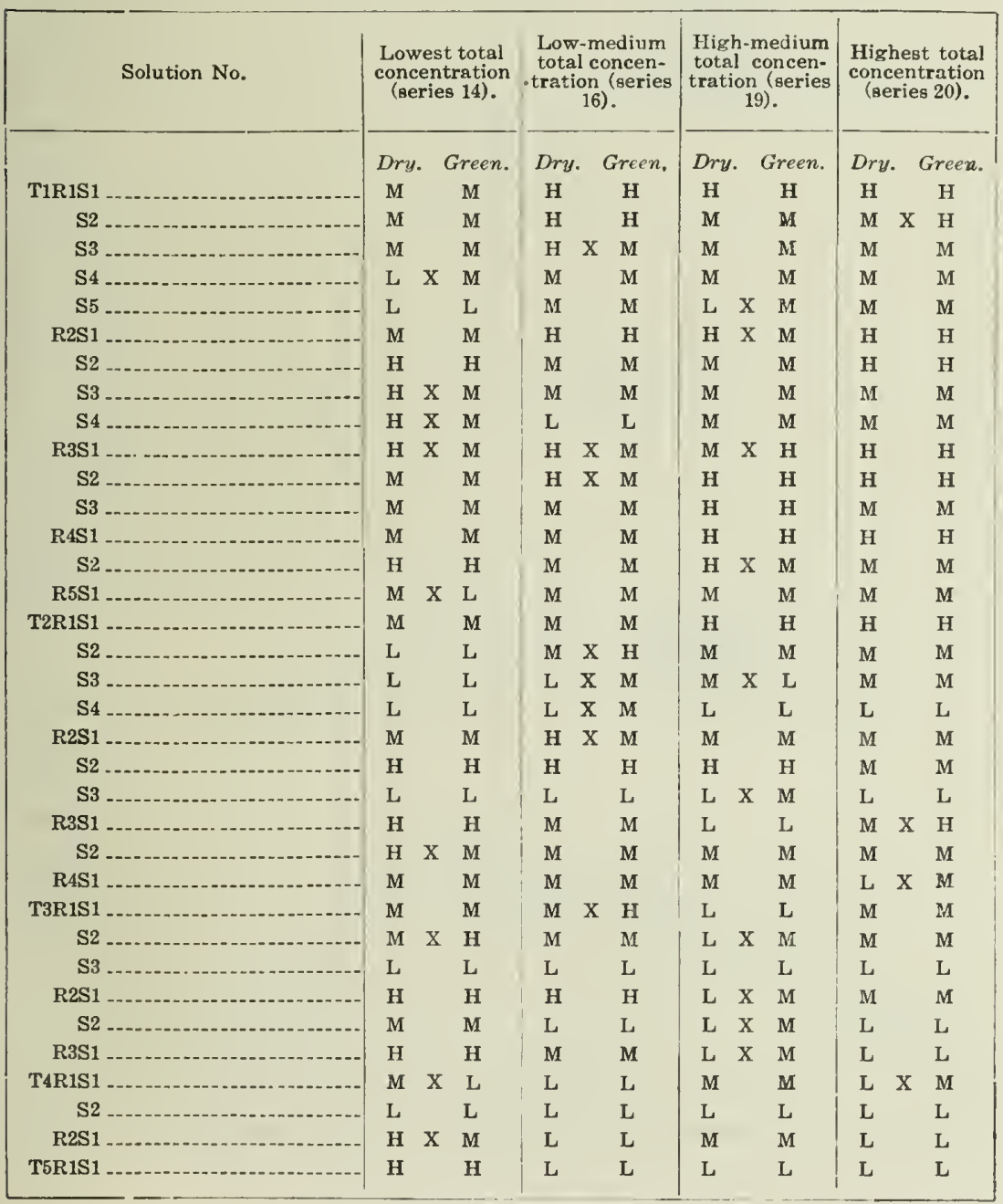


solution conditions. For the same reason, the detailed values need not be considered, attention being confined to the group designations only, for both dry yield and green weight. Table 12 shows the group designations (high, medium, or low) for dry yield and green weight of tops, for each set of salt proportions and for each of the four different total concentrations. In this table each series has a double column, the first for the dry yield and the second for the green weights. Where the group designations are different in the two cases the letter $\mathrm{X}$ is placed in the space between the two values; this brings out the frequency of discrepancies and shows for what sets of salt proportions and total concentrations they occur.

Inspection of Table 12 leads to the impression that dry yield and green weight are generally in agreement as far as placing the various culture solutions in the low, medium, or high group is concerned. Out of one hundred forty comparisons between the indications given by these two criteria only thirty-one, or 22 per cent of the total number, fail to show agreement. This means that the two criteria agree in 78 per cent of the cases; and, since these cases of agreement represent the whole range of environmental complexes here studied, it may be concluded that the two criteria are generally both influenced in about the same way, by total concentration, salt proportions, and nonsolution conditions. It should be emphasized that this conclusion is to be regarded as holding only for the plants and environments dealt with in these experiments; such a generalization is not warranted for the whole plant kingdom or for other solution types, etc. It may or may not hold for these other conditional complexes, for other plants (or for lowland rice plants in later developmental stages), etc.

With this warning as to the danger of attempting to generalize beyond the limits of the field actually investigated (a danger that seems not always to be appreciated fully in biological writing), attention may be turned more specifically to the cases that show disagreement in the indications of the two criteria here considered. In the first place, it may be inquired whether these discrepancies are any more or any less frequent with one total concentration than with another. Table 12 shows nine disagreements for the lowest total concentration, eight for the lowmedium, ten for the high-medium and only four for the highest total concentration; it therefore appears that, with higher total concentrations than are well suited to the development of this plant with this type of solution, the agreement between dry yield 
and green weight of tops may be expected to be better than occurs for what may be termed the optimal range of total concentration. The three less concentrated series nearly agree with one another in this regard, but the series with highest concentration shows less than half the number of discrepancies that any one of the other three shows. This fact may or may not be important; of course it is to be understood that, if the total concentration were made high enough to injure the plants seriously, each of the various dry yields must approach the

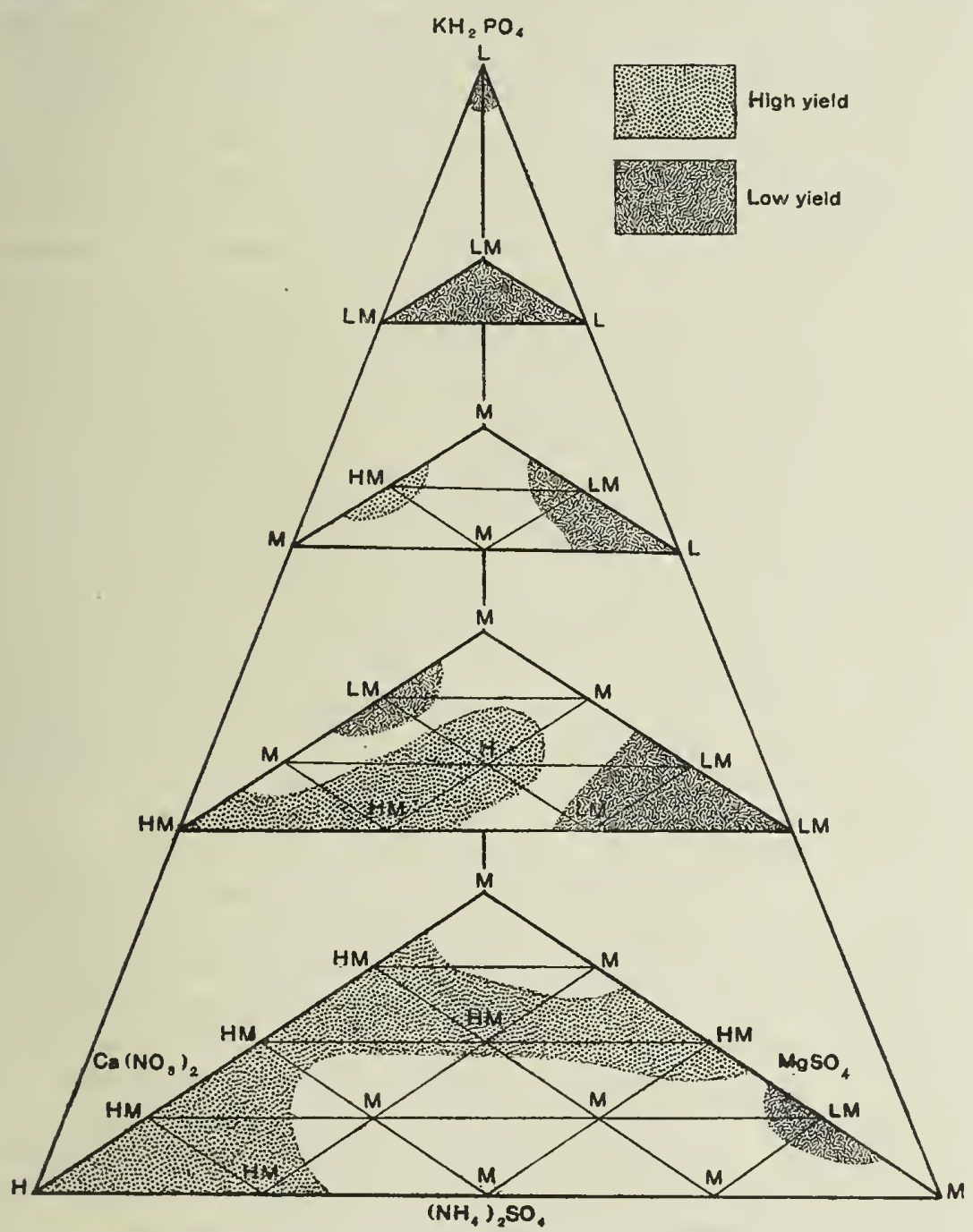

Fic, 8. Distribution of low, medium and high green-weight values for series 16 and 19 combined. 
corresponding green weight, as both approached the zero value where all growth was inhibited.

Turning next to the relation between the discrepancies shown in Table 12 and the various sets of salt proportions, it may be remarked that there are just three cases in which a discrepancy is recorded for two or more total concentrations of the same set of salt proportions. One of these cases refers to solution T1R3S1, for which disagreement between the two criteria is shown for the lowest three total concentrations, but not for the highest. The second case refers to solution T2R1S3, for which disagreement is recorded for the two medium total concentrations. The third case refers to solution T4R1S1, for which there is disagreement for the lowest and for the highest total concentration. Altogether, it appears that there is no evident relation between salt proportions, which supports the generalization stated on page 508, to the effect that these two criteria generally agree in their indications, and that (for the present study) one is to be regarded as about equivalent to the other.

Considering only the two medium total concentrations, the distribution of the low, medium, and high values of the green weight of tops, with reference to salt proportions, may be brought out diagrammatically as in the case of the dry yields. This is done by fig. 8, which is constructed in a manner similar to that followed for figs. 4 to 7 . The letter designations shown for green weight and for the two medium total concentrations (series 16 and 19) in Table 12 have been placed on the tetrahedral diagram (HL being replaced by M, as for the dry-yield diagrams) and the high and low areas have been demarked and distinguished by shading. For this particular diagram the HM-points are included in the high regions, and the LM-points are included in the low regions.

From this diagram it appears at once that this sort of summary of the green-weight data leads to the same general conclusions as were reached from the study of the dry-yield data. It appears that the most promising set of salt proportions on this basis is T1R1S1, and the least promising ones are T2R1S4, T3R1S3, T4R1S2, and T5R1S1 (the top apex). It seems safe, however, to allow the general conclusions derived from dry yields to stand as they are, and merely to remark that the points there emphasized are supported and substantiated by the indications derived from green weight of tops.

It is clear from what precedes that the thirty-five sets of salt 
proportions and the four total concentrations here dealt with did not differ significantly in their influence upon the ability of the plant tops to retain water. Calculating the water content as percentage of the corresponding green-weight value the result shows that the total range of these values is only from 79 to 87.5 per cent, and most of the values lie between 83 and 86 . It may be said that these tops were sensibly equally succulent for all cultures, irrespective of the total concentration or of the salt proportions. It is also clear that these tops were uniformly re-

TABLE 13.-Water absorption (cubic centimeters per six plants) during the culture period, for series 14, 16, 19, and 20, beginning June 19.

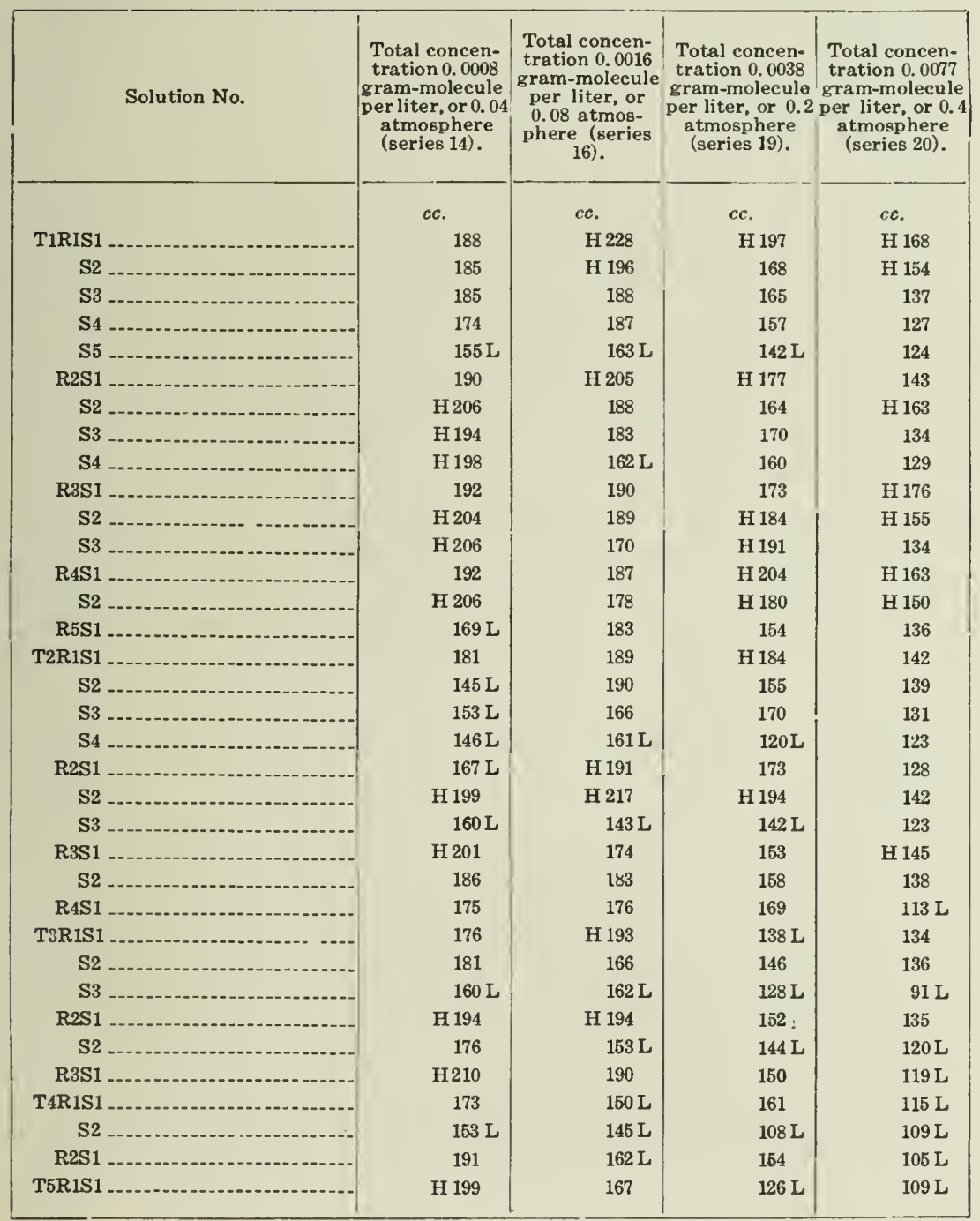


latively very dry, as compared with active plant tissues in general, and that the drying of leaf tips that occurred in many of the poorer cultures was without marked effect upon the percentage of water content.

In considering the green weight as a criterion for comparing the physiological efficiency of different cultures, etc., it should be remembered that there is probably a more or less pronounced daily fluctuation in the water content of leaves and small stems, as has been emphasized by Livingston and Brown, ${ }^{30}$ by Renner, ${ }^{31}$ by Edith B. Shreve, ${ }^{32}$ by Yuncher, ${ }^{33}$ and by others.

Water absorption.-The four simultaneous series carried out in the period beginning June 19 (series 14, 16, 19, and 20) also furnished comparative data on water absorption, which are presented in Table 13. These values are the amounts of water, in cubic centimeters, absorbed during the entire culture period.

Considering the very small amount of water retained by the plants (see the green weights and dry yields of tops), the absorption values clearly represent the amounts of water transpired, which, as Livingston ${ }^{34}$ has shown, may be generally considered as an approximate index of the leaf area, at least for young wheat plants. In studies like the present one the use of the total amount of water transpired during the growth period, as a criterion for comparing the plants of different cultures, seems to have been inaugurated by Whitney and Cameron, ${ }^{35}$ and it has been continued by Livingston, Britton, and Reid, ${ }^{36}$ and by many other later workers. It appears that Shive (1915) was the first, at least among those who have been engaged in the recent systematic study of salt relations by the method of solution cultures, to employ water absorption instead of transpirational water loss. Since this gives another quantitative criterion by which plants

${ }^{34}$ Livingston, B. E., and Brown, W. H., Relation of the daily march of transpiration to variation in water content of leaves, Bot. Gaz. 53 (1912) 309-330.

"anner, O., Beiträge zur Physik der Transpiration, Flora 100 (1910) 451-547.

${ }^{32}$ Shreve, Edith B., The daily march of transpiration in a desert perennial, Pub. Carnegie Inst. Washington (1914) No. 149.

${ }^{3}$ Yuncher, T. G., A study of the relation of soil moisture to transpiration and photosynthesis in the corn plant, Plant World 19 (1916) 151-161.

${ }^{34}$ Livingston, B. E., Relation of transpiration to growth in wheat, Bot. Gaz. 40 (1905) 178-195.

${ }^{25}$ Whitney, M., and Cameron, F. K., Investigation in soil fertility, Bull. U. S. Dept. Agr., Bur. Soils 23 (1904) .

${ }^{86}$ Livingston, B. E., Britton, J. C., and Reid, F. R., Studies on the properties of an unproductive soil, Bull. U. S. Dept. Agr., Bur. Soils 28 (1905) 39. 
may be compared, and especially since the amount of water absorption is much more easily determined for solution cultures than is any other quantitative plant value, it seemed desirable to make these water-absorption determinations in the present study.

The data in Table 13 show that the highest values are not generally found for the two medium total concentrations as was the case for dry yield and green weight. It is commonly understood that, except in special cases, the lower the total concentration the higher the rates of water absorption and transpiration, providing that the plants to be compared are all fairly healthy, and that all have been exposed to the same set of non-solution conditions. In spite of this consideration, however, the very highest water-absorption values for the one hundred forty simultaneous cultures here dealt with are for the low-medium total concentration (solutions T1R1S1 and T2R2S2). The highest total concentration here considered generally gives values lower than the corresponding ones of the other three total concentrations. Without trying to determine which one of the solutions may be expected to show the highest absorption rates, we may turn to the two medium total concentrations and make a comparison between their group designations ( $\mathrm{H}$ and $\mathrm{L}$ ) and those obtained from these two total concentrations in terms of dry yield and green weight of tops.

Such a comparison may be instituted by means of Table 14 , which is a reproduction of Table 12 with the water-absorption designations added as a third column for each series. The method followed is the same as was used for Table 12, and the notation is the same throughout.

Examination of Table 14 shows that the group designations for water absorption generally agree with those for green weight, and in the majority of cases agreement is perfect for all three criteria. In each of these four series there are from five to eight discrepancies between the evidence from green weight and that from water absorption, but there seems to be no relation between the number of discrepancies and the total concentration, unless such evidence may be suggested by the fact that series 16 (with the low-medium concentration) shows only five disagreements of this kind, while series 14 and 20 show seven each, and series 19 shows eight. It may be concluded immediately that water absorption is apparently just as satisfactory in discriminating between the different cultures of any series as is either dry yield or green weight. All three criteria appear to be about equally valuable. 
TABLE 14.-Comparison between dry and green weight of tops and water absorption, as to the indications from the four simultaneous series (14, 16,19 , and 20), beginning June 19.

\begin{tabular}{|c|c|c|c|c|c|c|c|c|c|c|c|c|}
\hline \multirow[t]{2}{*}{ Solution No. } & \multicolumn{3}{|c|}{$\begin{array}{l}\text { Lowest total } \\
\text { concentration } \\
\text { (series 14). }\end{array}$} & \multicolumn{3}{|c|}{$\begin{array}{c}\text { Low-medium } \\
\text { total concen- } \\
\text { tration (series } \\
16) .\end{array}$} & \multicolumn{3}{|c|}{$\begin{array}{c}\text { High-medium } \\
\text { total concen- } \\
\text { tration (series } \\
19 \text { ). }\end{array}$} & \multicolumn{3}{|c|}{$\begin{array}{l}\text { Highest total } \\
\text { concentration } \\
\text { (series 20). }\end{array}$} \\
\hline & $\begin{array}{c}\text { Dry } \\
\text { yield. }\end{array}$ & $\begin{array}{c}\text { Green } \\
w t .\end{array}$ & Abs. & $\begin{array}{c}\text { Dry } \\
\text { yield. }\end{array}$ & $\begin{array}{c}\text { Green } \\
\text { wt. }\end{array}$ & Abs. & $\begin{array}{c}\text { Dry } \\
\text { yield. }\end{array}$ & $\begin{array}{c}\text { Green } \\
\text { wt. }\end{array}$ & $A b s$. & $\begin{array}{c}\text { Dry } \\
\text { yield. }\end{array}$ & $\begin{array}{c}\text { Green } \\
\text { wt. }\end{array}$ & $A b s$ \\
\hline T1RIS1 _ & M & M & $\mathbf{M}$ & $\mathbf{H}$ & $\mathbf{H}$ & $\mathbf{H}$ & $\mathrm{H}$ & $\mathrm{H}$ & $\mathbf{H}$ & $\mathbf{H}$ & H & $\mathbf{H}$ \\
\hline S2 & M & $\mathrm{M}$ & M & $\mathbf{H}$ & H & $\mathbf{H}$ & M & $\mathbf{M}$ & M & $\mathrm{M} \mathrm{X}$ & $\mathbf{H}$ & $\mathbf{H}$ \\
\hline S3 .. & M & $\mathbf{M}$ & M & $\mathrm{H} \mathrm{X}$ & $\mathbf{M}$ & $\mathbf{M}$ & M & $\mathbf{M}$ & $\mathbf{M}$ & $\mathbf{M}$ & M & $\mathbf{M}$ \\
\hline S4 . - & $\mathrm{L} \mathrm{X}$ & M & M & M & $\mathbf{M}$ & $\mathbf{M}$ & M & M & M & $\mathbf{M}$ & M & M \\
\hline S5 & L & L & $\mathrm{L}$ & M & $\mathrm{M} \mathrm{X}$ & $\mathrm{L}$ & L $\mathrm{X}$ & $\mathbf{M}$ & X L & $\mathbf{M}$ & $\mathbf{M}$ & $\mathbf{M}$ \\
\hline $\mathrm{R} 2 \mathrm{~S} 1$ & $\mathbf{M}$ & $\mathbf{M}$ & M & $\mathbf{H}$ & $\mathrm{H}$ & $\mathrm{H}$ & $\mathrm{H} \times$ & $\mathrm{MX}$ & $\mathrm{H}$ & $\mathbf{H}$ & $\mathrm{H} \mathrm{Y}$ & $\mathrm{X} \mathbf{M}$ \\
\hline S2 & $\mathbf{H}$ & $\mathbf{H}$ & $\mathbf{H}$ & M & $\mathbf{M}$ & $\mathbf{M}$ & M & $\mathbf{M}$ & M & $\mathrm{H}$ & $\mathbf{H}$ & $\mathrm{H}$ \\
\hline S3 .. & $\mathrm{H} \mathrm{X}$ & $\mathrm{M} \mathrm{X}$ & $\mathbf{H}$ & M & M & $\mathbf{M}$ & M & $\mathbf{M}$ & M & M & M & M \\
\hline $\mathrm{S} 4 \ldots$ & $\mathrm{H} \mathrm{X}$ & $\mathrm{M} \mathrm{X}$ & $\mathbf{H}$ & L & $\mathbf{L}$ & $\mathbf{L}$ & $\mathbf{M}$ & M & M & M & $\mathbf{M}$ & M \\
\hline R3S1 ... & $\mathrm{HX}$ & M & M & H X & M & M & $M X$ & $\mathrm{H} \mathrm{X}$ & M & $\mathrm{H}$ & $\mathbf{H}$ & $\mathrm{H}$ \\
\hline S2 ... & M & $\mathrm{M} \mathrm{X}$ & $\mathbf{H}$ & H X & $\mathbf{M}$ & $\mathbf{M}$ & $\mathbf{H}$ & $\mathrm{H}$ & $\mathbf{H}$ & $\mathrm{H}$ & $\mathbf{H}$ & $\mathbf{H}$ \\
\hline S3 & $\mathbf{M}$ & $\mathrm{M} \mathrm{X}$ & $\mathbf{H}$ & M & $\mathbf{M}$ & $\mathbf{M}$ & $\mathbf{H}$ & $\mathbf{H}$ & H & M & $\mathbf{M}$ & $\mathbf{M}$ \\
\hline R4S1 _ & $\mathbf{M}$ & M & M & M & $\mathbf{M}$ & $\mathbf{M}$ & $\mathrm{H}$ & H & $\mathrm{H}$ & $\mathbf{H}$ & $\mathrm{H}$ & $\mathbf{H}$ \\
\hline S2 & $\mathbf{H}$ & $\mathrm{H}$ & $\mathbf{H}$ & M & M & M & H X & M X & $\mathrm{H}$ & M & M X & $\mathrm{X} \quad \mathrm{H}$ \\
\hline R5S1 ... & $\mathrm{M} \mathrm{X}$ & $\mathrm{L}$ & $\mathrm{L}$ & $\mathbf{M}$ & M & $\mathrm{MC}$ & M & M & $\mathbf{M}$ & $\mathbf{M}$ & $\mathbf{M}$ & M \\
\hline T2R1S1 ..... & $\mathbf{M}$ & $\mathrm{M}$ & $\bar{M}$ & $\mathbf{M}$ & $\mathbf{M}$ & M & $\mathrm{H}$ & $\mathbf{H}$ & $\mathrm{H}$ & $\mathbf{H}$ & H I & $\mathrm{X} \quad \mathrm{M}$ \\
\hline S2 & $\mathrm{L}$ & $\mathbf{L}$ & $\mathrm{L}$ & $\mathrm{M} \mathrm{X}$ & $\mathrm{H} \mathrm{X}$ & $\mathbf{M}$ & M & M & M & $\mathbf{M}$ & $\mathbf{M}$ & M \\
\hline S3 ... & L & $\mathbf{L}$ & $\mathrm{L}$ & L $X$ & $\mathbf{M}$ & M & $M X$ & L $X$ & M & $\mathbf{M}$ & $\mathbf{M}$ & M \\
\hline S4 ... & L & $\mathrm{L}$ & $\mathrm{L}$ & L $X$ & $M X$ & $\mathrm{~L}$ & $\mathrm{~L}$ & $\mathrm{~L}$ & $\mathrm{~L}$ & $\mathrm{~L}$ & & $\mathrm{X} \quad \mathrm{M}$ \\
\hline R2S1 & $\mathbf{M}$ & $\mathrm{M} \mathrm{X}$ & $\mathrm{L}$ & $\mathrm{H} \mathrm{X}$ & M X & $\mathrm{H}$ & $\mathbf{M}$ & $\mathbf{M}$ & M & $\mathbf{M}$ & $\mathbf{M}$ & M \\
\hline S2 & $\mathbf{H}$ & $\mathrm{H}$ & $\mathrm{H}$ & $\mathrm{H}$ & $\mathrm{H}$ & $\mathrm{H}$ & $\mathbf{H}$ & H & $\mathbf{H}$ & $\mathbf{M}$ & $\mathbf{M}$ & M \\
\hline S3 _.. & L & $\mathrm{L}$ & $\mathrm{L}$ & $\mathrm{L}$ & $\mathrm{L}$ & $\mathrm{L}$ & L $X$ & M X & $\mathrm{L}$ & L & L X & $\mathbf{M}$ \\
\hline R3S1 _.. & $\mathbf{H}$ & $\mathrm{H}$ & $\mathbf{H}$ & M & $\mathbf{M}$ & $\mathbf{M}$ & $\mathrm{L}$ & L $X$ & $\mathbf{M}$ & M X & $\mathbf{H}$ & H \\
\hline S2 & $\mathrm{H} \mathrm{X}$ & $\mathbf{M}$ & $\mathbf{M}$ & $\mathbf{M}$ & $\mathbf{M}$ & M & M & M & M & $\mathbf{M}$ & M & M \\
\hline R4S1 & $\mathbf{M}$ & $\mathbf{M}$ & M & M & $\mathbf{M}$ & M & M & M & M & L X & M X & $\mathrm{x}$ \\
\hline T3R1S1 .... & $\mathbf{M}$ & $\mathbf{M}$ & $\mathbf{M}$ & $\mathrm{M} \mathrm{X}$ & $\mathbf{H}$ & $\mathbf{H}$ & $\mathrm{L}$ & $\mathrm{L}$ & L & $\mathbf{M}$ & $\mathbf{M}$ & M \\
\hline S2 & $\mathrm{M} \mathrm{X}$ & $\mathrm{H} \mathrm{X}$ & M & $\mathbf{M}$ & M & IM & L X & M & M & M & M & M \\
\hline S3 & $\mathrm{L}$ & $\mathrm{L}$ & $\mathrm{L}$ & L. & $\mathbf{L}$ & $\mathrm{L}$ & L & $\mathrm{L}$ & L & $\mathrm{L}$ & L & L \\
\hline R2S1 & $\mathbf{H}$ & $\mathbf{H}$ & $\mathbf{H}$ & $\mathrm{H}$ & $\mathbf{H}$ & $\mathbf{H}$ & L X & M & M & M & $\mathbf{M}$ & $\mathbf{M}$ \\
\hline S2 & M & $\mathbf{M}$ & M & $\mathrm{L}$ & $\mathbf{L}$ & $\mathrm{L}$ & L $\mathrm{X}$ & $\mathrm{M} \mathrm{X}$ & L & $\mathrm{L}$ & L & L \\
\hline R3S1 & $\mathbf{H}$ & $\mathrm{H}$ & $\mathbf{H}$ & $\mathbf{M}$ & $\mathbf{M}$ & $\mathbf{M}$ & L $\mathrm{X}$ & M & M & $\mathrm{L}$ & L & L \\
\hline T4R1S1 ..... & M X & $\mathrm{L} \mathrm{X}$ & $\mathbf{M}$ & $\mathrm{L}$ & $\mathrm{L}$ & $\mathrm{L}$ & $\mathbf{M}$ & M & $\mathbf{M}$ & L $\mathrm{X}$ & $\mathbf{M}$ & $\mathrm{X}$ \\
\hline S2 & $\mathrm{L}$ & $\mathrm{L}$ & $\mathrm{L}$ & L & $\mathrm{L}$ & $\mathrm{L}$ & $\mathrm{L}$ & $\mathrm{L}$ & L & L & $\mathbf{L}$ & L \\
\hline R2S1 & H X & M & M & $\mathbf{L}$ & $\mathrm{L}$ & $\mathrm{L}$ & M & M & M & $\mathrm{L}$ & L & L \\
\hline T5R1S1 ..... & $\mathbf{H}$ & $\mathrm{H}$ & $\mathbf{H}$ & $\mathrm{L}$ & L $X$ & M & $\mathrm{L}$ & $\mathrm{L}$ & $\mathrm{L}$ & $\mathrm{L}$ & L & L \\
\hline
\end{tabular}

Looking further into this matter of disagreements between the indications of green weight and those of water absorption, it is seen that where this kind of discrepancy occurs along with a disagreement between the indications of dry yield and those of green weight, the three designations ( $\mathrm{L}, \mathrm{M}$, and $\mathrm{H}$ ) never occur together; there are always two like designations and one different one. A similar statement holds for the entire series of disagreements shown in Table 14; wherever a discrepancy 
occurs it is between two contiguous groups, $\mathrm{H}$ and $\mathrm{M}$, or $\mathrm{M}$ and L. These considerations constitute still further evidence in favor of the conclusion that all these plant criteria are about the same in their indications as to the relative physiological values of the various sets of salt proportions.

As in previous cases, it is instructive to place the water-absorption designations for the two medium total concentrations on the tetrahedral diagram and then indicate the regions of high and low values. Such a diagram is shown in fig. 9, which is markedly like the diagrams, figs. 4 to 8 . The experi-

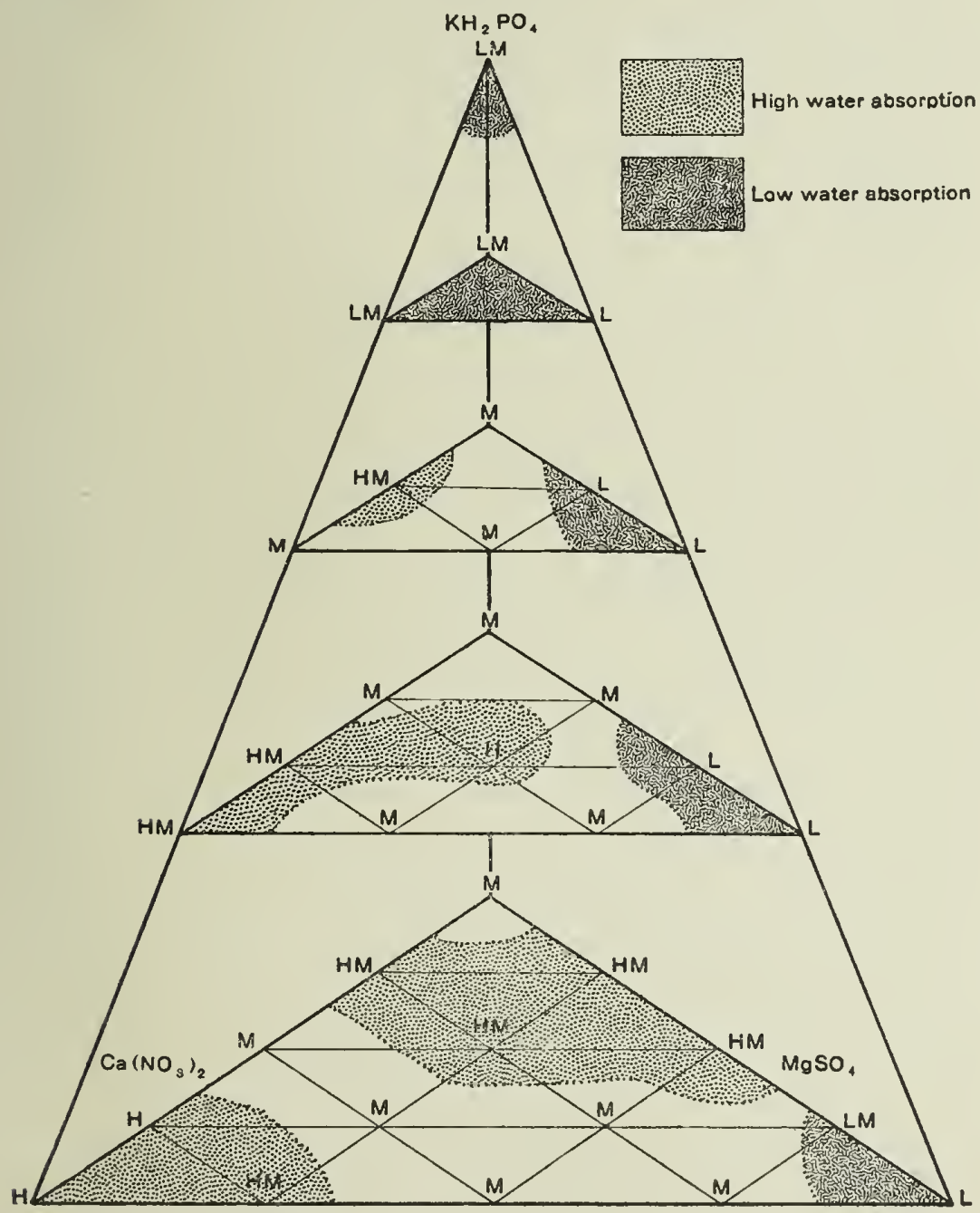

$\left(\mathrm{NH}_{4}\right)_{2} \mathrm{SO}_{4}$

FTG. 9. Distribution of low, medium and high water-absorption values for series 16 and 19 . 
mental data are so limited that detailed discussion of the differences is not warranted. It is clear, from the yield data, that the three sets of salt proportions selected as most generally promising are shown as most promising by the water-absorption data, as well as by the data for green weight. Also the two sets of salt proportions selected to represent badly balanced cultures are shown as belonging to the low group in fig. 9 .

FOUR-SALT TYPE B (MONOPOTASSIUM PHOSPHATE, MONOCALCIUM PHOSPHATE, MAGNESIUM SULPHATE, AMMONIUM SULPHATE)

As has been mentioned, the tests with the four-salt solution type B were carried out to determine whether the nitrate ion in the solutions of type A might be unnecessary, or even harmful. The lowest section of Table 3 shows the six experimental series that were carried out with this type of solution, three total concentrations $(0.0008,0.0016$, and 0.0038 gram-molecule per liter, or $0.04,0.08$, and 0.2 atmosphere) being simultaneously employed for the period beginning August 3 (series 23, 25, and 27), and again for that beginning September 9 (series 24, 26, and 28).

The better cultures of each series showed very satisfactory growth, excepting that the plants were always markedly affected in the latter part of the three-week period by a characteristic drying of the leaves backward from the tips. This was so pronounced and so characteristic of these type B solutions that it must be regarded as a serious form of physiological injury. The dry yields of tops and of roots gave values not markedly lower than the corresponding ones obtained with solution type $\mathrm{A}$, but the presence of the injury just mentioned made it impossible to regard even the best sets of salt proportions of type B as in any way approaching physiological equality with the best ones of type A. For this reason the data of series 23 to 28 will not be presented in the present paper. It may be noted further, however, that the highest total concentration here used (corre-sponding to the high-medium of solution type A) proved to be too high for the best growth, and that the lowest one here used seemed to be somewhat too low. The most promising solutions of this type had what was termed in the preceding discussions the low-medium total concentration $(0.0016$ gram-molecule per liter, or 0.08 atmosphere). It will be recalled that this total concentration seemed to be somewhat more promising than the others for type A. For type B, however, emphasis appears to be placed on the lowest and the low-medium total concentration rather than on the low-medium and the high-medium.

On account of the pronounced leaf injury present even in the 
best cultures of solution type $B$, it is concluded that this type is not at all well suited to the growth of these young rice plants, at least under the non-solution conditions here dealt with. A direct and simultaneous comparison between some of the best sets of salt proportions for type B with some of the best ones for type A will be considered in the following section of this paper.

It should be remembered that 4-salt solution type $B$ represents only one of many possible ways by which the ions potassium, calcium, magnesium, ammonium, phosphate, and sulphate might be brought together in solutions, without any nitrate, and the failure of any of these sets of salt proportions to give satisfactory growth in the plants here used is not to be regarded as definite proof that young rice plants actually require the nitrate ion. All that may be said is that these plantlets grew excellently well with certain sets of salt proportions of the 4-salt solution type with both ammonium and nitrate, while no set of proportions tried with ammonium but without nitrate gave passable development, on account of the generally present leaf injury.

FINAL COMPARISON BETWEEN THE THREE DIFFERENT SOLUTION TYPES

After the experiments whose results have thus far been considered had been completed and after the data given by them had been studied to some extent, but before the method of basing conclusions on agreement in group designations had been hit upon, the apparently best three sets of salt proportions were selected from each of the three solution types, for each of the lowest two total concentrations, and these were employed in a set for simultaneous test. In this lot there were thus six solutions of 4-salt type A, six of 4-salt type B, and three of 3-salt type I (increments of one-seventh). To these were added two different total concentrations of Shive's best solution for young wheat plants (3-salt type I, osmotic proportions, increments of one-tenth). Four like cultures, of 6 plants each, were employed in each case. The methods and treatment were the same as for the preceding larger series, and the culture period was from March 13 to April 3, 1919. The solution characteristics and the dry-yield data for tops, roots, and entire plants (each representing 6 plants but each derived as an average from four like cultures of 6 plants each) are presented in Table 15 . The numerical data are all expressed in terms of the corresponding yield value for solution AT1R2S1 (0.0016 gram-molecule per liter, or 0.08 atmosphere), taken as unity, the actual value for this solution being given in parentheses beneath the value 1.00. 
TABLE 15.-Relative yields of tops, roots, and entire plants for selected solutions of 4-salt type A, 4-salt type B, and 3-salt type I, final comparative series.

[Data are for six plants, being averages from four cultures of six plants each.]

\begin{tabular}{|c|c|c|c|c|c|}
\hline \multirow[b]{2}{*}{ Solution No. } & \multicolumn{2}{|c|}{ Total concentration. } & \multicolumn{3}{|c|}{ Dry yield. } \\
\hline & $\begin{array}{l}\text { Gram- } \\
\text { molecule per } \\
\text { liter. }\end{array}$ & $\begin{array}{l}\text { Atmos- } \\
\text { phere. }\end{array}$ & Tops. & Roots. & $\begin{array}{l}\text { Entire } \\
\text { plants. }\end{array}$ \\
\hline AT1R2S1 .. . & 0.0016 & 0.08 & 1.00 & a 1.00 & .1 .00 \\
\hline & & & $(0.169 \mathrm{~g})$. & $(0.079 \mathrm{~g})$. & $(0.996 \mathrm{~g})$. \\
\hline AT1R2S2 & 0.0008 & 0.04 & 0.94 & 1.05 & 0.98 \\
\hline AT2R3S1 & 0.0008 & 0.04 & 0.93 & 0.94 & 0.98 \\
\hline AT3R3S1 & 0.0008 & 0.04 & 0.83 & 1.00 & 0.88 \\
\hline AT2R1S1 ..... & 0.0016 & 0.08 & 0.81 & 1.02 & 0.88 \\
\hline AT2R2S2 & 0.0016 & 0.08 & 0.72 & 0.94 & 0.79 \\
\hline BT2R1S1 & 0.0016 & 0.08 & 0.97 & 1.02 & 0.99 \\
\hline BT1R2S1 & 0.0008 & 0.04 & 0.87 & 1.04 & 0.98 \\
\hline BT2R1S2 & 0.0016 & 0.08 & 0.85 & 1.03 & 0.91 \\
\hline BT1R2S2 & 0.0008 & 0.04 & 0.84 & 1.02 & 0.90 \\
\hline BT3R1S1 & 0.0016 & 0.08 & 0.81 & 1.00 & 0.87 \\
\hline BT3R2S1 & 0.0008 & 0.04 & 0.84 & 1.04 & 0.87 \\
\hline IR2S1b & 0.0022 & 0.10 & 0.44 & 0.89 & 0.59 \\
\hline IR3S1b & 0.0022 & 0.10 & 0.40 & 0.90 & 0.57 \\
\hline IR4S1b. .......... & 0.0022 & 0.10 & 0.40 & 0.87 & 0.55 \\
\hline IR5S2c & 0.0022 & 0.10 & 0.44 & 0.94 & 0.60 \\
\hline IR5S2c & 0.0382 & 1.75 & 0.47 & 0.92 & 0.62 \\
\hline
\end{tabular}

a All values are expressed in terms of the corresponding one for solution AT1R2S1 and the actual value for this solution is given in parentheses beneath the relative value 1.00 .

b Increment one-seventh.

c Increment of one-tenth osmotic proportions.

Although the data in Table 15 are derived from twenty-four plants grown simultaneously in four cultures of six plants each, as has been stated, and although it may be assumed that the aërial complex of conditions was practically the same for all, yet it seems necessary to disregard all minor differences brought out in the table. With this consideration in view, we may allow a plus or minus variation of 0.05 as negligible, so that 0.95 in the table becomes equivalent to all values from 0.95 to 1.05 , inclusive. In other words, the values from 0.95 to 1.05 may be considered as practically alike, all lying within the best group. On the basis of this agreement it is seen that just two solutions agree in belonging to the best group for all three criteria (yields of tops, roots, and entire plants), and that these two solutions are AT1R2S1 and BT2R1S1. It must be remarked, however, that the second of these solutions, and all of the B type in this series, produced the characteristic form of leaf injury noted above, so that this solution is not to be regarded as nearly so 
well balanced as is AT1R2S1. The last-named solution is undoubtedly the most promising of the present series, and it is the only one of the three previously selected as representing good physiological balance, that was included in the present series. The data of Table 15 therefore support the conclusion reached from the more thorough study of type A; namely, that T1R1S1, T1R2S1, and T2R1S1 are to be regarded as about equal and as very well balanced for these plants. This conclusion is especially strengthened by the fact that the solutions tested in the present series were selected because they showed high values in earlier tests, but before the analysis by agreements and disagreements had been completed. It is unfortunate that solutions AT1R1S1 and AT1R1S2 were not included in the final series.

It is of interest to emphasize that solution type $B$ is shown to be capable of giving yield values of the best group, in spite of the fact that these solutions always produced marked leaf injury.

With regard to the 3-salt solutions of the final series, Table 15 shows that the representative of this type gave entire plant yields of 0.62 or below, and top yields of 0.47 or below, while their root yields approach very nearly to being included in the best group, their values being from 0.87 to 0.94 . It may be suggested that the best sets of salt proportions of the 3-salt type I series of solutions, with the two low total concentrations as well as with the single higher one found to be nearly optimal for wheat plantlets (Shive), are very well balanced for the production of dry root yields, although they are very badly balanced according to the criteria of top yields or entire plants. This suggestion may possibly be of importance at some later time when the relations between the physiology of roots and that of tops is better understood and attracts more attention than is now the case.

It is obvious enough from Table 15 that none of these best 3 -salt solutions is at all well suited for young rice plants; they all belong in the poor group of this series, on the basis of yields both of tops and of whole plants. This result of the final series supports that reached on the basis of appearance of the plants, as stated in an earlier section of this paper.

The last two solutions shown in Table 15 deserve special attention. These have the salt proportions of Shive's best solution for young wheat plants (IR5S2) ; they are based on the scheme of osmotic (instead of molecular) proportions and on the triangular diagram with increments of one-tenth (instead of 
one-seventh, as in the case of the other 3-salt solutions here considered). It is a noteworthy fact that, although these rice plantlets have shown themselves very sensitive to total concentration for the well-balanced solutions (best ones of types A and B), yet the yield values shown in Table 15 are practically the same for both total concentrations here included. This set of salt proportions is badly balanced for young rice plants but it gives equally good yields whether the total concentration has an osmotic value of 0.1 or of 1.75 atmospheres. This equality was not shown, however, by the appearance of the plants; those with more concentrated solution were much more stunted than those with the weaker one (see Plate 1).

As to general appearance, all the plants with solution type A looked about alike; the differences brought out by the dry yields were not apparent. Also, the plants with solution type $B$ were like those with type $A$ in appearance, excepting for the leaf injury characteristic of the former group. On the other hand, the plants with 3-salt solution type I were all obviously much stunted and the leaves were yellowish rather than of the deep green color found in the case of types A and B in this series. Comparison of the two Shive solutions (0.1 and 1.75 atmospheres) shows that the one with the higher concentration exhibited much smaller and more stunted plants than did the other, in spite of the similar dry-yield values from these two solutions, as has been remarked. An idea of the general appearance of these plants may be gained from the photographs given in Plate 1 , which requires no further description than that given by its legend.

To summarize, this final comparative series still further emphasizes and supports the conclusions reached before; namely, that 3-salt solution type I (with nitrate but without ammonium) offers no promise, with any possible set of salt proportions, for good growth of lowland rice plants; that 4-salt solution type A (with both ammonium and nitrate) gives excellent growth of these plants with salt proportions about like those of solution T1R1S1, and with total concentrations between 0.0008 and 0.0016 gram-molecule per liter ( 0.04 and 0.08 atmosphere); and that 4-salt solution type B (with ammonium but without nitrate) may give excellent dry yields with properly selected sets of salt proportions (as T2R1S1), but is nevertheless badly balanced for the successful growth of rice plants on account of leaf injury. 


\section{SUMMARY}

The studies here reported deal with the mineral nutrition of lowland rice plants in solution cultures, for the phase of their development represented by the three-week period following germination. They involve experimental data on the growth of the plants in three different types of solutions: 3 -salt solution type I comprising, besides a trace of ferric phosphate, the three salts monopotassium phosphate, calcium nitrate, and magnesium sulphate; 4-salt solution type A comprising, besides a trace of ferric phosphate, the three salts just mentioned together with ammonium sulphate; and 4-salt solution type B comprising, besides a trace of ferric phosphate, the four salts monopotassium phosphate, monocalcium phosphate, magnesium sulphate, and ammonium sulphate. Each type was studied with reference to a large number of different sets of salt proportions and several different total salt concentrations. The experiments were carried out in the spring and summer in a greenhouse in Baltimore, and the results are to be considered as applicable to the climatic conditions prevailing there.

For each solution type the various sets of salt proportions were arranged on the basis of molecular proportions, instead of on osmotic proportions, as was done in several previous studies dealing with salt proportions and physiological balance in nutrient media. With this improvement in the method of planning and preparing the numerous solutions to be tested it is possible to make up a single, somewhat highly concentrated stock solution for any given set of molecular salt proportions and, by simple dilution of portions of this stock solution, to obtain solutions with the same set of salt proportions but with lower concentrations.

The following are the main generalizations derived from the experimental data:

1. No set of salt proportions of 3-salt type I gave even fair growth.

2. Excellent growth was obtained with proper sets of salt proportions of 4-salt solution type A. This suggests that these plants require the ammonium ion, thus apparently differing from many other plant forms.

3. It appears highly improbable that young rice plants could thrive with any 3-salt type of solution; there is no doubt that rice requires the kations potassium, calcium, and magnesium (as well as a little ferrum) like other plants, and the ammonium-ion cannot be introduced into a 3 -salt solution without its being the 
kation of one of the three salts used, which means that its introduction can be accomplished (in a 3-salt solution) only by omitting either potassium, calcium, or magnesium.

4. With 3-salt solution type I the nearest approach toward good growth was obtained. With solutions in which not more than one-eighth of the molecular total is due to calcium nitrate, the proportions of the other two salts seem to have been without influence in determining which sets of salt proportions were least badly balanced.

5. The best sets of salt proportions of 4-salt solution type A gave the most satisfactory growth that was obtained.

6. The best solutions of type B gave about as good growth as did the best ones of type A, by the criteria of size, yield, and water-absorption; but even these best solutions of type $B$ always produced a marked and characteristic leaf injury, so that no solution of this type is to be regarded as at all suited to the growth of these plants. This suggests that these young rice plants require (at least within the range of these experiments) not only the ammonium ion but also the nitrate ion.

7. The best solution for these plants is one that has a total concentration of 0.0016 or 0.0038 gram-molecule per liter (of all salts taken together), or an osmotic value of about 0.08 or about 0.2 atmosphere. It may be said that the most promising total concentration for these plants lies between these limits, probably nearer the lower one. The best total concentration for young rice plants is thus very much lower than that for any other form of plant hitherto studied by these general methods. (Wheat thrives best with a total concentration represented by an osmotic value of between 1.5 and 2.5 atmospheres.)

8. For the range of total concentration just mentioned ( 0.08 to 0.2 atmosphere) the best solutions (4-salt type A) are characterized by having very high relative molecular partial concentrations of magnesium sulphate. They generally have comparatively low relative molecular partial concentrations of monopotassium phosphate and calcium nitrate. The most promising solution for these plants may be stated as having about 0.002 grammolecule per liter (of all salts), the salts being present in about the following molecular proportions:

$$
\mathrm{KH}_{2} \mathrm{PO}_{4}:\left(\mathrm{NH}_{4}\right)_{2} \mathrm{SO}_{4}: \mathrm{Ca}\left(\mathrm{NO}_{3}\right)_{2}: \mathrm{MgSO}_{4}=1: 1 \frac{1}{2}: 1 \frac{1}{2}: 4 \text {. }
$$

It is safe to say that one very excellent solution would have the potassium, ammonium, and calcium salts in about the same proportions, while the molecular partial concentration of the 
magnesium salt should be four or five times as great as that of any one of the others. The tolerance of these plants for magnesium sulphate is especially remarkable.

9. The results of these experiments led to the conclusion that good growth of tops was generally accompanied by good growth of roots, a feature with regard to which these plants seem to differ from wheat.

10. Dry yield of tops, dry yield of roots, green weight of tops, and the amount of water absorbed during the three-week period, all appear to furnish valuable criteria for comparing growth in these different solutions, and all four criteria are in good general agreement. 



\section{ILLUSTRATIONS}

Plate 1

Representative cultures of the final comparative series, at the end of the culture period.

FIG. 1. Four-salt type A, T1R2S2 (0.04 atmosphere).

2. Four-salt type A, T2R1S1 (0.08 atmosphere).

3. Four-salt type A, T2R2S2 (0.08 atmosphere).

4. Four-salt type B, T2R1S2 (0.08 atmosphere).

5. Four-salt type B, T1R2S1 (0.04 atmosphere).

6. Three-salt type I (molecular proportions, increments of one-seventh R2S1 (0.00217 gram-molecule per liter, or 0.1 atmosphere).

7. Three-salt type I (osmotic proportions, increments of one-tenth) R5S2 (0.1 atmosphere).

8. Same as 7 , but total concentration, 1.75 atmospheres.

\section{TEXT FIGURES}

FIG. 1. Diagram, showing relative values of top length for series 4 , with 3 -salt solution type I (increments of one-seventh, total concentration of 0.0061 gram-molecules per liter or 0.23 atmosphere). Lightly shaded area includes best-balanced sets of salt proportions; heavily shaded area includes poorest sets.

2. Diagram, showing relative values of root length for series 4 , with 3 -salt solution type I (increments of one-seventh, total concentration of 0.0061 gram-molecule per liter or 0.23 atmosphere).

3. Diagrams, showing good and poor sets of salt proportions for four plant forms.

4. Diagram, showing top-yield values for the thirty-five different sets of salt proportions, with low-medium total concentration.

5. Diagram, showing root-yield values for the thirty-five different sets of salt proportions, with low-medium total concentration.

6. Diagram, showing top-yield values for the thirty-five different sets of salt proportions, with high-medium total concentration.

7. Diagram, showing root-yield values for the thirty-five different sets of salt proportions, with high-medium total concentration.

8. Diagram, showing distribution of low, medium, and high greenweight values for series 16 and 19 combined.

9. Diaglam, showing distribution of low, medium, and high waterabsorption values for series 16 and 19 . 



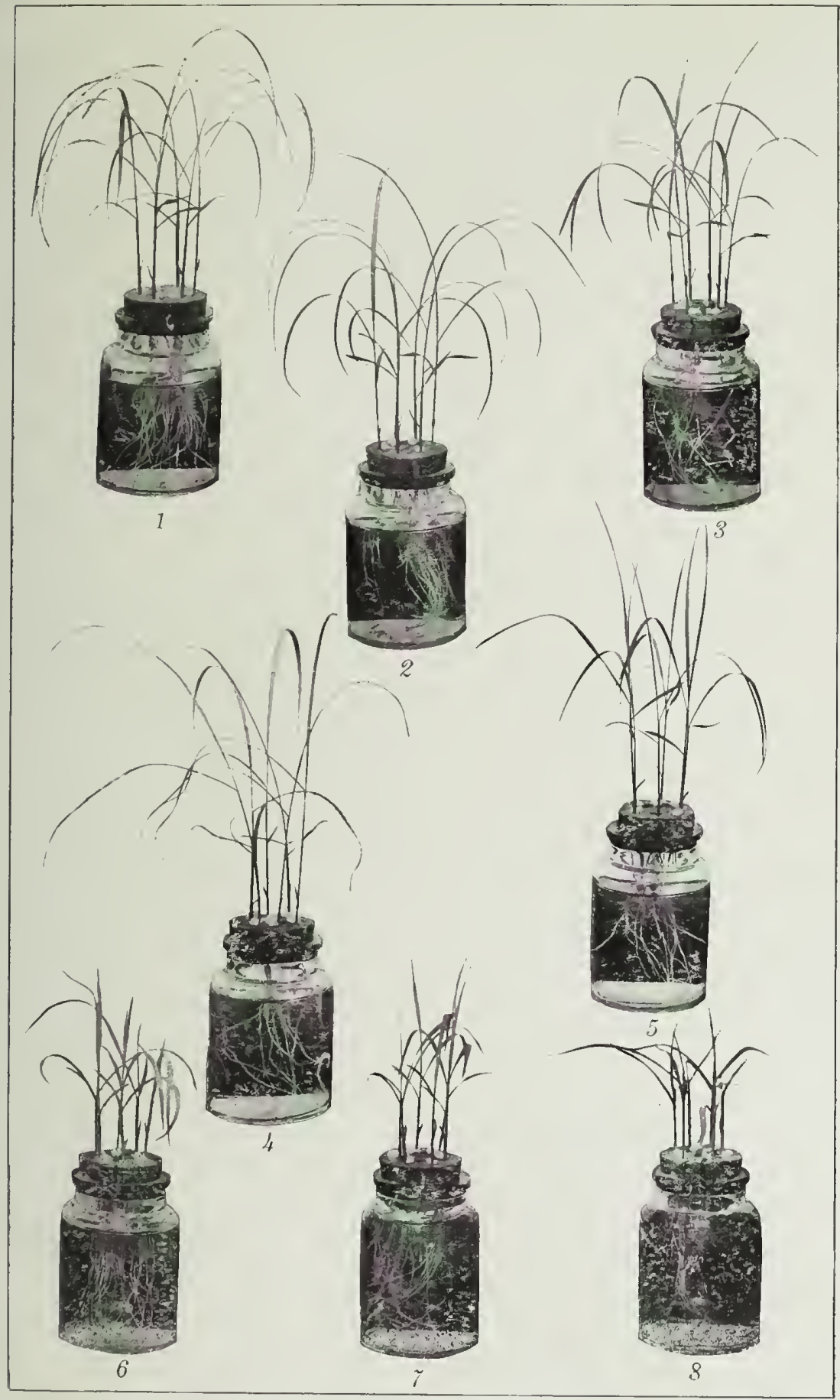

Plate 1. REPRESENTATIVE CULtUREs oF the FINAL COMPARATIVE SERIES, AT THE END OF THE CULTURE PERIOD. 
